University of Louisville

ThinkIR: The University of Louisville's Institutional Repository

Electronic Theses and Dissertations

$5-2012$

\title{
The SNS logistics network design : location and vehicle routing.
}

Yepeng Sun 1976-

University of Louisville

Follow this and additional works at: https://ir.library.louisville.edu/etd

\section{Recommended Citation}

Sun, Yepeng 1976-, "The SNS logistics network design : location and vehicle routing." (2012). Electronic Theses and Dissertations. Paper 1403.

https://doi.org/10.18297/etd/1403

This Doctoral Dissertation is brought to you for free and open access by ThinkIR: The University of Louisville's Institutional Repository. It has been accepted for inclusion in Electronic Theses and Dissertations by an authorized administrator of ThinkIR: The University of Louisville's Institutional Repository. This title appears here courtesy of the author, who has retained all other copyrights. For more information, please contact thinkir@louisville.edu. 


\title{
THE SNS LOGISTICS NETWORK
}

\section{DESIGN: LOCATION AND VEHICLE ROUTING}

\author{
By
}

Yepeng Sun

B.S. in Computer Science, Northeastern University, Shen Yang, China, 2000

M.S. in Computer Science, Aalborg University, Aalborg, Denmark, 2006

M.S. in Industrial Engineering, University of Louisville, KY, USA, 2009

\author{
A Dissertation \\ Submitted to the Faculty of the \\ J.B. Speed School of Engineering of the University of Louisville \\ in Partial Fulfillment of the Requirements \\ for the Degree of
}

Doctor of Philosophy

Department of Industrial Engineering

Speed School of Engineering

University of Louisville

Louisville, Kentucky

May 2012 


\section{THE SNS LOGISTICS NETWORK \\ DESIGN: LOCATION AND VEHICLE ROUTING}

By

Yepeng Sun

B.S. in computer Science, Northeastern University, Shen Yang, China, 2000

M.S. in computer Science, Aalborg University, Aalborg, Denmark, 2006

M.S. in Industrial Engineering, University of Louisville, KY, USA, 2009

A Dissertation Approved on

April 26, 2012

By the following Dissertation Committee:

Dr. Sunderesh S. Heragu

Dr. Gerald W. Evans

Dr. Lihui Bai

Dr. Ruth Carrico

Dr. John S. Usher 


\section{ACKNOWLEDGEMENTS}

I am heartily thankful to my supervisors Dr. Sunderesh S. Heragu and Dr. Gerald W.

Evans. Without their guidance, encouragement and support, I would never have been able to finish my dissertation.

I would also like to thank Dr. Lihui Bai, Dr. Ruth Carrico and Dr. John S. Usher. As my graduation committee members, they have contributed their time and effort to better my work.

I would like to express my gratitude to all RTDSS research team members. The dynamic communication and collaboration among RTDSS research members has inspired my research and opened my mind.

I would also like to thank every person, who has ever helped me grow up during my study at University of Louisville (Uofl). My experience at Uofl results in a $\mathrm{PhD}$, but the meaning it can bring to me is beyond a PhD. 


\title{
ABSTRACT \\ THE SNS LOGISTICS NETWORK DESIGN: LOCATION
}

\author{
AND VEHICLE ROUTING
}

Yepeng Sun

April 26, 2012

Large-scale emergencies caused by earthquake, tornado, pandemic flu, terrorism attacks and so on can wreak havoc to communities. In order to mitigate the impact of the events, emergency stockpiles of food, water, medicine and other materials have been set up around the US to be delivered to the affected areas during relief operations. One type of stockpile is called the Strategic National Stockpile (SNS). The SNS logistics network is designed to have multiple stages of facilities, each of which is managed by different levels of governmental authorities - federal, state and local authorities. The design of a logistics network for delivery of the SNS materials within a state are explored in this dissertation. There are three major areas of focus in this dissertation: (1) the SNS facility location model, which is used to determine sites for locating Receiving, Staging and Storage (RSS) and Regional Distribution Nodes (RDNs) to form a logistics network to 
deliver relief material to Points of Demand (PODs), where the materials are directly delivered to the affected population; (2) the SNS Vehicle Routing Problem (VRP), which is used to assist the SNS staff in determining the numbers of various types of trucks, and the routing schedules of each truck to develop an operational plan for delivering the required relief materials to the assigned PODs within the required duration; (3) the location-routing analysis of emergency scenarios, in which the facility location model and the VRP solution are integrated through the use of a computer program to run on several assumed emergency scenarios.

Using real data from the department of public health in the Commonwealth of Kentucky, a transshipment and location model is formulated to determine the facility locations and the transshipment quantities of materials; a multiple-vehicle routing model allowing split deliveries and multiple routes per vehicle that must be completed within a required duration is formulated to determine the routing and scheduling of trucks. The facility location model is implemented using Microsoft Solver Foundation and C\#. An algorithm combining the Clark and Wright saving algorithm and Simulated Annealing is designed and implemented in $\mathrm{C} \#$ to solve the VRP. The algorithm can determine whether there is shortage of transportation capacity, and if so, how many of various types of trucks should be added for optimal performance. All the solution algorithms are integrated into a webbased SNS planning tool.

In the location-routing analysis of emergency scenarios, a binary location model and an algorithm for solving VRP solution are integrated as a computer program to forecast the feasibility of distribution plans and the numbers of required trucks of various types. The 
model also compares the costs and benefits of direct and indirect shipment. A large-scale emergency scenario in which a specific type of vaccine is required to be delivered to the entire state of Kentucky is considered. The experiments are designed based on the real data provided by the Kentucky state government. Thus the experimental results provide valuable suggestions for future SNS preparedness planning. 


\section{TABLE OF CONTENTS}

ACKNOWLEDGEMENTS ............................................................................. iii

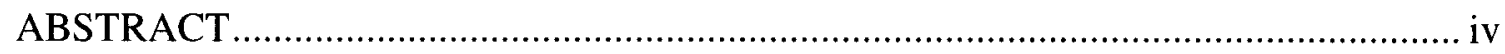

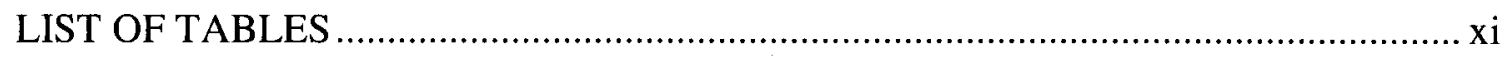

LIST OF FIGURES ….......................................................................................

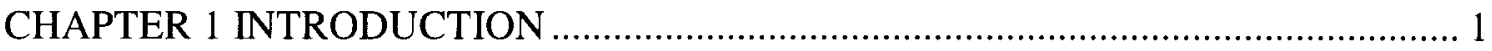

1.1 Background on Strategic National Stockpile.............................................. 2

1.2 A Real Time Decision Support System for Health Care and Public Health Sector

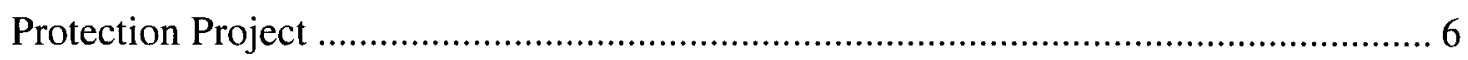

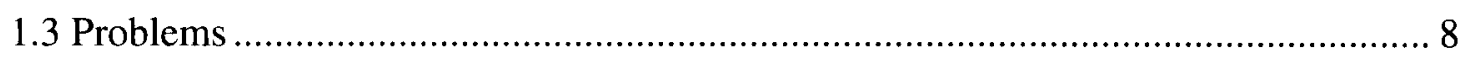

CHAPTER 2 LITERATURE REVIEW ........................................................ 12

2.1 Literature Review on Facility Location Problem .......................................... 12

2.1.1 Typical Facility Location Problems .......................................................... 15 
2.1.2 Facility Location Problem for Regular Healthcare Service or Regular Emergency Response

2.1.3 Facility Location Problem for Large-Scale Emergency Service 33

2.1.4 Literature Review on Simulation Models in Healthcare and Emergency Response 38

2.2 Literature Review on the Vehicle Routing Problem (VRP)

2.3 Literature Review on Location-Routing Problems (LRPs)

CHAPTER 3 SNS FACILITY LOCATION PROBLEM 51

3.1 Introduction 51

3.1 Initial Mathematical Models and Experimental Analysis 53

3.3 Transshipment and Location Model 63

3.4 Experiments and Result Analysis 66

CHAPTER 4 SNS VEHICLE ROUTING PROBLEM .70

4.1 Introduction .70

4.2 Model and Solution .72

4.2.1 Mathematical Model .72

4.2.2 Solution Algorithm. .75 
4.3 Experiments and Result Analysis

CHAPTER 5 LOCATION-ROUTING ANALYSIS OF EMERGENCY SCENARIO... 95

5.1 Introduction 95

5.2 Models and Solution Algorithm 97

5.3 Scenario Analysis 100

5.3.1 The Feasible DT1 and $\boldsymbol{D T} 2$ 102

5.3.2 Truck Resource Planning Policies. 108

5.3.3 Indirect Shipment vs Direct Shipment 110

CHAPTER 6 CONCLUSION

6.1 Contributions

6.2 Further Work

6.2.1 The Practical Extensions of the Current Work.

6.2.2 Intelligent Agent-based Transportation Planning and Directing System for Large-scale Emergency Relief Operations 120

REFERENCES 122

APPENDIX A THE LINGO FILE OF MATHEMATICAL MODEL 1 142

APPENDIX B THE LINGO FILE OF MATHEMATICAL MODEL 2 144 
APPENDIX C BENCHMARKING SNS VRP SOLUTION

APPENDIX D THE INPUT DATA OF SCENARIO ANALYSIS 162

CURRICULUM VITAE. 166 


\section{LIST OF TABLES}

Table 1 Numbers of Decision Variables and Constraints of Model 1

Table 2 Candidate RDN and RSS Sites

Table 3 Sensitivity Analysis of the Model

Table 4 The Output of Model 2 62

Table 5 The Execution Results of Transshipment \& Location Model

Table 6 Summary of Capacity Constrained VRP Test Instances. 92

Table 7 Summary of Solomon Test Instances 92

Table 8 The Candidate Shipment Solutions

Table 9 Results of Capacity Constrained Test Instances 147

Table 10 Results of Solomon 25 Test Instances 152

Table 11 Results of Solomon 50 Test Instances 155

Table 12 Results of Solomon 100 Test Instances 157

Table 13 Population and Vaccine Demands of Counties in Kentucky 162 


\section{LIST OF FIGURES}

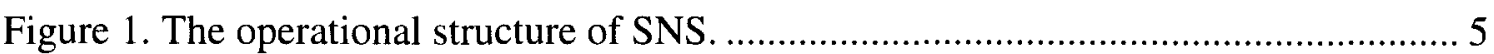

Figure 2. SNS decision support system for location and vehicle routing....................... 7

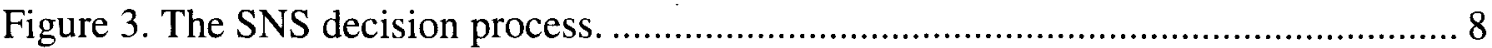

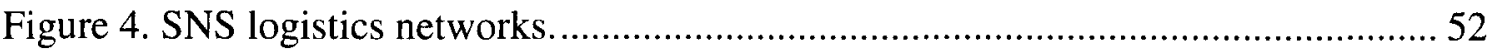

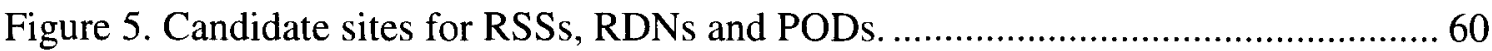

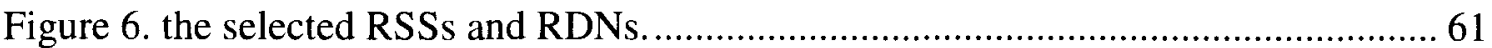

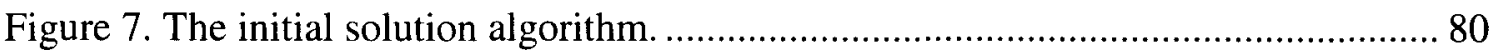

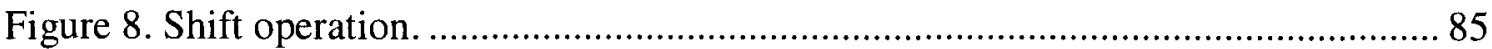

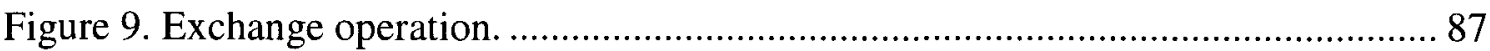

Figure 10. The location-routing analysis of large-scale emergency scenarios............... 96

Figure 11. The relationship between location-assignment solution and VRPs. ............. 96

Figure 12. The number of late trips of $1^{\text {st }}$ stage transportation under heavy demand.... 104

Figure 13 . The average lateness of $1^{\text {st }}$ stage transportation under heavy demand......... 104 
Figure 14. The number of late trips of $1^{\text {st }}$ stage transportation under light demand....... 105

Figure 15 . The average lateness of $1^{\text {st }}$ stage transportation under light demand.

Figure 16. The number of late trips of $2^{\text {nd }}$ stage transportation under heavy demand... 106

Figure 17. The average lateness of $2^{\text {nd }}$ stage transportation under heavy demand........ 106

Figure 18. The number of late trips of $2^{\text {nd }}$ stage transportation under light demand..... 107

Figure 19. The average lateness of $2^{\text {nd }}$ stage transportation under light demand.

Figure 20 . The number of different trucks of $1^{\text {st }}$ stage transportation when DT $1=18$ hrs under heavy demand. 108

Figure 21 . The number of different trucks of $1^{\text {st }}$ stage transportation when DT $1=18 \mathrm{hrs}$ under light demand.

Figure 22. The number of different trucks of $2^{\text {nd }}$ stage transportation under heavy demand.

Figure 23. The number of different trucks of $2^{\text {nd }}$ stage transportation under light demand.

Figure 24. Comparison of total travel distance among the candidate solutions under heavy demand.

Figure 25. Comparison of total load capacity among the candidate solutions under heavy demand. 
Figure 26. Comparison of number of late trips among the candidate solutions under heavy demand.

Figure 27. Comparison of average lateness among the candidate solutions under heavy demand.

Figure 28. Comparison of total travel distance among the candidate solutions under light demand.

Figure 29. Comparison of total load capacity among the candidate solutions under light demand. 114

Figure 30. Comparison of number of late trips among the candidate solutions under light demand.

Figure 31. Comparison of average lateness among the candidate solutions under light demand. 115 


\section{CHAPTER 1 INTRODUCTION}

In this dissertation, two issues relevant to state-level SNS logistics network design including the location and assignment problem and the vehicle routing problem are investigated. The corresponding models and solution algorithms are developed. And these are implemented in an online, real-time decision support system using realistic input data provided by the Kentucky's Department of Public Health. The results can be analyzed to give practical advice to SNS logistics network design and deployment in the real world applications.

The SNS logistics network is designed to efficiently and effectively distribute relief materials during large-scale emergencies. Large-scale emergencies include events such as earthquakes, tornadoes, pandemic outbreaks and bio-terrorism. These emergencies impact the population seriously in unpredictable ways, and often require a quick dispatch of a large amount of relief materials including medicine, food and other items such as power equipment, portable telecommunication equipment and mobile hospitals. The relief operations require an efficient utilization of the available resources such as warehouses and trucks. A decision support system that can assist decision makers to make resource allocation decisions in real-time during a large-scale emergency is needed. 
In addition, the relief operations for large-scale emergencies require scientific preparedness plans to procure and pre-position sufficient resources before the occurrence of large-scale emergencies with respect to different scenarios.

This dissertation focuses mainly on facility location problems and vehicle routing problems for large-scale emergency response. In Chapter 1, the motivation, background and the research problem are introduced. In Chapter 2, the relevant literature is reviewed. The SNS facility location model is presented in Chapter 3 and the SNS Vehicle Routing Model and the corresponding solution algorithm in Chapter 4. In Chapter 5, a binary location model and the SNS vehicle routing solution algorithm are integrated to analyze an assumed emergency scenarios and evaluate alternative operational plans.

\subsection{Background on Strategic National Stockpile}

Because the focus of our work is associated with the SNS, this section will introduce some background knowledge on SNS including its goals, organizational structure between federal, state and local levels and the relevant operations. The Centers for Disease Control and Prevention's (CDC) Strategic National Stockpile is one of the preparedness plans for dealing with large-scale emergencies. The SNS was established by the Department of Health and Human Services (HHS) and CDC in 1999. The CDC website states that "the SNS is a national repository of antibiotics, chemical antidotes, antitoxins, life-support medications, IV administration, airway maintenance supplies, and medical/surgical items. The SNS is designed to supplement and re-supply state and local 
public health agencies in the event of a national emergency anywhere and at any time within the U.S. or its territories." [1]

For fast and flexible response, SNS prepares two types of federal stockpiles [1]:

\section{- 12-hour Push Packages}

The 12-hour push packages are prepared stockpiles including pharmaceuticals, antidotes, and medical supplies, which are the first batch materials ready at any time to be delivered to the affected areas quickly to relieve the situation in a timely manner, as soon as the corresponding incident is identified by the relevant authorities. The push packages are stored in secure warehouses, whose locations are strategically determined for immediate deployment. The required time window for delivering the push packages from the federal level managed warehouse to the state level managed warehouses (i.e., RSSs) is 12 hours.

- Vendor Managed Inventory

If the incident requires additional medical supplies, the vendor managed inventory (VMI) supplies will be delivered to the affected areas within 24 to 36 hours. If the situation of the incident can be analyzed, the relief actions can be identified clearly, the items of the VMI can be configured to fit the specific needs of the incident. In this case, the VMI can be used as the first batch of materials delivered to the affected area instead of the 12-hour push package. 
SNS units at the federal, state and local levels collaborate with each other to ensure that the supplies can be delivered to the area affected by a disaster or emergency to protect the public, as shown in Figure 1. The local health department is usually at the frontline and can recognize events, which could cause large-scale emergency situations leading to a quick exhaustion of local medical supplies. When this occurs, they will report the event and the corresponding need to the state level officers, and the officers from both local and state levels will assess the trend and determine if they should send a request to the CDC for obtaining SNS supplies. Once the CDC receives a request from the state authorities, the officials in the CDC will hold an electronic conference with the relevant state and local officials to assess the situation and determine if the SNS supplies should be delivered to the affected area. After the SNS stockpiles are delivered to the designated RSS sites at the state level, the authority to manage the SNS materiel will be transferred to the state and local authorities. State and local authorities will then begin to break down the supply packages, repackage them and distribute them to PODs or the affected areas. During the deployment of SNS stockpiles, the CDC will dispatch a Technical Advisory Response Unit (TARU) team to assist the state to receive the 12-hour push package or manage the RSS sites.

Each state will develop its own plans or operating guidelines for dispensing the SNS medical supplies due to the transfer of authority of managing the SNS material. For example, the state of Rhode Island designs its own medical emergency distribution system to receive, store and dispense SNS packages as well as the state or private resources [2]. CDC issues a preparedness guideline [3] and an operational guideline [4] to 
direct the state officials to develop a preparedness plan and execute the receiving, storing and distributing the SNS material.

The research presented in this dissertation will be inspired mainly by the SNS logistics network design for Kentucky, but it can be extended to a general logistics network design for large-scale emergency response, and the knowledge accumulated from the project can be applied to similar projects of other states.

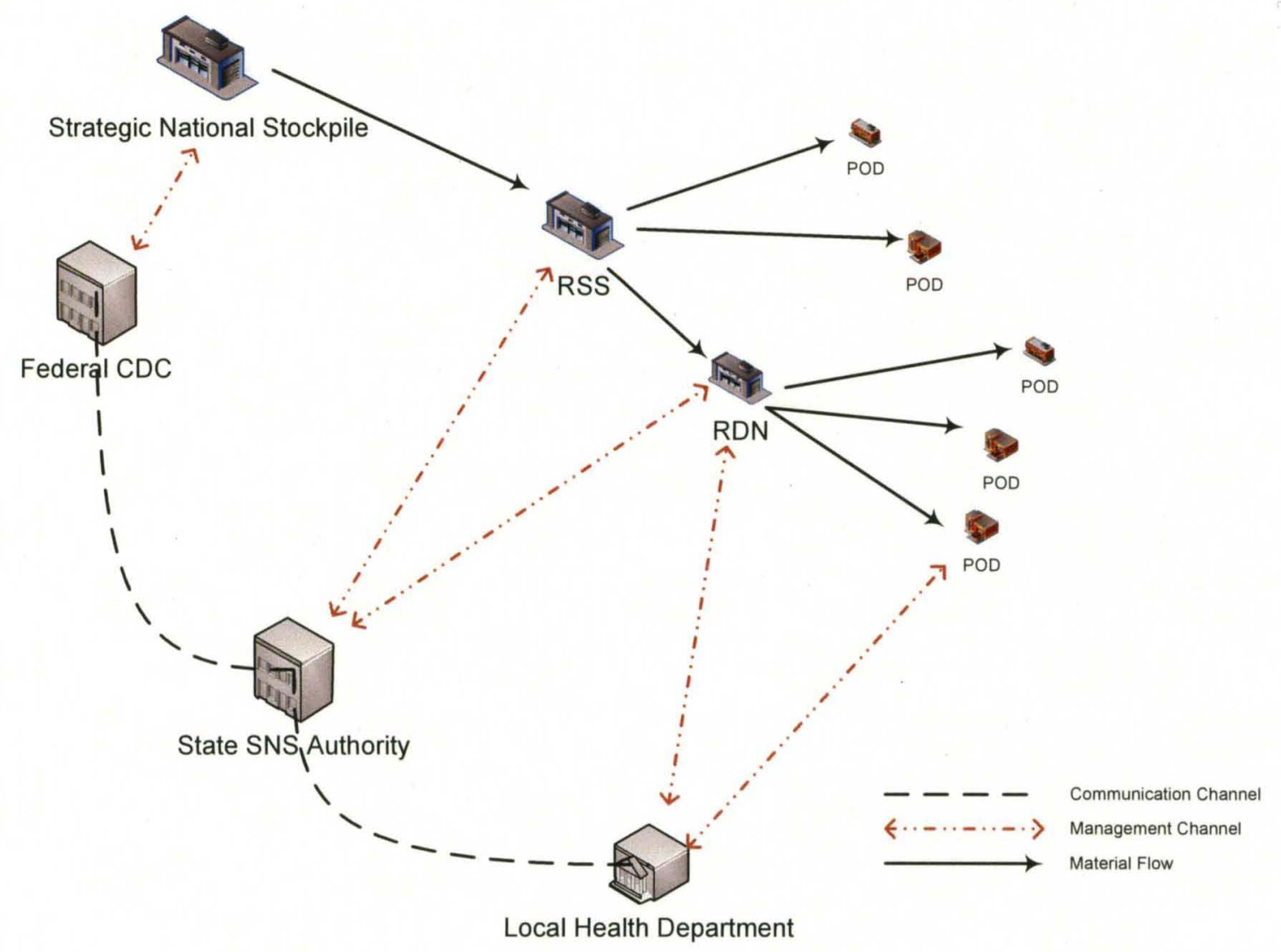

Figure 1. The operational structure of SNS. 


\subsection{A Real Time Decision Support System for Health Care and}

\section{Public Health Sector Protection Project}

The research in this dissertation is funded and inspired by the Real Time Decision Support System for Health Care and Public Health Sector Protection Project [5] in the Real-time Decision Support System Lab at the Department of Industrial Engineering, University of Louisville. This lab is dedicated to "developing a real-time, decisionsupport system (RTDSS) to help personnel in the healthcare and public health (HPH) as well as emergency services sectors (ESS) make real-time decisions relative to allocation and re-allocation of scarce resources in the aftermath of a pandemic influenza or other viral attack" [5]. Dr. Heragu, the Project Director, says "some studies indicate that up to 40 percent of the population could be stricken and hospitals could be operating at $50 \%$ of their capacity during a pandemic attack. During a time of medical surge when we really need HPH as well as ESS personnel and equipment to be operating at full capacity, the challenge for planners is to allocate the few resources at their disposal in the most efficient manner in response to fast changing conditions on the ground so that a large number of people can be served in as short a time as possible. [5]"

This research is a sub-project at this lab. Based on this research, we develop a two-stage decision support system as shown in Figure 2. In the first stage, the user provides the information of PODs, RDNs and RSSs, the location algorithm then determines open RDNs and RSSs as well as the assignment relationship between RSSs, RDNs and PODs to forms a logistics network. In the second stage, taking the result of the first stage as 
input, the user provides the information of trucks, the routing algorithm then determines the routing of each truck at each open RSS or RDN.

As another application of the research, we integrate the location and vehicle routing algorithms, and design various scenarios of large-scale emergencies with various delivery duration requirements and the demand using data provided by Kentucky's Department of Public Health. Then we input those scenarios into the integrated algorithm, and analyze the cost and benefits of alternative operational plans. The results provide practical advice on the long-term SNS preparedness planning.

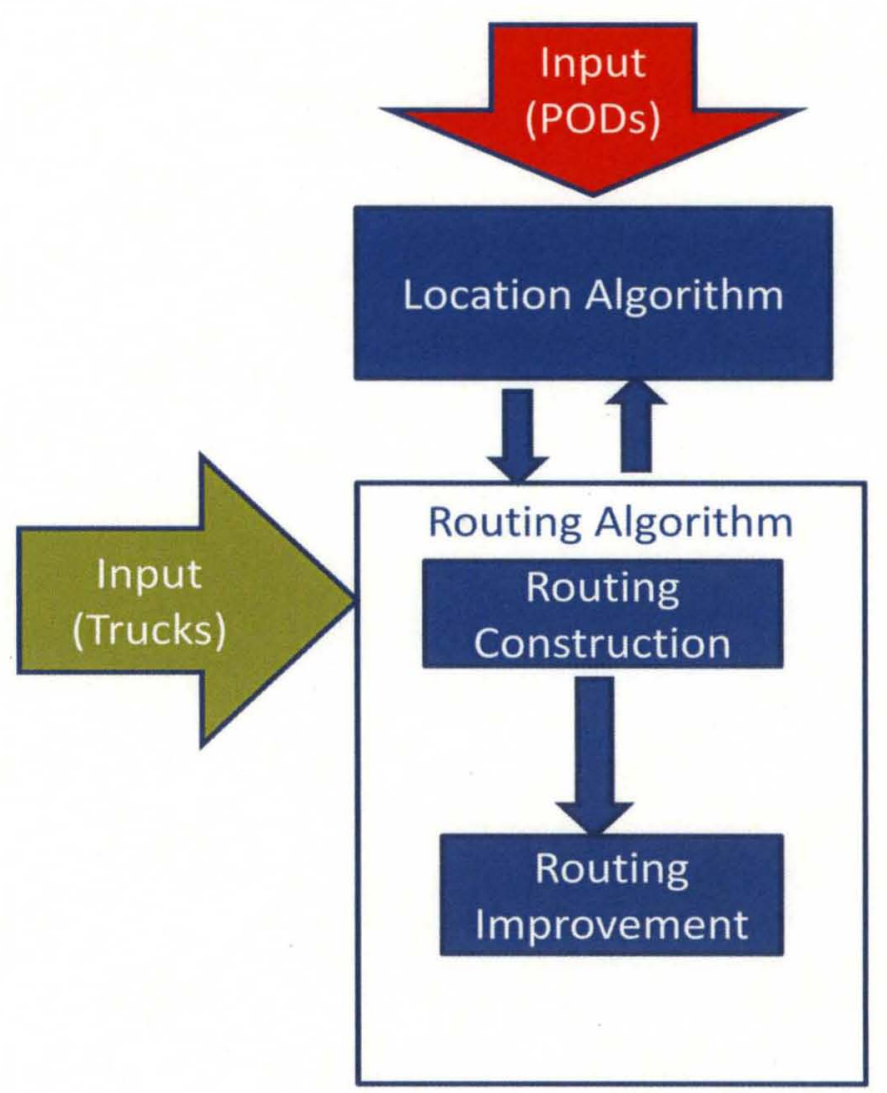

Figure 2. SNS decision support system for location and vehicle routing. 


\subsection{Problems}

In this dissertation, we are concerned with three problems including SNS facility location problem, SNS vehicle routing problem and the location-routing analysis for alternative large-scale emergency scenarios.

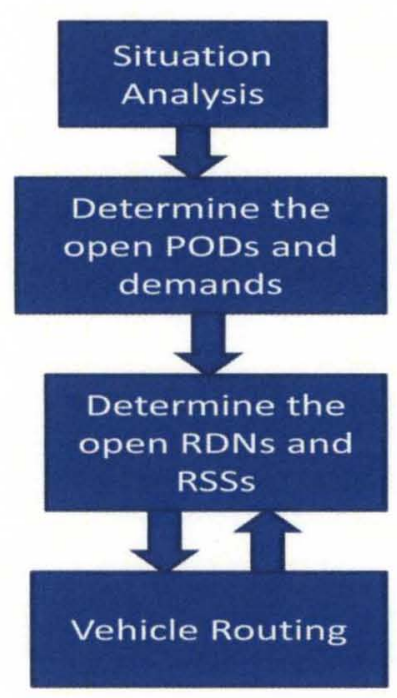

Figure 3. The SNS decision process.

Figure 3 shows the decision process associated with the state-level SNS operations. In the first phase of the process, once a large-scale emergency occurs in an area, the SNS authorities will analyze the potential effects or situation, and decide if the SNS packages should be delivered to the affected area. In the second phase, the SNS authorities determine the PODs that must be open and the corresponding demand at those PODs according to the situational analysis performed in the first phase. In the third phase, the SNS authorities determine the open RSSs and RDNs and the assignment relationship between RSSs, RDNs and PODs by using the SNS facility location module of the SNS decision support system developed based on our model. In the fourth phase, based on the 
results obtained from the previous phases, the SNS authorities schedule the routing of the trucks prepared for the relief operations by using the vehicle routing module of the SNS decision support system. The facility location decision making and the vehicle routing decision making could be an iterative process: sometimes the SNS authorities could change the location decisions and resolve the vehicle routing repeatedly, until they obtain satisfying solutions.

In the SNS facility location problem, given the candidate locations of RSSs and RDNs, the open PODs and their demands, and the transportation cost between locations, we will answer the following questions in order to form a logistics network with minimum cost:

(1) Which set of RSSs should be opened?

(2) Which set of RDNs should be opened?

(3) Which RDNs or RSS should each open POD be assigned to? Which RSS should an RDN be assigned to? If a POD is assigned to an RDN or RSS, then a truck starting off from that RDN or RSS will deliver a specific load of materials to that POD. The assignment of RDNs to RSSs has a similar meaning.

(4) What quantity of materials should be transported from one site to another? The material is transported from RSSs to PODs either via the intermediate level RDNs or directly.

In the SNS vehicle routing problem, given the locations of the depot and the served nodes, the delivery quantity of materials required by the served nodes, the data of trucks and the 
required maximum delivery duration, we will answer the following questions to form routing schedules for trucks with the minimum delivery cost:

(1) What is the visitation sequence of nodes for each truck?

(2) How much material will be unloaded at each node from a truck in a route?

(3) If the capacity of trucks cannot satisfy the delivery requirements (i.e., there is shortage of trucks), how many of various types of trucks must be procured in order to obtain the best performance?

In the location-routing analysis of large-scale emergency scenarios, we will integrate a binary SNS facility location model and the SNS VRP solution algorithm as a software module, design different emergency scenarios in terms of the affected area, the required maximum delivery duration and the material demand as the inputs, and determine the best policies to select trucks and operate under various scenarios. The following questions should be answered:

(1) How many trucks of various types are required for responding to a specific largescale emergency scenario? What types of trucks are preferred in terms of the size of trucks with respect to the specific scenarios?

(2) There are two shipment modes including direct shipment and indirect shipment via RDNs for transporting materials from RSSs to PODs. Which shipment mode provides the best performance in terms of the responsiveness and the utilized resources? 
Mathematical modeling techniques such as linear programming, mixed-integer programming or other more complex mathematical programming methodologies, will be applied to formulate and solve the above problems. Heuristic algorithms will be developed to provide fast solutions for the models. 


\section{CHAPTER 2 LITERATURE REVIEW}

This chapter includes three sections. In Section 2.1, various types of facility location problems and associated models are reviewed. In Section 2.2, the vehicle routing problems relevant to this dissertation are reviewed. Various types of location-routing problems are reviewed in Section 2.3 in order to inspire the integration of facility location models and vehicle routing models.

\subsection{Literature Review on Facility Location Problem}

Facility location decisions are critical strategic elements in a logistics network. The high cost of location or relocation of facility sites requires logistics planners to make location decisions based on long-term considerations. Once the facilities are sited on some locations, the logistics planners expect the facilities to operate continuously for a longterm period. Therefore, it is necessary to develop intelligent and effective approaches for solving facility location problems. In this section, a thorough literature review of facility location issues is done to evaluate the historical research work initiated by many researchers, in order to inspire our research work. First we summarize several review papers, and discuss the classification schemes; second we review the relevant papers grouped by:

- Typical facility location problems; 
- facility location problems for regular healthcare service or regular emergency response;

- facility location problems for large-scale emergency response individually.

Location problems are classified into three categories in [6]: static and deterministic location problems, dynamic location problems, and stochastic location problems. For static and deterministic location problems, three basic patterns of the problems including the $P$-median problem, the covering problem, the $P$-center problems, and their variants, are presented. For dynamic location problems, the relevant research considering frequent facility relocation and facility expansion over time, are reviewed. For stochastic location problems, the models considering travel time, supply and demand pattern and vehicles availability with stochastic characteristics are presented; the use of queuing theory to analyze location problems is also surveyed. Finally, several scenario planning models and the related regret-based model are introduced.

A representative survey of major location problems is presented in [7]. This study briefly describes different types of location models that have been developed and indicates how they relate to each other. This paper develops a classification system of location problems in terms of their objectives, decision variables and system parameters. It also divides the solution techniques for location problems into exact solution approaches and heuristic solution approaches.

A formal classification scheme for location models is introduced in [8]. This classification scheme is written as "Pos1/Pos2/Pos3/Pos4/Pos5": Pos 1 represents the 
information about the number and type of new facilities; Pos 2 represents the type of the location model with respect to the decision space; Pos3 represents a description of particulars of the specific location model, such as information about the feasible solutions and capacity restrictions; Pos4 represents the relation between new and existing facilities; and Pos5 represents the description of the objective function.

Some of the research which has contributed to the current state-of-the-art is reviewed in [9]. Location problems are categorized into three types: continuous location models, network location models and mixed-integer programming models. The latter two types of models actually are discrete optimization models. Discrete facility location models can be classified as: (1) single- vs. multi-stage models, (2) uncapacitated vs. capacitated models, (3) single- vs. multi-product models, (4) static vs. dynamic models, (5) deterministic vs. stochastic models, (6) models with and without routing options included, and (6) singlevs. multi-objective models.

Optimization approaches to deal with facility location problems under uncertainty are reviewed in [10]. Facility location problems under uncertainty are divided into two categories: stochastic facility location problems, in which the probability distribution of the uncertain inputs are known, and the common goal is to optimize the expected value of some objective function with a recourse; robust facility location problems, in which the probability distribution of uncertain inputs are unknown, and the objective is to optimize the performance of the facilities in the worst case. 
Many location problems with inherently multi-objective natures are reviewed in [11]. But this paper does not review preference-based techniques such as those involving multicriteria utility analysis, analytical hierarchy process and so on.

Because the purpose of this dissertation is to explore facility location planning problem for large-scale emergency response, the literature review will be classified into three groups: typical facility location problems, in which the general knowledge of facility location planning will be surveyed; the facility location problems for regular healthcare service or regular emergency response, in which the special considerations of facility location planning for regular healthcare service and emergency response will be investigated; and the facility location problems for large-scale emergency response, which is a target of this dissertation.

\subsubsection{Typical Facility Location Problems}

In this subsection, typical location problems will be reviewed to solidify our understanding of the knowledge in this field, and help us identify the characteristics of our problem. Instead of giving a restricted defined classification scheme, this subsection classifies the reviewed papers in terms of the issues that are concerned in the facility location problems, and it can help us answer the following questions: (1) Is the space in our problem continuous or discrete? (2) What kinds of objectives will our models seek?

(3) What constraints must be considered in our model? (4) How many stages are there in the SNS logistics network? (5) How can the time-dynamic properties of our problem be incorporated? (6) What stochastic factors should be considered in our models? (7) How 
do the facility location decisions, vehicle routing decisions and inventory control decisions affect each other?

\section{(1) Topology of Location Problems}

Facility location models are identified with different topological structures including continuous location models, hub connection models, discrete network models and so on, with respect to the corresponding topological characteristics of the facility and demand sites.

Continuous location models are identified with two attributes in [9]: (1) The solution space is continuous, and any point on this space can be used to site facilities; (2) Distance is measured with a suitable metric such as Euclidean metric, $l_{p}$-distance metric and so on. One of the simplest continuous location models is to determine the coordinates $(x, y)$ of a newly added single facility to serve a set of known demand points on a plane. The model can be expressed as:

$$
\min \sum_{k=1}^{n} w_{k} * d_{k}(x, y), \text { where } d_{k}(x, y)=\sqrt{\left(x-a_{k}\right)^{2}+\left(y-b_{k}\right)^{2}}
$$

where $\left(a_{k}, b_{k}\right)$ is the coordinate of demand point $k$, and $w_{k}$ is the weight of the distance between the new facility and demand point $k$. 
In [12] a continuous location model is introduced to solve the problem of selecting a location on a plane for a new facility which competes with other facilities so that it can maximize the market share.

A hub is a special facility that serves as a central platform for switching, transshipping and sorting the materials between many facilities around it. Hub connection models are used to solve the problems concerned with locating hub facilities and allocating demand nodes to hubs in order to route the transportation between the nodes around hubs. A typical network hub location problem is that, given a network with $n$ nodes in which the set of origins, destinations and potential hub locations are identified, given the amounts of material flow between origin-destination pairs, the cost measurement of flows on links in the network (cost, time, distance), and the hub-to-hub transportation discount factor $\alpha$, the objective is to minimize the total cost, by determining the optimal locations of hubs and the transportation routes. A survey of hub connection models is provided in [13].

In discrete network models, the underlying network structure as well as the locations of the demand points to be served and the potential locations of service facilities are given. The problem is then to locate the facilities to optimize some objective, which is usually a function of distance (e.g., travel time or cost). In the corresponding mathematical models, two sets of binary variables are defined: one is to decide which facility is to be opened; the other is to define the assignment policies, answering which facility serves which demand point. A hub connection model is a specific case of a discrete network model. Many discrete network location models are reviewed in [14]. 
The problem addressed in this dissertation is a discrete network location problem, in which a specific set of locations are selected from a set of identified candidate sites for locating RSSs or RDNs so as to satisfy the demand at PODs and improve the operational performance.

\section{(2) Objective of Facility Location Models}

Based on the objective functions, facility location models are categorized as three types: the $p$-median model, the covering model and the $p$-center model. There are two others as well: $p$-dispersion problem and the maxisum location problem.

The $p$-median model is introduced in [15] to find the location of $p$ facilities and minimize the weighted total distance between demand points and the assigned facilities. Its objective function is usually expressed as $\min \sum_{i} \sum_{j} h_{i} d_{i j} y_{i j}$, where $h_{i}$ is the demand at point $i, d_{i j}$ is the distance between demand point $i$ and facility $j$, and $y_{i j}$ is a binary variable indicating whether facility $j$ serves point $i$ or not. In [16], a variant of $p$-median model is introduced to minimize the total fixed cost of open facilities and the transportation costs. Many metaheuristic approaches for solving $p$-median problems are surveyed in [17].

The Maximal Covering Location Models (MCLP) are examined with several applications in [18]. The MCLP [19]is developed to determine locations for siting facilities that would maximize the total demand population served by the facilities within a pre-specified maximal service distance or a required time window in [19]. The corresponding objective 
function is usually expressed as $\max \sum_{i} a_{i} y_{i}$, where $a_{i}$ is the demand of point $i$, and $y_{i}$ is a binary variable indicating whether the facility is open or not. As the predecessor of M.C.L.P, the location set-covering problem [20] seeks to find the minimum number of facilities and their locations such that each demand point can be served within some prespecified maximal service distance or the required time window by a facility.

The $p$-center model determines the locations of $p$ facilities and minimizes the maximum distance between the demand points and their closest facilities [15]. Its objective function is expressed as $\min W$, where $W \geq \sum_{j \in J} h_{i} d_{i j} y_{i j}$ for each $i \in I, h_{i}$ is the demand at point $i, d_{i j}$ is the distance between facility $j$ and point $i$, and $y_{i j}$ indicates whether or not facility $j$ is assigned to point $i$. In [21], a $p$-center problem in the continuous plane is introduced to determine the optimal locations of one or more additional facilities in a region with given demand points and one or more pre-existing facilities.

In contrast to the $p$-center problem, the $p$-dispersion problem involves the maximization of the minimum distance between any pair of facilities [22], and this type of model can be applied when the facilities must be distributed widely. For example, the facilities must be sited to be far away from each other so that they can survive military attacks or earthquakes.

In contrast to the $p$-median problem, the maxisum location problem involves the location of $p$ facilities and maximizes the total weighted distance between the demand points and their corresponding assigned facilities [23]. This model can be applied to locate facilities such as prisons, power plants, waste repositories and so on. 
The problem addressed in this dissertation is concerned with multiple objectives. The first concern is the coverage which is similar to MCLP. The identification of PODs has already considered the coverage of the population, and our model must consider the coverage of RSSs or RDNs on the selected PODs. The second concern is the time constraint which is similar to the $p$-center model: the logistics network design must guarantee that the medical supplies can be delivered from RSSs to each POD directly or via the corresponding RDNs within the required time window. The third concern is the total cost which usually consists of two parts including the total fixed cost of operating facilities at selected sites and the transportation costs corresponding to the assignment policies, and the corresponding mathematical models are usually similar to $p$-median models. The first two objectives might be re-formulated as constraints in our model, and the third objective would be formulated as the objective function.

\section{(3) Capacitated Models}

In most of the above models, there is a basic underlying assumption that the facilities being sited are uncapacitated. However, this assumption is not always realistic. Often there are some capacity limitations associated with the facilities such as production capacity, warehouse capacity, or availability of transportation vehicles.

The capacitated form of the maximal covering location problem is examined in [24]. In the mathematical model, the capacity constraint is expressed as $\sum_{i \in I} a_{i} x_{i j} \leq K_{j} \forall j \in J$, where $I, J$ are the index sets of all demand points and potential facility sites respectively, 
$a_{i}$ represents the demand at point $i, x_{i j}$ is a binary variable indicating whether or not facility $j$ serves demand point $i$, and $K_{j}$ represents the upper limit of capacity of facility $j$.

Three types of capacity constraints might be considered in our problem:

(1) Warehouse capacity

The CDC requires an RSS warehouse to be approximately 12,000 square feet for receiving, storing, and repackaging a 12-hour Push Package or VMI materials [25]. An RDN warehouse might also have to satisfy some space requirements depending on the size of the service area to which it is assigned. However, if all the identified candidate sites have already satisfied the capacity requirements, we need not include capacity constraints into our mathematical models.

(2) Transportation capacity

A lesson learned from Rhode Island's drill exercise is that the transportation system might be a distribution bottleneck during a large-scale emergency due to the limited number of vehicles [2]. This study suggests that each site needs a dedicated vehicle fleet. If the transportation vehicles are scarce resources in the SNS distribution system, we do need to consider the capacity constraints of transportation and develop intelligent utilization policies of vehicles. Otherwise, we do not need consider it in our mathematical models.

(3) Staffing

The staffing level is another factor we may consider in our model, especially because during a pandemic outbreak the staffing level itself can be disrupted 
due to the infection of staff. The staff includes medical workers at PODs, warehouse workers at RSSs and RDNs, the drivers of vehicles and other SNS on-site staff.

\section{(4) Multi-stage Models}

If the facilities are to distribute the items directly to the demand points, then the singlestage model should be applied. If the facilities are to distribute the items to the demand points via several intermediate facilities, then a multi-stage model should be applied.

A multi-stage logistics network consisting of multiple plants and multiple distribution centers is studied in [26]. In the logistics network, the items produced in plants are delivered to customers via intermediate distribution centers (DCs). The problem is to determine the subset of plants and DCs to form a logistics network that can satisfy all the capacity requirements and demands required by the customers with minimum cost. In the mathematical model, two sets of decision variables are defined: One set of variables are binary, defining the logistics network structure, indicating which facilities are open and specifying the assignment; the other set of variables are continuous, determining the quantity of items produced in plants, or shipped between facilities. Obviously the Kentucky SNS logistics network fits a multi-stage model. We must consider the stages from RSSs to RDNs and from RDNs to PODs in our mathematical models.

\section{(5) Dynamic Models}


In static facility location models, it is assumed that once the facilities are sited, they will operate over a predetermined length of time. However, during this time, many of the model parameters, such as demands and operation costs, are likely to change. Therefore, dynamic facility location models are introduced, in which the sites of facilities change over time according to the changes of one or more of the input parameters.

A simple dynamic location problem on a plane is introduced in [27], in which the location of a facility changes over several time periods, and the objective is to minimize the total cost including the transportation cost and the relocation cost. A dynamic programming algorithm is developed to solve the problem.

A dynamic uncapacitated facility location problem is presented in [28], in which the opening of new facilities and the closing of existing facilities are executed over time, and its objective is to minimize the total costs including the cost of closing and opening facilities, operation costs, distribution costs so as to meet demands specified in different time periods at various customer locations. In [29], a similar problem is solved with a two-stage heuristic approach including a drop phase and a local search phase.

\section{(6) The Stochastic Model}

Dynamic models attempt to optimize facility location decisions over a specified time horizon. These dynamic models assume all the input parameters are static and deterministic; however, many parameters such as available resources, travel time, facility 
costs, demand pattern and so on, are uncertain and dynamic. The stochastic models deal with uncertainties in the problems.

A probabilistic facility location model for standard response coverage of fire protection is studied in [30]. The model accounts for the possibility that a vehicle may be busy serving a call when a new call arrives. The model assures a pre-specified level of reliability for the availability of services through a chance constraint instead of adding a penalty cost of failure to serve calls within the desired time in the objective function.

A facility location problem with stochastic customer demand and immobile servers is studied in [31]. The approach represents service facilities as a set of simple $\mathrm{M} / \mathrm{M} / 1$ queuing systems. In the model, the constraint that the customers travel to the closest open facility is enforced. Moreover, a constraint is placed on the maximum expected waiting time at each open facility. The problem is to select sites from a set of candidate facility locations to minimize customers' total traveling cost and waiting cost, while satisfying the above constraints. A greedy-dropping heuristic algorithm is used to give an initial solution. Then a Tabu search algorithm based on "facility swap" is used to refine the initial solution.

According to [32], the problems with uncertainty are divided into 2 categories: problems with uncertainty which can be described by a probability distribution, and problems with uncertainty without a probability distribution. The former can be tackled by stochastic programming, whose common goal is to optimize the expected value of some objective 
functions; the latter can be tackled by robust optimization, which attempts to optimize the performance of the system under the worst-case.

Applying a stochastic programming technique requires a large amount of accurate data which can derive the probability distribution of the input parameters. It might be infeasible to collect the required data due to the unpredictable properties of large-scale emergencies. Thus we would adopt robust optimization to deal with uncertainties in our problem. Another way to deal with uncertainties is by using discrete event simulation, which is a convenient way to capture the stochastic properties in the real system.

\section{(7) The Integrated Models}

Logistics network design includes three sub-problems: location-allocation problems, vehicle routing problems, and inventory control problems. In reality, there exist high dependencies between these sub-problems. High-quality facility location decisions can facilitate efficient vehicle routing. On the other hand, an intelligent vehicle routing can reduce the actual transportation cost usually considered as an objective function in facility location models. Inventory control policies decide the frequency of transportation between facilities, and thus affect the actual transportation cost and operation cost. Thus, the integrated models place facility location problems into the context of a holistic logistics design combining these three sub-problems.

A model to simultaneously optimize location, allocation, capacity, inventory, and routing

decisions in a stochastic logistics system is presented in [33]. The problem is formulated 
as a mixed integer convex program, and its objective is to minimize the total cost consisting of the fixed cost of operating the distribution centers, the holding costs of the expected working inventory and safety stock, and the annual distribution cost from the distribution centers to the customers. Four sets of decision variables are defined including a set of binary variables indicating the route visitation sequence for each vehicle, a set of binary variables indicating whether or not the distribution center is open, a set of binary variables indicating the assignment policies and a set of continuous variables indicating the order size at distribution centers.

A model combining location and transportation problems and considering multiple transportation options, multiple demand periods and stochastic demand, is studied in [34]. The problem is solved at two levels: at the design level, the location and allocation decisions are determined; at the operational level, the transportation decisions are determined.

There are two ways to deal with the integration of location-allocation problem, inventory control problem and vehicle routing problem. One is to tackle them with mathematical models individually with well-defined interfaces between these models, and then integrate them with simulation models or heuristic approaches. The other is to construct a model integrating those problems together from the start. In the latter case the model would become so complicated that the model can only be solved with heuristic approaches. 
The SNS logistics networks are multi-stage, and a single level of authority (federal, state or local) is in charge at each stage. The federal authority is responsible for shipping the SNS packages from national repositories to state-managed RSSs. The state authorities take the responsibility to manage the received SNS packages. Finally the local authorities are responsible for delivering the items to the affected populations. Due to the divided responsibilities among the multiple levels of authorities, the first way to deal with the integration is preferred. The "divide and conquer" approach can allow the mathematical models to become tractable.

\subsubsection{Facility Location Problem for Regular Healthcare Service or Regular Emergency Response}

A selected set of papers on facility location problems related to emergency service siting models is reviewed in [35]. These location models are divided into three categories: (1) basic deterministic covering models, which are usually introduced in most review papers on facility location models. (2) deterministic models considering backup coverage; in these models a demand point is covered by one server and at least another backup server. (3) probabilistic models which allow randomness in server availability, and these models include reliability constraints in terms of the availability of the servers.

Another review paper [36] noted that the location-oriented literature to solve the problems in the context of planning emergency systems can be divided into two categories. The first category is concerned mainly with spatial considerations, just as shown in most continuous or discrete optimization models. The second category is 
concerned with the event-service sequence requirements, by capturing random properties of the events and applying queuing theory.

As an early work on location of emergency service facilities, [37] is concerned with a facility-location problem requiring the maximum time or distance between a user and his or her closest service provider to be within a predetermined range. An upper limit is placed on the response time or distance from the facilities to any point of demand. The objective is to determine the minimum-cost spatial arrangement of service facilities that can adequately cover the service area.

A hierarchical structure of social, economic and political criterions for health care facilities location planning is introduced in [38]. The hierarchical structure consists of user sector criteria, operator sector criteria, and community sector criteria in terms of three different stakeholders. The user sector contains the criteria that include degree and nature of illness or ailment, travel time, convenience, service cost, comfort and travel cost for patients. The operator sector contains the criteria that include the operation cost, travel time and travel cost for staff, accessibility to supporting institutions, and level of service offered. The community sector contains the criteria that include economic impact on community, environmental effects, community attitude and so on. A framework of optimization models which matches groups of people to their required service according to the capabilities of healthcare facilities handling illness is developed. The objective function maximizes the utility in terms of single-attribute or multi-attribute. 
In [39], the problem of locating emergency service facilities is studied under the assumption that the incidents occur randomly over a given region with uniform distribution. Thus, the distance from the location of the emergency service unit to the location of the incident is also random, hence the response time is stochastic. In the mathematical model, a chance constraint is introduced to guarantee the service reliability within a specific probabilistic level, and the objective function involves the minimization of the total expected response time.

In [40], the extension of a single-objective static maximal covering location problem to a multi-objective dynamic covering location problem is presented. In this mathematical model, the objective is to maximize the demand coverage in each period. The decision variables specify the opening or closing of facilities and the allocation of the facilities to the demand points in each period. An illustration of a municipal ambulance location siting problem is used to demonstrate the application of this model. A utility function is constructed to solve the multi-objective aspects of the problem. Fuzzy goal programming is introduced to deal with multi-objective covering-based vehicle location models for emergency service in [41].

In [42], a hierarchical programming model is introduced to achieve two objectives simultaneously. The primary objective is to minimize the number of ambulances needed to satisfy emergency calls. The secondary objective is to maximize the extent of multiple coverage of zones. 
The number of vehicles within a specific service area is a critical factor to determine the response time for an emergency call emanating from that area, thus assigning the limited number of vehicles to EMS stations according to the stochastic demand and the traveling time needs an intelligent approach. In [43], a maximal expected coverage location model considering stochastic traveling time and stochastic demand is developed and integrated into a decision support system (actually an EMS simulation model) to assist EMS planners to allocate vehicles to their services areas.

The performance of an emergency medical service system can be affected by the number of vehicles deployed and their locations. Most studies of EMS systems address the vehicle location problem in a deterministic manner without realizing that some vehicles might be busy and cannot respond to a call. In [44], a deterministic maximal covering location model is extended to address this defect, by considering the numbers of vehicle at different locations and the probabilities of each vehicle being busy. In another similar study [45], a model is presented to determine the location of a fixed number of stations and ambulances on a network so that the population covered by the standard service is maximized.

The concepts and applications of backup coverage in facility location problems are surveyed in [46]. Most facility location models assume the facilities can always provide services so that each demand point is only covered by one facility. In case of an emergency, this could be fatal if one facility fails to work. Backup coverage (the alternative coverage for a demand point) is suggested as a decision criterion in modeling the location of emergency services on a network. In this paper, two sets of formulations 
are introduced: one is to enforce mandatory first coverage with the least number of open facilities while maximizing the secondary coverage; the other is to maximize the demand covered by the first coverage and the second coverage with a tradeoff policy. Hierarchical programming is applied to deal with the multi-objective properties in this problem. In another similar study presented in [47], workload capacities and backup service are considered to site emergency service facilities.

An application of maximal set covering location models for determining emergency medical service vehicle deployment in Austin, Texas in 1978, is presented in [48]. The application consists of three modules: (1) a data analysis package used to analyze the pattern of demand in terms of population and zones; (2) computer mapping programs used to divide the city into "analysis zones" and display the results; (3) a location model used to take the inputs from (1) and (2), and determine the vehicle deployment and covering policies. In another similar application presented in [49] for determining ambulance deployment in Santo Domingo, Dominican Republic, the objective function is to maximize the multiple coverage of demand within a user-specified critical response time, with the minimum number of facilities. The multiple coverage is considered due to the unreliability of the transportation system in developing countries.

In [50], the emergency vehicle bases are modeled as a set of spatially distributed queuing systems, in which the vehicles are represented as servers. The problem is to maximize the expected number of calls which can be reached within the required time window, by assigning emergency vehicles to these queuing systems intelligently. 
In [51], a model is built for locating emergency service stations and determining the number of vehicles to be placed in each station with the required reliability constraints. In the model, a system failure is defined as the inability of a vehicle to respond to a demand call within an acceptable amount of time. Based on the assumption that the arrival process of calls follows a Poisson distribution, a formula is built to calculate the probability that a call cannot obtain an available vehicle service from its covering stations. The model includes a chance constraint to enforce the system reliability. Similar to [51], [52] represents the recent progress on this research, and involves the construction of a reliability constraint with queuing theory from server perspective.

Inspired by the above literature review mentioned in this section, the following issues relevant to our problem are discussed:

(1) The upper limit of response time or distance is always a critical factor to consider while designing a logistics network for emergency service. Emergency service requires fast response in order to reduce the mortality or morbidity, and relieve the seriousness of the situation. If the relief resources are close to the location of incidents, the emergency relief actions can be conducted immediately. However, the occurrences of incidents over time and locations are stochastic, but our resources are limited, thus the locations of resources must satisfy the requirement that the resources can be delivered to the location of each possible incident within the required time window.

(2) The stochastic factors in designing emergency logistics networks to be considered include changing demand over time or locations (i.e., the occurrence of incidents 
over time and locations), the availability of resources such as vehicles, staff and transportation time.

(3) Reliability versus Backup Coverage: Whether we need to apply a reliability model or backup coverage to our problem depends on the requirement. In our problem, the logistics network is required to deliver SNS supplies to the demand points within a required time window during a large-scale emergency, and the emergent demand must be satisfied rather than be assured with a specific level of reliability allowing some failures. Therefore, we would consider backup coverage rather than reliability constraints in our mathematical model.

(4) Queuing theory: When the focus is to reduce the waiting time caused by the bottleneck processes due to the limited resources, it is better to apply queuing theory to our models. However, our problem focuses on reducing the transportation cost caused by the traveling distance and the operation cost of operating facilities, hence queuing theory is not needed.

\subsubsection{Facility Location Problem for Large-Scale Emergency Service}

In [53], Eva K. Lee et al introduced the decision support system RealOpt [54], which focuses on mass dispensing of medical supplies for protecting the general population under scarce staffing resources and within a very tight time window. RealOpt can be used to investigate the following problems: (1) determine the locations for POD facility setup; (2) design an efficient floor layout for PODs via an automatic graph-drawing tool; (3) determine required staffing levels and provide efficient staff allocation plans at each POD; and (4) perform disease spread analysis, understand and analyze the infection within 
PODs. The approach of combining simulation and optimization is applied to solve the problem. The simulation model captures the realistic operational details, inputs the solution from the optimization model, and outputs average waiting time, average queue length, average utilization rate, average cycle time and throughput in PODs as the feedback to the optimization model. The optimization model applies adaptive heuristic algorithms to speed up the convergence toward the desired solution that produces the satisfying system performance.

In the POD-Location model of [53], the regional population is divided into sub-regions called grids. Each grid is associated with its population. Each grid has a set of candidate POD locations. The problem is to select locations for the POD from these candidate locations and determine the corresponding covering policies between PODs and grids. This problem is solved via a two-stage approach. In the first stage, the minimum number of PODs is determined in order to reduce the operation cost of PODs. In the second stage, the minimum travel distance and time is found for the population to reach its assigned POD.

Facility location models for large-scale emergency services are studied in [55]. There are two differences between large-scale emergencies and other emergencies which are specified. Compared to other emergencies, large-scale emergencies bring sudden and tremendous demands to the EMS which overwhelm first responders. Another significant difference is the low frequency of large-scale emergencies. These differences require redundant and dispersed siting of EMS facilities for responding large-scale emergencies, so that more medical supplies can be mobilized within the tight time window to reduce 
mortality and morbidity, and a large number of facilities can also survive from disasters and remain operable. The facility location models for large-scale emergencies must also consider the relevant attributes of each area and the likelihood for a particular emergency to occur in each area. The impacts of emergencies on the demand and the capability of resources are also taken into account in the models. In its illustrative examples, three scenarios including a dirty bomb attack, an anthrax attack and a smallpox attack by terrorists are analyzed, the models are applied to these three scenarios and give different results compared to the traditional facility location models. A two-stage heuristic algorithm combining Tabu Search (TS) and Simulated Annealing (SA) is developed to solve the problem.

A facility location problem for setting up a global humanitarian relief chain in response to a quick-onset disaster is studied in [56]. A model is developed to determine the number and locations of distribution centers in the relief network and the amount of relief supplies to be stocked at each distribution center to meet the needs of the population affected by the disasters. This model is a variant of the maximal covering location model, integrating the location-assignment problem and inventory control problem, considering multiple types of items, and enforcing budgetary constraints and capacity restrictions. Similar to [55], the model also identifies a set of scenarios and the probability of occurrence of each scenario. The objective function is the maximization of the expected total coverage on the demands under different scenarios.

Similar to [56], a model is formulated to determine facility location and allocation, the required stocking levels for emergency supplies, and distribution proportion of those 
supplies to demand points after a disaster in [57]. It also considers the disruption of the disaster on the pre-positioned stocks and the transportations. The model is formulated as a two-stage stochastic mixed integer program. In the first stage, decision variables specify the locations and sizes of facilities, as well as the stocking levels of various types of supplies. In the second stage, decision variables specify the distribution proportion of available supplies to demand points corresponding to specific scenario events and transportation network conditions. In [58], a similar two-stage stochastic model is developed to solve similar problems.

A large spectrum of published disaster response models addressing public health or health care delivery are reviewed in [59]. These papers are classified respectively in terms of the type of disaster and response decisions considered, targeted decision makers, choice of outcomes, modeling methodology, and reporting format. Inspired by these reviewed models, six recommendations for model development on this topic are provided:

- The health sector disaster response models should address real-world problems;

- The models should be designed for maximum ability by response planners;

- The models should strike the appropriate balance between simplicity and complexity;

- The models should include appropriate outcomes that extend beyond those considered in traditional cost-effectiveness analyses;

- And the models should be designed to evaluate many uncertainties inherent in disaster response. 
Based on the above literature review, the difference between our research and the research presented in the above literature is discussed below:

(1) The logistics network structure and aim of our work is different from that of Lee et al's work [53]. Their work focuses on locating PODs considering the affected population as the major factor, and their models are not built based on a multistage logistics network structure. Our work focuses on developing a multi-stage SNS logistics network with quick and flexible response by intelligently deciding the sites of facilities.

(2) All studies presented in [55], [56], [57] and [58] apply stochastic programming to the facility location problem for large-scale emergency relief logistics networks. The occurrence of alternate scenarios and the impact of the emergencies on the demand or the capabilities of the resources are considered. However, in order to do this, it is necessary to know or estimate accurately the probabilities of occurrence of alternate scenarios and the impact of disasters on the demand and the resources, but we usually lack sufficient data to estimate this information. In our work, it is assumed that the status of the situation including the demand and the availability of facilities can be assessed in real-time due to the advancement of communication technologies. Thus the location decisions can be made in realtime based on the real-time assessment. Instead of applying stochastic programming, mixed-integer programming model and heuristic solution will be applied in our work. 


\subsubsection{Literature Review on Simulation Models in Healthcare and Emergency}

\section{Response}

A simulation model of POD operation is developed in [60]. An optimization model for staff assignment and facility layout is combined with this simulation model. A comparison between the results from the simulation and the actual observation of an anthrax-drill exercise is made. The comparison validates the model and approach, even if the model is applied with little historical data.

Similar to [60], another discrete event simulation model used to determine staffing levels for each process in a hypothetical antibiotic distribution center operated in low, medium, and high disease prevalence scenarios caused by bioterrorism attack is presented in [61]. The simulation software package Arena and the embedded optimization engine OptQuest are used [62].

An SNS drill exercise held by the District of Columbia department of health is demonstrated in [63]. This drill exercise is designed to test its plan for operating mass dispensing centers (i.e., PODs) during a bioterrorist attack or other emergencies. The main goals of the exercise were to maximize the throughput of the PODs and quantify the resources (e.g., numbers and types of staff) necessary to respond to various types and sizes of events. Based on the exercise, a computer simulation model is developed and driven by the data collected from the exercise. From the comparison between the exercise and the simulation, they found that the dispensing center could achieve a throughput of 
2.5 persons per minute. The model predicts that if additional staffs can be deployed, the throughput can be improved to 4 to 5 persons per minute.

The work performed in the Center for Emergency Response Analytics (CERA) is described in [64]. Discrete-event simulation is used to help Bay Island develop its plan for responding to an anthrax attack. Specifically the simulation model is also a POD simulation similar to that presented in [60], [61] and [63], which can be used to evaluate candidate PODs, alternative dispensing processes, staffing plans, and traffic-management strategies.

In [65], a discrete event simulation model is used to estimate the throughput of the vaccination clinic. In the model, if the number of clients (arrival intensity) increases, the staff members can be reassigned to different workstations. The model is used to validate whether or not a mass influenza/pneumococcal vaccination clinic could vaccinate 15,000 clients in $17 \mathrm{hrs}$, optimize personnel configuration to maximize the number of clients vaccinated, and estimate the costs and revenue.

All the papers described above are associated with simulations of POD operations under large-scale medical emergency response. None of them does matter with facility location for large-scale emergency response logistics networks.

In [66], a discrete event simulation model is used to tackle a facility location problem, although it is not relevant to large-scale emergency response. This paper addresses the integrated design of production-distribution networks including both the supply chain 
configuration (facility location and assignment) and related operational decisions such as order splitting, transportation allocation and inventory control. A decision support system combining a genetic algorithm based optimization and a discrete event simulation model is developed to optimize the logistics network design by considering facility location decisions and inventory control decisions simultaneously.

In [67], a real-world large-scale uncapacitated warehouse facility location problem is simulated on a digital map in order to generate approximate solutions. A Geographic Information System (GIS) is used to extract the transportation cost, the warehouse candidate sites, the fixed cost of warehouses. Heuristic Greedy-Interchange and Balloon Search is used to optimize the selection of warehouse location.

An agent-based framework for modeling and solving location problems is proposed in [68]. The demand points are represented as a set of passive immobile agents, whereas the facilities to be located are represented as a set of active agents. The interaction between these agents is modeled as gravity forces or anti-gravity forces in physics. Each active agent is attracted by the gravity forces from the passive agents, and pushed away by the anti-gravity forces from other active agents. Each active agent moves on the continuous space, until all the agents find satisfying locations on the space, which leads to appropriate locations covering all the demand points. 


\subsection{Literature Review on the Vehicle Routing Problem (VRP)}

There exists a large amount of literature on the VRP. In this dissertation only a subset of the papers relevant to our specific problems and solutions are reviewed. All major types of vehicle routing problems and the relevant solutions and applications are presented in [69]. An overview of exact and approximate solution algorithms for vehicle routing problems is presented in [70]. A complete classification scheme for vehicle routing problems is given in [71].

Our vehicle routing problem allows split deliveries (i.e., a node can be served by two routes). In [72], a vehicle routing model with split deliveries is formulated, and a solution based on a constraint relaxation branch and bound algorithm is developed. In [73], a Tabu heuristic algorithm for solving a vehicle routing problem with time windows and split deliveries is introduced. In [74], an optimization solution is based on statistical summary of the solution set obtained from a Tabu heuristic. In [75], the initial solution for a split deliveries VRP is constructed by the Clarke and Wright saving algorithm, then a mixedinteger program model is formulated to determine the exchange of nodes between different routes.

There are several papers focusing on the VRP for relief operations during large-scale emergencies. The real-time vehicle routing problems are reviewed in [76]. The vehicle routes are determined in real-time dynamically based on the current status of vehicle locations, travel times and customer requests. An event such as a new user request, the arrival of a vehicle at a destination or the update of travel times could cause re- 
optimization, thus the corresponding solutions must be efficient enough to provide a new solution quickly. The objectives are usually multiple and are concerned with cost, service response time, throughput and so on.

In [77], a planning model combining a multi-commodity network flow problem and a vehicle routing problem is integrated into a natural disaster logistics decision support system. The model addresses the dynamic time-dependent transportation problem that needs to be solved repetitively for each specified time interval during an ongoing disaster. The model generates plans dynamically for delivering relief supplies according to the changing condition during each planning time interval. The plans include the optimal mixed pick-up and delivery schedules for vehicles within the considered planning time interval as well as the optimal quantities and types of materials picked up and delivered on the routes. A similar model is developed in [78], in which a two-phase solution is adopted. In the first phase, a stochastic VRP is solved using the ant colony optimization. In the second phase, the dispatch of commodities is formulated as an integer multicommodity flow problem based on the routings constructed in the first phase.

In [79], a comparison between the pharmaceutical supply chain and the emergency supply chain is made. Various governmental programs relevant to large-scale emergency relief are investigated, and the gaps between the status quo and a desired system are identified. The value and complexity of optimal vehicle routing in large-scale emergency relief operations is highlighted. 
In [80] and [81], two similar models are formulated to route vehicles and minimize the unmet demand and time delay. The first adopts a global search algorithm, and the second adopts a hybrid heuristic algorithm combining Clarke and Wright saving algorithm with Tabu search. In [82], the TSP and VRP models and solutions for minimizing the maximum arrival time and minimizing the average arrival time are developed to deal with routing for relief efforts.

In [83], a two-stage vehicle routing model for minimizing unmet demand and time delay is formulated. In the planning stage, the problem is modeled as a stochastic VRP, in which the demand at nodes and the travel times are uncertain. In the operational stage, the problem is a knapsack problem which assigns the realized demands to the routes constructed in the planning stage.

In our solution algorithm, the Clarke and Wright saving algorithm is used to construct an initial solution, and simulated annealing is used to improve the solution. The Clarke and Wright saving algorithm is based on the merging of routes to reduce the total travel distance [84]. In [85-87], the theory, method and application of simulated annealing is introduced. In [88], a comparative study between a Genetic Algorithm, a Simulated Annealing and a Tabu Search is made. In [89], a simulated annealing heuristic algorithm is developed for solving a vehicle routing problem with time windows.

\subsection{Literature Review on Location-Routing Problems (LRPs)}


In location-routing problems, the facility location decisions and the vehicle routing decisions are correlated and placed into one model, thus seeking for optimal location and routing solutions simultaneously. There are two review papers on LRPs. In [90], a hierarchical taxonomy and classification scheme is developed to categorize the LRP studies in terms of the problem perspective and the solution method. In terms of the problem perspective, one major scheme is to categorize LRP into single-stage LRP and two-stage LRP. The former is primarily concerned with both the location of a set of facilities serving customers and the routing schedules of vehicles departing from facilities and visiting customers. The latter expands its context to a two-layer productiondistribution network involving two-stage transportation including from plants to warehouses and from warehouses to customers. In terms of the solution method, LRP solutions are categorized into exact algorithms and heuristics. Due to the NP-hard characteristics of LRP, heuristics are introduced.

The recent advancements of LRP studies are surveyed in [91]. The heuristic algorithms for solving deterministic LRPs include sequential methods, clustering-based methods, iterative methods and hierarchical methods. In clustering-based methods, the customers are partitioned into clusters first, then a depot is assigned to each cluster and a TSP is solved for each cluster. In iterative methods, the routing stage and the location stage are executed iteratively, and each of them provides feedback to the next execution of the other stage for improvement. In hierarchical methods, the routing is nested within the location solution, in which each neighborhood solution search of location decisions could trigger an evaluation or resolving of routing decisions. Several new LRPs with stochastic, dynamic, or non-standard hierarchical structure are also reviewed in [91]. 
In [92], using standard test data and three LRP solutions, it is found that the best solution for the location decisions without consideration of routing costs does not necessarily generate the lowest cost for the later routing decisions. In [93], four simulation-based algorithms are used to show that the combined LRP algorithms can provide better quality solutions than sequential algorithms. In [94], a comparative study of effects of different cluster methods on LRP solutions are made.

The routing distance estimation formula is studied in LRP studies. In [95], it is found that the expected routing distance between a depot and a customer is determined by the radial distance between them and the average value of the maximum number of customers that can be served by one route in a single-depot and multiple-customer location problem in a continuous plane. In [92], it is recognized that an optimal solution obtained from a typical location-allocation model in terms of radial distance does not necessarily generate the lowest cost solution for routing models in terms of the routing distance. In [96], two routing length estimators are used to determine a location/allocation scheme in a locationallocation-first, routing heuristics-second algorithm.

The Traveling Salesman Location Problem (TSLP) determines the location of a central facility where a tour starts from and visits all customers. In [97], the problem is introduced to determine the minimum cost location of a central facility in continuous space, when a traveling salesman visits some or all of $m$ existing facilities randomly.

In [98], an exact algorithm is used to determine a depot location among a set of candidate points in order to minimize the total depot operating and routing costs in a TSP with 
multiple salesmen. The algorithm is implemented by relaxing the sub-tour elimination constraints and binary constraints and introducing them only when they are violated.

In [99], an exact algorithm using a constraint relaxation technique is presented to solve a multi-depot vehicle-capacitated LRP. The problem is to select depot sites from up to twenty sites within a reasonable number of iterations, determine how many vehicles are to be based at each selected depot and construct vehicle routes. A similar problem is solved by using an graph representation, transforming it into an equivalent constrained assignment problem, and applying a branch and bound algorithm to seek the optimal solution in [100]. In [101], a two-stage location-routing problem is solved as a generalized assignment problem based on Benders decomposition.

In [102], a heuristic algorithm based on location-allocation-first, route-second for an initial solution construction and an improvement algorithm is developed to determine the allocation of hospitals to blood banks and the routing of periodic blood supply deliveries.

In [103], a three-phase sequential method for solving a practical LRP is introduced. The customers are clustered according to their geographical proximity and vehicle capacity. The assignment of customer clusters to suppliers or consolidation terminals is determined by a mathematical model. Finally the routes associated with each cluster are determined using a TSP algorithm.

In [104], a location-allocation-first, route-second LRP algorithm is used to determine the optimal locations of the home bases and the secondary training sites for the mobile 
trainers. The mobile trainers travel from the home bases and visit all the secondary training sites assigned to the home bases.

In [105], a heuristic algorithm consisting of two simulated annealing algorithms for solving a LRP sequentially is used to solve a multi-depot LRP. In [106], a sequential simulated annealing algorithm for solving a location-routing-loading problem for bill delivery services is developed.

In [107] and [108], a two-level LRP for a newspaper distribution network is presented. The newspaper distribution network consists of three levels of facilities including a printing office (PO), a set of transfer points (TPs) and sales points (SPs). The problem is to determine the locations of the PO, TPs, the routing from PO to TPs or SPs and the routing from TPs to SPs with the minimization of operational costs. Three heuristic algorithms are proposed. The first converts the problem to a spanning tree satisfying the constraints with the returning arc deleted. The second adopts a "location-allocation-first, routing-second" approach. The third adopts a "routing-first, location-allocation-second" approach.

In [109], a LRP mathematical model of a distribution network consisting of four levels of facilities is developed and later extended to a dynamic version. A similar multi-level supply chain network design with routing is introduced in [110], and a heuristic algorithm based on LP relaxation and Tabu search is developed for solving it. 
In [111], a LRP is formulated as a Hamiltonian problem, in which the optimal depot locations together with the optimal routes of salesmen must be determined. Several mathematical formulations for the following types of problems are presented: (1) There are neither fixed costs for the depots, nor restriction on the number of depots; (2) There are fixed costs for the depots, but no restriction on the number of depots; (3) There are no fixed costs for the depots, but there is an upper bound on the number of depots; (4) There is more than one salesman based at each depot; (5) Demand points can be visited multiple times by different salesmen. An exact algorithm is developed based on a relaxation of sub-tour elimination constraints. In [112], several heuristic algorithms are introduced for solving the Hamiltonian $p$-median problem.

In [113], a three-phase heuristic algorithm is used to solve a warehouse LRP. In the first phase, the algorithm determines a rough routing plan. In the second phase, the locations of distribution centers are selected, and the routes are allocated to the selected distribution centers according to their distance. In the third phase, the solution is improved by reallocating customers to routes. In [114], a mathematical model for an LRP with consideration of inventory control is presented, and a two-phase heuristic algorithm consisting of a route-first, location-second initial solution and an improvement algorithm is developed to solve the problem.

In [115], a two-phase tabu search is applied to solve a LRP. In the first phase, a specified number of non-tabu swap or add operations on depot locations selection are executed. In the second phase, the routing configuration is updated by a specified number of non-tabu insert or swap operations. 
In [116], an integrated multi-depot hub-location VRP for network planning of parcel delivery service is solved by a heuristic algorithm with multiple iterations between location, allocation and routing decisions. A heuristic algorithm combining variable neighborhood search and tabu search is developed to solve a LRP with non-linear cost function in [117]. In [118], a linear solution of a LRP is used as the initial solution for a tabu search heuristic and provides a lower bound for the heuristic solution. In [119], a continuous LRP model is solved via an iterative heuristic algorithm based on the Weiszfeld procedure.

In [120], three heuristic algorithms are proposed to solve a LRP. Two of those are hierarchical algorithms, every time the location decisions are adjusted by "Add" or "Drop" operations, the affected customers are re-assigned to new routes, until an acceptable solution is obtained.

A nested heuristic for solving LRPs is developed based on tabu search in [121]. A method to approximately estimate the effects of depot location changes on the routing cost is developed.

In [122], a class of two-stage stochastic location-routing models is developed with chance constraints on the probability of route failures or constraints on the expected penalty caused by route failures. The first stage determines the depot locations and vehicle routes. The second stage deals with the failures that occurs as the vehicle capacity is exceeded during pickup at some point, and the vehicle has to return the depot, empty its load and resume the collection at the point where its capacity was exceeded. In [123], 
a two-stage stochastic LRP is presented, in which the demand is uncertain and a penalty is incurred when some nodes are not served due to the vehicle capacity constraints. 


\section{CHAPTER 3 SNS FACILITY LOCATION PROBLEM}

In this chapter, the SNS facility location problem is introduced, a corresponding facility location model is developed, and the effectiveness of the model is discussed.

\subsection{Introduction}

A multi-stage logistics network consisting of strategic national stockpiles at the federal level, Receiving, Staging and Storage (RSS) and Regional Distribution Nodes (RDNs) at the state level, and Points of Dispense (PODs) at the local level, is formed as shown in Figure 4. There are 12 federal level SNS warehouses strategically located across the United States. Once a state is affected by a large-scale emergency requires the SNS supplies, the stocks will be delivered to the affected state as soon as possible. Each state is required to develop its own plan to receive the materials and distribute them to the affected population. To dispense the materials to the public with a state during a largescale emergency, the state-level SNS authority identified a large number of POD locations to cover the population across the state and dispense the materials to the affected population directly. RSSs are responsible for receiving SNS 12-hour push packages or VMI packages from federal strategic national stockpiles, storing the medical supplies, repacking them and distributing them to the assigned RDNs or PODs. There could be a limited number of RSSs allowed to be open during an emergency. For example, only one RSS is allowed to be open in Kentucky for any emergency event. 
RDNs work as intermediate level warehouses, which receive and store the supplies transported by trucks from RSSs, and can cover their neighboring PODs and refill the inventory at PODs quickly and flexibly with available on-site transportation resources. PODs are responsible for receiving the supplies from RDNs or RSSs (it can receive shipment from RSSs directly), and dispensing the supplies to the public directly.

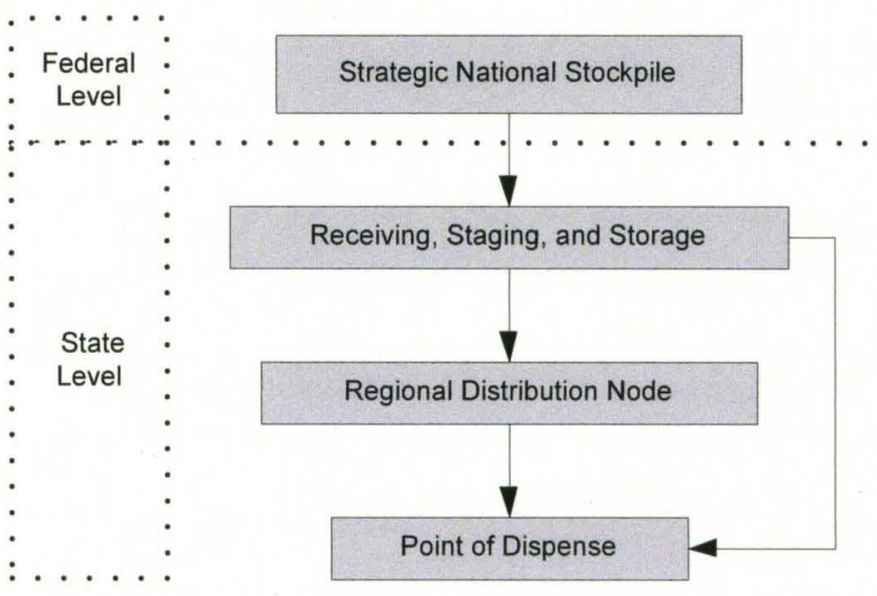

Figure 4. SNS logistics networks.

The state-level SNS authorities identify a large number of candidate RSS and RDN sites. Once a large-scale emergency occurs, they can identify the open PODs according to the scale of the emergency. Then they are required to select and open a set of RSSs and RDNs and determine the assignment among RSSs, RDNs and PODs to form a logistics network.

The selection of locations for RSSs and RDNs affects the speed of delivery of the SNS supplies. If the selected RDNs sites are close to their assigned PODs, the inventory of PODs can be refilled quickly with flexible transportation even in case of surge demand. If 
the selection of locations for RSSs is properly planned, the transportation from RSSs to RDNs can be accomplished within the required duration with fewer trucks.

Moreover, since the selection of facility location is a strategic decision, an optimized selection of locations for RSSs and RDNs can reduce the operation costs with long-term benefits. There is a perception that there are more RDNs than required, and the number of required RDNs can be reduced while still satisfying the demand at PODs within the required duration. The problem is to use mathematical models to determine the location of RSSs and RDNs from the candidate sites. The problem can be stated as below:

Given a set of PODs and their corresponding locations and demands, a set of candidate sites for siting RSSs and RDNs, determine the required number of RSSs and RDNs, their corresponding locations, and determine the corresponding assignment of PODs to RSSs or RDNs and RDNs to RSSs to form a logistics network, so that it can satisfy the demand at the PODs with the minimal cost.

\subsection{Initial Mathematical Models and Experimental Analysis}

Two initial models are developed, an illustrative example is constructed and the results are discussed to develop some insights for further research.

In the first model, the underlying assumption is that the SNS supplies can only be delivered from an RSS to PODs via an RDN, i.e., there is no direct transportation from the RSS to PODs. The inputs include the origin-destination (O-D) distance matrix between RSSs and RDNs, the O-D distance matrix between RDNs and PODs, the fixed 
cost of operating each RSS and RDN, the transportation cost per unit distance, the velocity of vehicles in each stage of transportation, and the required delivery duration. The decision variables include the RSS and RDNs that will be open as well as the paths from the RSS to PODs via RDNs (i.e., the assignment configuration between the RSS and RDNs, and between RDNs and PODs.).

Parameters:

$i$ : index of RSSs $i=1, \cdots, l$;

$j:$ index of RDNs $j=1,2, \cdots, m$;

$k$ : index of PODs $k=1,2, \cdots, n$;

$D_{i j}$ : routing distance from $\operatorname{RSS} i$ to $\operatorname{RDN} j$;

$E_{j k}$ : routing distance from $\operatorname{RDN} j$ to $\operatorname{POD} k$;

$T C$ : the required delivery duration;

$F_{i}$ : the fixed cost of operating RSS $i$;

$C_{j}$ : the fixed cost of operating RDN $j$;

$H$ : the transportation cost per unit of distance;

$V_{1}$ : the velocity of vehicles during the transportation stage from RSSs to RDNs;

$V_{2}$ : the velocity of vehicles during the transportation stage from RDNs to PODs;

Decision Variables:

$R_{i}=1$, if RSS $i$ is open; 0 , otherwise;

$o_{j}=1$, if RDN $j$ is open; 0 , otherwise;

$P_{i j k}=1$, if RSS $i$ serves $\operatorname{POD} k$ via RDN $j ; 0$, otherwise; 
The objective function (1) minimizes the fixed cost of operating the open RSS and RDNs

$$
\min \sum_{i=1}^{l} F_{i} * R_{i}+\sum_{j=1}^{m} C_{j} * O_{j}+\sum_{i=1}^{l} \sum_{j=1}^{m} \sum_{k=1}^{n} P_{i j k} * H *\left(D_{i j}+E_{j k}\right)
$$

Subject to

$\sum_{i=1}^{l} \sum_{j=1}^{m} P_{i j k} \geq 1$ for $k=1, \cdots, n$;

$2+\frac{D_{i j}}{V_{1}} * P_{i j k}+\frac{E_{j k}}{V_{2}} * P_{i j k} \leq T C$ for $i=1, \cdots, l ; j=1, \cdots, m ; k=1, \cdots, n ;$

$\sum_{i=1}^{l} R_{i}=1$

$P_{i j k} \leq R_{i}$ for $i=1, \cdots, l ; j=1, \cdots, m ; k=1, \cdots, n$;

$P_{i j k} \leq O_{j}$ for $i=1, \cdots, l ; j=1, \cdots, m ; k=1, \cdots, n$;

$R_{i}=0$ or 1 for $i=1, \cdots, l$;

$o_{j}=0$ or 1 for $j=1, \cdots, m$;

$P_{i j k}=0$ or 1 for $i=1, \cdots, l ; j=1, \cdots, m ; k=1, \cdots, n$;

as well as the cost of transporting material from the RSS to PODs via RDNs. Constraint (2) guarantees that each POD is covered by the SNS delivery system. Constraint (3) assures the SNS can arrive at PODs from the RSS within the required delivery duration. This constraint incorporates 30 minutes loading/unloading time at the RSS, RDNs as well as PODs. Constraint (4) allows only one RSS to be opened. Constraint (5) assures that the selected path can only start from an open RSS. Constraint (6) assures that the selected paths can only go via the open RDNs. Constraints (7), (8) and (9) limit the decision 
variables to be binary variables. Table 1 shows the number of decision variables and constraints of this model for two specific scenarios.

Table 1 Numbers of Decision Variables and Constraints of Model 1

\begin{tabular}{|c|c|c|c|c|c|c|c|c|c|c|c|c|c|c|c|}
\hline \multirow{2}{*}{$\begin{array}{l}\text { No. } \\
\text { of } \\
\text { RS } \\
\text { Ss }\end{array}$} & \multirow{2}{*}{ 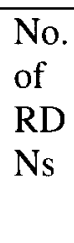 } & \multirow{2}{*}{$\begin{array}{l}\text { No. } \\
\text { of } \\
\text { PO } \\
\text { Ds }\end{array}$} & \multicolumn{4}{|c|}{$\begin{array}{l}\text { No. of Decision } \\
\text { Variables }\end{array}$} & \multicolumn{9}{|c|}{ No. of Constraints } \\
\hline & & & $R_{i}$ & $o_{j}$ & $P_{i j k}$ & Total & (2) & (3) & (4) & (5) & (6) & $(7)$ & $(8$ & (9) & total \\
\hline$l$ & $m$ & $n$ & $l$ & $m$ & $\operatorname{lm} n$ & $\begin{array}{l}l \\
+m \\
+l m n\end{array}$ & $n$ & $l m n$ & 1 & $l m r$ & $\operatorname{lm} n$ & $l$ & $m$ & $\operatorname{lm} n$ & $\begin{array}{l}4 \operatorname{llm} n \\
+m \\
+n \\
+l \\
+1\end{array}$ \\
\hline 2 & 10 & 20 & 2 & $\begin{array}{l}1 \\
0\end{array}$ & 400 & 412 & 20 & $\begin{array}{l}40 \\
0\end{array}$ & 1 & $\begin{array}{l}40 \\
0\end{array}$ & $\begin{array}{l}40 \\
0\end{array}$ & 2 & 10 & 400 & 1641 \\
\hline 2 & 50 & 250 & 2 & $\begin{array}{l}5 \\
0\end{array}$ & $\begin{array}{l}250 \\
00\end{array}$ & $\begin{array}{l}2505 \\
2\end{array}$ & $\begin{array}{l}25 \\
0\end{array}$ & $\begin{array}{l}25 \\
00 \\
0\end{array}$ & 1 & $\begin{array}{l}25 \\
00 \\
0\end{array}$ & $\begin{array}{l}25 \\
00 \\
0\end{array}$ & 2 & 50 & $\begin{array}{l}250 \\
00\end{array}$ & $\begin{array}{l}1003 \\
03\end{array}$ \\
\hline
\end{tabular}

In the second model, we assume that the direct shipments between RSSs and PODs are allowed. Thus, a new set of parameters $B_{i k}$ and a new set of decision variables $L_{i k}$ are added.

Parameters:

$i$ : index of RSSs $i=1, \cdots, l$;

$j:$ index of RDNs $j=1,2, \cdots, m$;

$k$ : index of PODs $k=1,2, \cdots, n$;

$B_{i k}$ : routing distance from $\mathrm{RSS} i$ to $\operatorname{POD} k$; 
$D_{i j}:$ routing distance from RSS $i$ to $\operatorname{RDN} j$;

$E_{j k}$ : routing distance from $\operatorname{RDN} j$ to $\operatorname{POD} k$;

$T C$ : the required delivery duration;

$F_{i}$ : the fixed cost of operating RSS $i$;

$C_{j}$ : the fixed cost of operating $\operatorname{RDN} j$;

$H$ : the transportation cost per unit of distance;

$V_{1}$ : the velocity of vehicles during the transportation stage from RSSs to RDNs;

$V_{2}$ : the velocity of vehicles during the transportation stage from RDNs to PODs;

Decision Variables:

$R_{i}=1$, if RSS $i$ is open; 0 , otherwise;

$O_{j}=1$, if RDN $j$ is open; 0 , otherwise;

$P_{i j k}=1$, if RSS $i$ serves POD $k$ via $\operatorname{RDN} j ; 0$, otherwise;

$L_{i k}=1$, if RSS $i$ serves POD $k$ directly; 0 , otherwise;

$$
\begin{aligned}
\min \sum_{i=1}^{l} F_{i} * R_{i} & +\sum_{j=1}^{m} C_{j} * O_{j}+\sum_{i=1}^{l} \sum_{j=1}^{m} \sum_{k=1}^{n} P_{i j k} * H *\left(D_{i j}+E_{j k}\right) \\
& +\sum_{i=1}^{l} \sum_{k=1}^{n} L_{i k} * H * B_{i k}
\end{aligned}
$$

Subject to

$$
\sum_{i=1}^{l} \sum_{j=1}^{m} P_{i j k}+\sum_{i=1}^{l} L_{i k} \geq 1 \text { for } k=1, \cdots, n ;
$$


$2+\frac{D_{i j}}{V_{1}} * P_{i j k}+\frac{E_{j k}}{V_{2}} * P_{i j k} \leq T C$ for $i=1, \cdots, l ; j=1, \cdots, m ; k=1, \cdots, n$

$1+\frac{B_{i k}}{V_{3}} * L_{i k} \leq T C$ for $i=1, \cdots, l ; k=1, \cdots, n$;

$\sum_{i=1}^{l} R_{i}=1$

$P_{i j k} \leq R_{i}$ for $i=1, \cdots, l ; j=1, \cdots, m ; k=1, \cdots, n$;

$L_{i k} \leq R_{i}$ for $i=1, \cdots, l ; k=1, \cdots, k$;

$P_{i j k} \leq O_{j}$ for $i=1, \cdots, l ; j=1, \cdots, m ; k=1, \cdots, n$;

$R_{i}=0$ or 1 for $i=1, \cdots, l$;

$o_{j}=0$ or 1 for $j=1, \cdots, m$;

$P_{i j k}=0$ or 1 for $i=1, \cdots, l ; j=1, \cdots, m ; k=1, \cdots, n$;

$L_{i k}=0$ or 1 for $i=1, \cdots, l ; k=1, \cdots, n$;

The objective function (10) includes the cost of transporting material from RSSs to PODs directly. In constraint (11), each POD must be served by one RDN or one RSS. Constraint (13) guarantees the direct shipment from RSSs to PODs within the required delivery duration. Constraint (16) ensures that a direct shipment from RSSs to PODs can only occur at an open RSS. The other constraints have similar meaning as in Model 1.

\section{An Illustrative Example:}

In order to show the effectiveness of the above two models, we use the following example. We assume that the velocity of vehicles in both stages is $45 \mathrm{mph}$, the 
transportation cost per unit distance is $\$ 4$ per mile, and the required delivery duration is 5 hours. The two candidate RSS sites are selected randomly. Ten candidate RDN sites and twenty candidate POD sites are randomly selected around the triangle area between Louisville, Lexington and Cincinnati. Figure 5 shows these sites using Google Earth Maps, on which the boxes indicate RSS sites, the balloons denoted by $\mathrm{N}$ indicate RDN sites, and the balloons denoted by $\mathrm{P}$ indicate POD sites. We also assumed the data for the fixed operation cost of opening these RSSs and RDNs as shown in Table 2.

Table 2 Candidate RDN and RSS Sites

\begin{tabular}{|l|r|}
\hline RDN & Fixed Cost \\
\hline 1 & 100,000 \\
\hline 2 & 95,000 \\
\hline 3 & 100,000 \\
\hline 4 & 100,000 \\
\hline 5 & 10,000 \\
\hline 6 & 100,000 \\
\hline 7 & 100,000 \\
\hline 8 & 100,000 \\
\hline 9 & 100,000 \\
\hline 10 & 100,000 \\
\hline & \\
\hline RSS & Fixed Cost \\
\hline 1 & $1,000,000$ \\
\hline 2 & $1,200,000$ \\
\hline
\end{tabular}




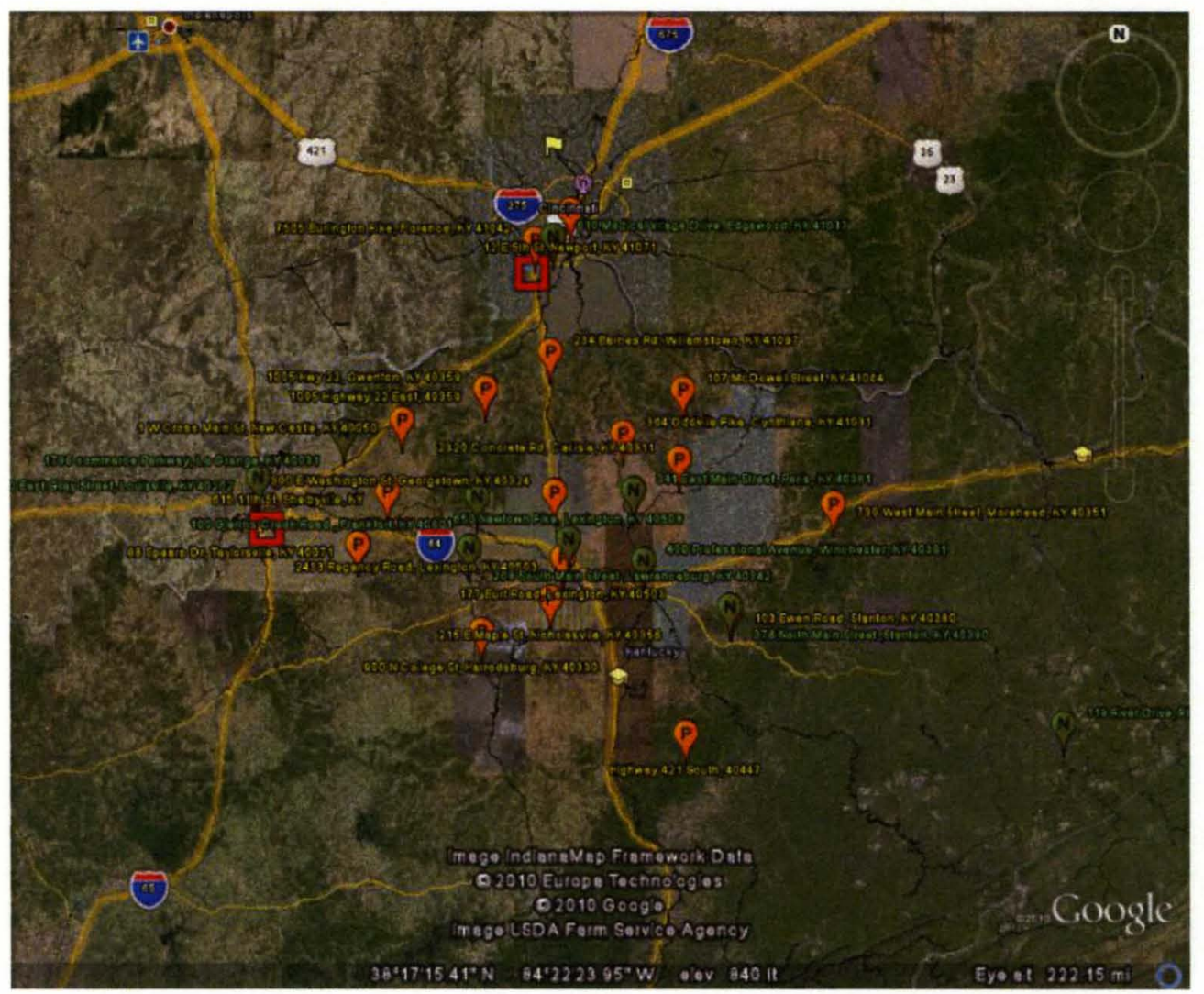

Figure 5. Candidate sites for RSSs, RDNs and PODs.

Using the above inputs, a Lingo file developed based on the first model is shown in Appendix A. In the solution, RSS 2 is selected to be open along with RDN 1 and RDN 8, as shown in Figure 6. RSS 2 and RDN 8 are very close to each other. If we permit direct shipments from RSS to PODs, RSS 2 could replace RDN 8 to serve the neighboring areas.

A sensitivity analysis in terms of the required delivery duration is conducted as shown in Table 3. When the required time window is 4 hours ( $\mathrm{TC}=4$ "hrs" ), there is no feasible solution. As it is increased to 5 hours, the optimal solution is to open RSS 2, RDN 1 and RDN 8. When the required delivery duration is 6 hours or more, the solution is to open 
RSS 1 and RDN 5. The illustrating example shows that our model is effective in assuring the SNS deliveries within the required delivery duration.

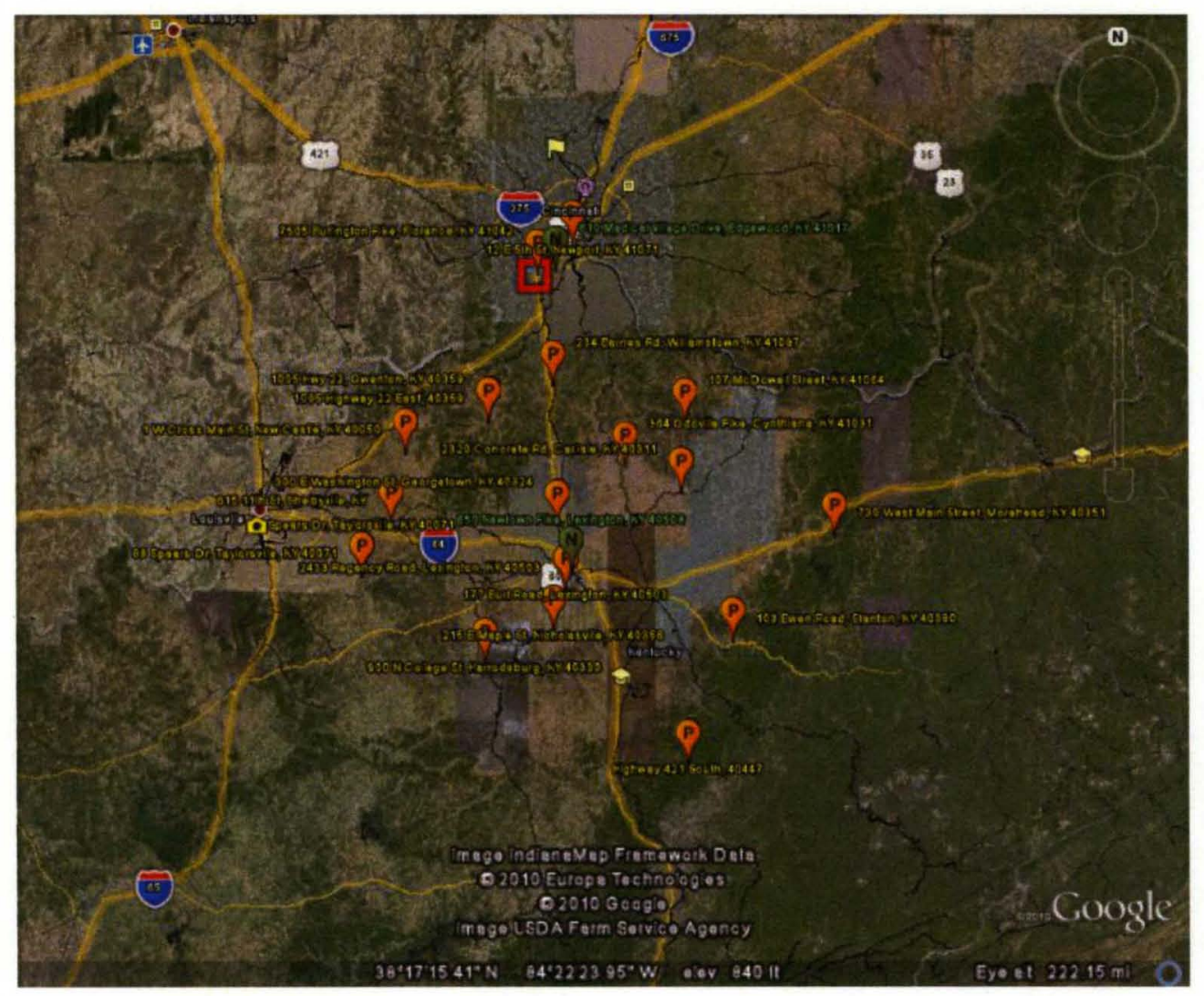

Figure 6. the selected RSSs and RDNs.

The Lingo file developed based on the second model is shown in Appendix B. Taking the same inputs as Model 1, this model gives the outputs shown as in Table 4. When $T C=3 \mathrm{hrs}$, there is no feasible solution; when $T C=4 \mathrm{hrs}$ or over $4 \mathrm{hrs}$, the direct shipments from RSS1 to all PODs are the best solutions. 
Table 3 Sensitivity Analysis of the Model

\begin{tabular}{|l|l|l|l|l|}
\hline $\begin{array}{l}\text { The Required } \\
\text { Time } \\
\text { Window(hrs) }\end{array}$ & 4 & 5 & 6 & 7 \\
\hline Solution & Infeasible & $\begin{array}{l}\text { RSS 2, RDN1 and } \\
\text { RDN 8 }\end{array}$ & RSS 1, RDN 5 & RSS 1, RDN 5 \\
\hline
\end{tabular}

Table 4 The Output of Model 2

\begin{tabular}{|c|c|c|c|c|}
\hline $\begin{array}{c}\text { The Required } \\
\text { Time } \\
\text { Window(hrs) }\end{array}$ & 3 & 4 & 5 & 6 \\
\hline Solution & Infeasible & RSS1 & RSS1 & RSS1 \\
\hline
\end{tabular}

\section{Analysis of Model 1 and Model 2:}

Based on the output of Model 1 and Model 2, we can have the following analysis:

(1) Reducing the number of RDNs can satisfy the delivery duration requirement. In the illustrative example of Model 1, the number of required RDNs is reduced from 10 to 2 or even 1.

(2) The direct shipments from RSSs to PODs are recommended. From the comparison of the solutions between Model 1 and Model 2, it can be concluded 
that removing the intermediate level RDNs and shipping the supplies from RSSs to RDNs directly can shorten the delivery time and reduce the total cost.

(3) The resources for transporting materials from RSSs to PODs directly or via RDNs should be considered in further research. With the assumption of unlimited transportation resources in the underlying, the above two models give the results as indicated in (1) and (2). It is necessary to re-evaluate (1) and (2) under a more realistic assumption of limited transportation resources.

\subsection{Transshipment and Location Model}

Given the open PODs and their demands, the candidate sites for RSSs and RDNs and the corresponding fixed cost of opening them, and the transshipment cost per pallet between sites, the transshipment and location model is formulated to determine the RSSs and RDNs to open, the quantity of materials shipped from open RSSs to RDNs, from open RDNs to PODs and from open RSSs to PODs, to minimize the total cost including the transshipment cost and the total fixed cost of opening facilities.

Sets:

I: set of available RSSs;

$J$ : set of available RDNs;

$K$ : set of open PODs;

Parameters:

$a_{i j}$ : transportation cost per pallet from $\operatorname{RSS} i$ to $\operatorname{RDN} j, i \in I, j \in J$; 
$b_{j k}$ : transportation cost per pallet from $\operatorname{RDN} j$ to $\operatorname{POD} k, j \in J, k \in K$;

$c_{i k}$ : transportation cost per pallet from RSS $i$ to $\operatorname{POD} k, i \in I, k \in K$;

$F_{i}$ : fixed cost of opening or operating RSS $i, i \in I$;

$G_{j}$ : fixed cost of opening or operating $\operatorname{RDN} j, j \in J$;

$D_{k}$ :number of pallets demanded at POD $k, k \in K$;

$N$ : maximum number of allowed open RSSs;

$C_{j}$ :maximum number of pallets that can be handled at $\operatorname{RDN} j, j \in J$;

Decision Variables:

$x_{i j}$ : number of pallets shipped from RSS $i$ to $\operatorname{RDN} j, i \in I, j \in J$;

$y_{j k}$ : number of pallets shipped from $\operatorname{RDN} j$ to $\operatorname{POD} k, j \in J, k \in K$;

$z_{i k}$ : number of pallets shpped from RSS $i$ to POD $k, i \in I, k \in K$;

$U_{i}=\left\{\begin{array}{rr}1 & \operatorname{RSS} i \text { is open, } i \in I \\ 0 & \text { otherwise; }\end{array}\right.$

$V_{j}=\left\{\begin{array}{rr}1 & \mathrm{RDN} j \text { is open, } j \in J \\ 0 & \text { otherwise }\end{array}\right.$

$\min \sum_{i \in I} \sum_{j \in J} a_{i j} * x_{i j}+\sum_{j \in J} \sum_{k \in K} b_{j k} * y_{j k}+\sum_{i \in I} \sum_{k \in K} c_{i k} * z_{i k}+\sum_{i \in I} F_{i} * U_{i}+\sum_{j \in J} G_{j} * V_{j}$

subject to: 


$$
\sum_{i \in I} U_{i} \leq N
$$

$$
\sum_{j \in J} y_{j k}+\sum_{i \in I} z_{i k} \geq D_{k} \forall k \in K
$$

$$
\sum_{i \in I} x_{i j} \leq C_{j} V_{j} \forall j \in J
$$

$$
\sum_{i \in I} x_{i j}=\sum_{k \in K} y_{j k} \forall j \in J ;
$$

$$
\sum_{j \in J} x_{i j}+\sum_{k \in K} z_{i k} \leq M * U_{i} \quad \forall i \in I
$$

$x_{i j} \geq 0, y_{j k} \geq 0, z_{i k} \geq 0, \forall i \in I, j \in J, k \in K$

$U_{i}=1$ or $0, \quad V_{j}=1$ or $0 \quad \forall i \in I, j \in J, k \in K$

The objective function (22) minimizes the total cost including the transshipment cost from RSSs to RDNs, from RDNs to PODs and from RSSs to PODs. The maximum number of open RSSs is specified in (23). Constrains (24) assure that the demand at each POD must be satisfied. The throughput capacity constraints at each RDN are specified in (25). Constraints (26) enforces the flow balance at RDNs. Constraints (27) assure that only open RSSs can supply pallets, $M$ is a very large positive number in these constraints. Constraints (28) and (29) are data type constraints for decision variables. 
In the above model, $a_{i j}, b_{j k}, c_{i k}$ are transportation rates between RSSs and RDNs, between RDNs and PODs and between RSSs and PODs, which are measured by dollars per pallet from an origin site to a destination site. We can only calculate them approximately before the vehicle routes are determined exactly. Suppose the routing distance between site $i$ and site $j$ is $d_{i j}$, the average cost for each truck per mile is $\$ 2$, and the average capacity of trucks measured by pallets can be calculated, then the transportation rate (measured by $\$ /$ mile) between site $i$ and site $j$ is $\frac{d_{i j^{*}(\$ 2 / m i l e)}}{\text { average capacity of trucks }}$. The transportation rates between two sites are proportional to the routing distance between them, and adjusted by the dollars per mile and the average capacity of the trucks.

\subsection{Experiments and Result Analysis}

The exact solution of the transshipment and location model in Section 3.3 is implemented in the SNS planning tool kits due to its effectiveness and quick response. The solution is implemented with Microsoft Solver Foundation, which is a .Net runtime software package for mathematical programming, modeling and optimization [124]. Table 5 lists the execution results of 32 test cases. The first column labeled by "Test Case" lists the IDs of the test cases; the second column labeled by "\# of RSSs" lists the number of candidate RSSs in each test case; the third column labeled by "\# of RDNs" lists the number of candidate RDNs in each test case; the fourth column labeled by "\# of PODs" lists the number of candidate PODs in each test case; the fifth column labeled by "Max \# of open RSSs" lists the maximum number of allowable open RSSs, which is denoted as $N$ in the model; the sixth column labeled by "\# of DVs" lists the number of decision 
variables in the model; the seventh column labeled by "\# of Constraints" lists the number of constraints except the data type constraints on decision variables; the eighth column labeled by "\# of open RSSs" lists the number of open RSSs in the solution; the ninth column labeled by "\# of open RDNs" lists the number of open RDNs in the solution; the tenth column labeled by "Execution Time" lists the time to run the program on each test case, measured in seconds. These tests are run on a computer with $3.40 \mathrm{GHz}$ Intel Pentium 4 CPU, 3.39 GHz 2G RAM, and Microsoft windows XP Profession 2002.

Table 5 The Execution Results of Transshipment \& Location Model

\begin{tabular}{|c|c|c|c|c|c|c|c|c|c|}
\hline $\begin{array}{l}\text { Test } \\
\text { Case }\end{array}$ & $\begin{array}{l}\text { \# of } \\
\text { RSSs }\end{array}$ & $\begin{array}{c}\text { \# of } \\
\text { RDN } \\
S \\
\end{array}$ & $\begin{array}{c}\text { \# of } \\
\text { POD } \\
s \\
\end{array}$ & $\begin{array}{c}\text { Max \# } \\
\text { of open } \\
\text { RSSs }\end{array}$ & $\begin{array}{l}\text { \# of } \\
\text { DVs }\end{array}$ & $\begin{array}{c}\text { \# of } \\
\text { Constraint } \\
s\end{array}$ & $\begin{array}{l}\text { \# of } \\
\text { open } \\
\text { RSSs } \\
\end{array}$ & $\begin{array}{l}\text { \# of } \\
\text { open } \\
\text { RDNs }\end{array}$ & $\begin{array}{l}\text { Execution } \\
\text { Time } \\
\text { (seconds) }\end{array}$ \\
\hline 1 & 2 & 65 & 5 & 1 & 532 & 138 & 1 & 4 & 6.08 \\
\hline 2 & 2 & 65 & 10 & 1 & 867 & 143 & 1 & 8 & 2.3 \\
\hline 3 & 2 & 65 & 20 & 1 & 1537 & 153 & 1 & 17 & 5.69 \\
\hline 4 & 2 & 65 & 30 & 1 & 2207 & 163 & 1 & 25 & 11 \\
\hline 5 & 2 & 65 & 50 & 1 & 3547 & 183 & 1 & 26 & 6.17 \\
\hline 6 & 2 & 65 & 50 & 1 & 3547 & 183 & 1 & 28 & 10.78 \\
\hline 7 & 2 & 65 & 70 & 1 & 4887 & 203 & 1 & 35 & 12.92 \\
\hline 8 & 2 & 65 & 90 & 1 & 6227 & 223 & 1 & 40 & 17.33 \\
\hline 9 & 2 & 65 & 110 & 1 & 7567 & 243 & 1 & 42 & 11.25 \\
\hline 10 & 2 & 65 & 130 & 1 & 8907 & 263 & 1 & 46 & 14.14 \\
\hline 11 & 2 & 65 & 150 & 1 & $\begin{array}{c}1024 \\
7\end{array}$ & 283 & 1 & 41 & 35.94 \\
\hline 12 & 2 & 65 & 170 & 1 & $\begin{array}{c}1158 \\
7\end{array}$ & 303 & 1 & 42 & 19.45 \\
\hline 13 & 2 & 65 & 190 & 1 & $\begin{array}{c}1292 \\
7\end{array}$ & 323 & 1 & 51 & 34.34 \\
\hline 14 & 2 & 65 & 210 & 1 & $\begin{array}{c}1426 \\
7\end{array}$ & 343 & 1 & 52 & 27.34 \\
\hline 15 & 2 & 65 & 230 & 1 & $\begin{array}{c}1560 \\
7\end{array}$ & 363 & 1 & 52 & 31.4 \\
\hline 16 & 2 & 65 & 250 & 1 & $\begin{array}{c}1694 \\
7\end{array}$ & 383 & 1 & 59 & 30.78 \\
\hline 17 & 2 & 65 & 260 & 1 & $\begin{array}{c}1761 \\
7\end{array}$ & 393 & 1 & 50 & 35.13 \\
\hline
\end{tabular}




\begin{tabular}{|c|c|c|c|c|c|c|c|c|c|}
\hline \multicolumn{9}{|c|}{ Average Execution Time of Test Cases $1-17$} & 18.36 \\
\hline 18 & 3 & 65 & 30 & 1 & 2303 & 164 & 1 & 21 & 6.09 \\
\hline 19 & 3 & 65 & 90 & 1 & 6383 & 224 & 1 & 41 & 24.53 \\
\hline 20 & 3 & 65 & 150 & 1 & $\begin{array}{c}1046 \\
3\end{array}$ & 284 & 1 & 44 & 64.42 \\
\hline 21 & 3 & 65 & 210 & 1 & $\begin{array}{c}1454 \\
3\end{array}$ & 344 & 1 & 51 & 75.95 \\
\hline 22 & 3 & 65 & 260 & 1 & $\begin{array}{c}1794 \\
3\end{array}$ & 394 & 1 & 56 & 63.25 \\
\hline \multicolumn{9}{|c|}{ Average Execution Time of Test Cases $18-22$} & 46.848 \\
\hline 23 & 4 & 65 & 30 & 1 & 2399 & 165 & 1 & 23 & 23.8 \\
\hline 24 & 4 & 65 & 90 & 1 & 6539 & 225 & 1 & 40 & 62.06 \\
\hline 25 & 4 & 65 & 150 & 1 & $\begin{array}{c}1067 \\
9\end{array}$ & 285 & 1 & 43 & 63.33 \\
\hline 26 & 4 & 65 & 210 & 1 & $\begin{array}{c}1481 \\
9\end{array}$ & 345 & 1 & 55 & 67.06 \\
\hline 27 & 4 & 65 & 260 & 1 & $\begin{array}{c}1826 \\
9\end{array}$ & 395 & 1 & 51 & 94.42 \\
\hline \multicolumn{9}{|c|}{ Average Execution Time of Test Cases $23-27$} & 62.134 \\
\hline 28 & 4 & 65 & 210 & 2 & $\begin{array}{c}1481 \\
9\end{array}$ & 345 & 2 & 53 & 356.77 \\
\hline 29 & 4 & 65 & 260 & 2 & $\begin{array}{c}1826 \\
9\end{array}$ & 395 & 2 & 53 & 191.23 \\
\hline 30 & 4 & 65 & 260 & 3 & $\begin{array}{c}1826 \\
9\end{array}$ & 395 & 3 & 57 & 452.76 \\
\hline 31 & 5 & 0 & 1500 & 5 & 7505 & 1506 & 5 & 0 & 57.75 \\
\hline 32 & 10 & 0 & 1500 & 5 & $\begin{array}{c}1501 \\
0\end{array}$ & 1511 & 10 & 0 & 585.85 \\
\hline
\end{tabular}

These test cases are created randomly with different problem sizes in terms of the number of RSSs, RDNs and PODs. From all the results, it can be observed that our solution can reduce the total cost by reducing the number of open RDNs. Another criterion to evaluate the solution is the execution time of the program. The web-based SNS planning tool kit requires that a decision request had better to be responded to within 2 minutes due to the session timeout setting in web-based systems. The test cases $(1-17)$ are relatively smaller size of problems, in which there are only two candidate RSSs, only one RSS can be open, there are about 65 candidate RDNs, and there are about 260 PODs to be selected to be open. From the results of test cases $(1-17)$, it can be observed that the 
execution time is very short, since the average execution time is 18.36 seconds and the maximum execution time is 35.13 seconds. Thus the solution performs well for problems in small states. In test cases $(18-27)$, the problems are extended to have three or four RSSs, the execution time is prolonged but still can be accepted by the requirements of the web-based SNS planning tool kit. Test cases (28-30) allow more than one RSSs to be open, and the execution time becomes too long for a web-based system. Test cases 31 and 32 try to solve the SNS facility location problem in Texas, in which there is no intermediate RDNs, the relief materials are delivered from RSSs to PODs directly and there could be more candidate RSSs and PODs in the problem. It can be observed that our solution cannot work well on this type of problems in terms of the execution time. Therefore, it is necessary to develop heuristics algorithms for solving the types of problems in test cases $(28-32)$ in the future. 


\section{CHAPTER 4 SNS VEHICLE ROUTING PROBLEM}

In this chapter, the SNS VRP is described, the model for the VRP is formulated and the corresponding solution algorithm is developed. A comparison is made between our solution algorithm and the current best practices.

\subsection{Introduction}

The SNS facility location model and the corresponding solution determine the open set of RSSs and RDNs and the corresponding assignment to form a logistics network for responding to a large-scale emergency. In the logistics network, each open RSS or RDN is taken as a depot, and the PODs or RDNs assigned to the depot are the nodes served by the depot. Once a depot receives relief materials, a specified set of trucks deliver the materials to the served nodes from the depot. Each truck loads a specified quantity of materials required by the nodes in a route served by the truck at the depot. Each truck visits each served node along the route and unloads the required materials and returns to the depot. Therefore, a VRP model should be formulated to determine the routes for each truck in the context of SNS distribution operations.

The SNS VRP model must assure that all the delivery tasks should be accomplished within a specified duration. It is required to provide a plan for quick dispatch of the relief 
materials to the area affected by a large-scale emergency. The more quickly the materials are delivered to the affected population, the more effectively the damage caused by the emergency can be mitigated. Therefore, a maximum delivery duration constraint is required in the formulation of our VRP model.

The SNS VRP model allows more than one route per truck. In a typical VRP model, it is assumed that a truck can only serve one route. However, considering the heavy demand and scarcity of truck resources during a large-scale emergency, a truck is allowed to serve multiple routes. After a truck completes one route and returns to the depot, it takes a break for maintenance, refueling and so on, then goes to serve another route, as long as the maximum delivery duration constraint is not violated.

The SNS VRP model allows split deliveries, i.e., a node can be served by more than one route. If the demand at a node is too large to be carried by even the largest truck in one trip, the demand at the node should be met by multiple deliveries. The deliveries for such a node are assigned to different routes served by either the same truck or different trucks respectively.

A general multiple-vehicle VRP model allowing split deliveries and multiple routes per truck with a total delivery duration constraint, is formulated in this chapter. 


\subsection{Model and Solution}

\subsubsection{Mathematical Model}

The notations and conventions are defined as below.

\section{$\underline{\text { Notations }}$}

$L:$ set of trucks;

$V L$ : set of virtual trucks;

$T L$ : set of truck types;

$K_{l}$ : the capacity of truck $l$, virtual truck $l$ or truck type $l, l \in L \cup V L \cup T L$;

$o:$ the depot ;

$N_{o}$ : the set of nodes visited by trucks starting from depot $o$;

$N$ : the set of nodes, $N=\{o\} \cup N_{o}$;

$R D_{s}$ : quantity of materials to be shipped from depot $o$ to node $s, s \in N_{o}$;

$d_{i j}$ : distance from node $i$ to node $j, i, j \in N$;

$L T$ : the average loading time at depot $o$;

$U T$ : the average unloading time at each visited node;

$B T$ : the break duration between two consecutive trips for a truck;

$V:$ the average speed of trucks; 
$D T:$ the maximum allowed duration for delivery of all pallets to the targeted PODs;

$M T_{l}:$ maximum number of trips for truck $l, M T_{l}=\sum_{s \in N_{o}} \frac{R D_{s}}{K_{l}}$ (the definition of $M T_{l}$ assumes an extreme case that all the delivery tasks are accomplished by just truck $l$ );

\section{Conventions:}

( ): a tuple, consisting of a set of variables, sets or ordered lists;

\langle\rangle : an ordered list, consisting of a sequence of nodes along a route;

$\{$ \}: a set, which is used to represent a set of elements;

Decision Variables:

$R_{u v r l}=1$ if node $u$ immediately precedes node $v$ in the $r$ th route of truck $l, u, v \in N, l \in$ $L, r=1, \cdots, M T_{l} ; 0$ otherwise;

$S_{u r l}$ : quantity of materials shipped to node $u$ on the $r$ th route of truck $l, u \in N_{o}, l \in L, r=$ $1, \cdots, M T_{l}$

Objective and Constraints:

$\min \sum_{l \in L} \sum_{r=1}^{M T_{l}} \sum_{u \in N} \sum_{v \in N, u \neq v} d_{u v} * R_{u v r l}$

Subject to:

$$
\sum_{v \in N_{o}} R_{\text {ovrl }} \leq 1 \quad \forall l \in L, r=1, \cdots, M T_{l}
$$




$$
\begin{aligned}
& \sum_{s \in N} R_{\text {surl }}=\sum_{d \in N} R_{u d r l} \quad \forall l \in L, u \in N, r=1, \cdots, M T_{l} \\
& \sum_{l \in L} \sum_{r=1}^{M T_{l}} S_{u r l}=R D_{u} \quad \forall u \in N_{o} \\
& \sum_{s \in N} R_{\text {surl }} \geq \frac{S_{u r l}}{R D_{u}} \forall u \in N_{o}, l \in L, r=1, \cdots, M T_{l} \\
& \sum_{u \in N_{o}} S_{u r l} \leq K_{l} \forall l \in L, r=1, \cdots, M T_{l} \\
& \sum_{r=1}^{M T_{l}}\left(L T * \sum_{d \in N_{o}} R_{o d r l}+\sum_{u \in N} \sum_{v \in N_{o}, u \neq v} U T * R_{u v r l}+\sum_{u \in N} \sum_{v \in N, u \neq v} \frac{d_{u v}}{V} * R_{u v r l}\right) \\
& +\sum_{r=2}^{M T_{l}}\left(B T * \sum_{d \in N_{o}} R_{o d r l}\right) \leq D T \forall l \in L \\
& \sum_{u \in S} \sum_{v \in S} R_{u v r l} \leq|S|-1 \forall S \subset N_{o} \text { and }|S| \geq 2, l \in L, r=1, \cdots, M T_{l} \\
& R_{u v r l}=1 \text { or } 0 \forall u, v \in N, l \in L, r=1, \cdots, M T_{l} \\
& S_{u r l} \geq 0 \forall u \in N, l \in L, r=1, \cdots, M T_{l}
\end{aligned}
$$

The objective (30) minimizes the total distance traveled by the trucks. It is assumed that the total operational cost is proportional to the total traveled distance in our model. Constraints (31) enforce that each truck only leaves a depot at most once for each route it serves. Constraints (32) enforce that each node must be entered and exited by the same 
truck in one route. Constraints (33) assure that the demand at each node must be satisfied by one or more routes. Constraints (34) formulate the relationship between two sets of decision variables. If no materials are delivered to a node in a route, then any truck serving this route does not stop at this node. Constraints (35) enforce truck capacity constraints. The quantity of materials measured in pallets delivered on a route cannot exceed the capacity of the serving truck. Constraints (36) guarantee that all the delivery tasks are completed within the required maximum duration, and includes load, unload, travel and break times between two consecutive trips for a truck. Instead of minimizing the delay time in their objective functions as done in other research (see [80], [81], [82] and [83] ), we use these constraints to assure quick response. Constraints (37) are subtour elimination constraints. Constraints (38) and (39) are data type constraints for decision variables.

Summing up constraints (34) over the routes of all trucks yields the following constraints:

$$
\sum_{l \in L} \sum_{r=1}^{M T_{l}} \sum_{s \in N} R_{s u r l} \geq \frac{1}{R D_{u}} * \sum_{l \in L} \sum_{r=1}^{M T_{l}} S_{u r l}=1 \forall u \in N_{o}
$$

which implies that each node must receive at least one visit. Thus there is no need to add constraints (40) into our model.

\subsubsection{Solution Algorithm}

A heuristic algorithm is developed to solve the above VRP model. This algorithm is required to give quick response to decision requests, because a web-based decision 
support system is developed based on this algorithm. A heuristic algorithm can give solution much faster than an exact solution, since VRPs are NP-hard.

\subsubsection{Solution Definition}

The data structure of a SNS VRP solution is defined first. A solution, denoted as $S$, is a set of routes served by a specific set of trucks without violating the maximum delivery duration constraints and truck capacity constraints. $S=\left\{R_{1}, R_{2}, \cdots, R_{i}, \cdots, R_{p}\right\}, p$ is the number of routes. $R_{i}$ represents a valid route in solution $S$. $R_{i}=\left(l_{i}, a_{i}, b_{i}, t_{i}, w_{i},\left\langle o, n_{i 1}, n_{i 2}, \cdots, n_{i q}, o\right\rangle\right)$, where $l_{i}$ represents a truck or a virtual truck assigned to this route, $l_{i} \in L \cup V L ; a_{i}, b_{i} \in\{0\} \cup R^{+}, a_{i}$ is the time of truck $l_{i}$ leaving depot $o$, and $b_{i}$ is the time of truck $l_{i}$ returning to depot $o$; $t_{i}$ is the duration that truck $l_{i}$ travels along the route, and $t_{i}=b_{i}-a_{i} ; w_{i}$ is the quantity of materials measured in pallets loaded on route $R_{i} ;\left\langle o, n_{i 1}, n_{i 2}, \cdots, n_{i q}, o\right\rangle$ is the visitation sequence of nodes on route $R_{i}$, which indicates a tour traveled by truck $l_{i}$ starting from depot $o$, visiting nodes $n_{i 1}, n_{i 2}, \cdots, n_{i q}$ sequentially, and finally returning to depot $o$. According to the SNS VRP model, a valid route must satisfy the following two constraints:

- $b_{i} \leq D T$, i.e., all the delivery tasks must be completed within the required delivery duration;

- $w_{i}=\sum_{j=1}^{q} R D_{n_{i j}} \leq K_{l_{i}}$, i.e., the total load on a route cannot exceed the capacity of the assigned truck; 
The objective function of solution $S$, denoted as $f(S)$, is the total travel distance of all routes in solution $S . f(S)=\sum_{i=1}^{p} C\left(R_{i}\right)$, where $C\left(R_{i}\right)$ is the total distance of route $R_{i}$, $C\left(R_{i}\right)=d_{o, n_{i 1}}+\sum_{j=1}^{q-1} d_{n_{i j}, n_{i, j+1}}+d_{n_{i q}, o}$

Because a truck can serve more than one route in our model, the schedule of a truck or a virtual truck $l$, denoted as $S T_{l}$, can be calculated from solution $S$. Suppose that $S T_{l}=$ $\left\langle\left(0, b_{1}, R_{l 1}\right),\left(a_{2}, b_{2}, R_{l 2}\right), \cdots\left(a_{i}, b_{i}, R_{l i}\right),\left(a_{i+1}, b_{i+1}, R_{l, i+1}\right), \cdots\left(a_{n}, b_{n}, R_{l n}\right)\right\rangle$, where $R_{l i}$ is the $i$ th route served by truck $l, a_{i}$ is the time of truck $l$ departing from depot $o$ during the service for $R_{l i}, b_{i}$ is the time of truck $l$ returning to depot $o$ during the service for $R_{l i}$.

Finish_Time $(l)$ is the time of truck $l$ completing its deliveries. This function is defined as follows:

Finish_Time $(l)= \begin{cases}0, & \text { if truck } l \text { has no routes scheduled; } \\ b_{n}, & \text { if truck } l \text { has } n \text { routes scheduled; }\end{cases}$

According to the SNS VRP model, a valid schedule of a truck $S T_{l}$ should satisfy the following constraints:

- $a_{i+1}=b_{i}+B T$ for $i=1, \cdots, n-1$, i.e., the time sequence of all trips taken by the truck;

- Finish_Time $(l) \leq D T$, i.e., all delivery tasks must be completed within the required delivery duration;

\subsubsection{Initial Solution Algorithm}

The algorithm used to construct an initial solution for our SNS VRP model is developed based on the Clarke and Wright saving algorithm with additional considerations of 
duration constraints, truck capacity constraints, split deliveries and multiple routes per truck.

Figure 7 demonstrates the structure of the initial solution algorithm. In "Initialization", the saving value matrix is built, and the Initial Route List $(I R L)$ is formed. Each data element in the saving value matrix corresponds to a distance saving. For example, when two routes $\langle o, \cdots, i, o\rangle$ and $\langle o, j, \cdots, o\rangle$ can feasibly be merged as a single route $\langle o, \cdots, i, j, \cdots o\rangle, s_{i j}=d_{i o}+d_{o j}-d_{i j}$ is the saved distance corresponding to the data element at $(i, j)$ of the saving value matrix. In $I R L$, the algorithm creates a route for each single served node, and no truck is assigned to those routes. After the initialization, the algorithm begins to merge or split the routes in $I R L$, then assigns available fitting trucks to them and put the routes with assigned trucks to the Finished Route $\operatorname{List}(F R L)$, until $I R L$ is empty. $F R L$ is the result of the initial solution.

For each route $R$ chosen from $I R L$, the algorithm examines the available largest truck with capacity $K_{\max }$, whose current schedule allows it to serve route $R$ while not violating the required delivery duration constraint. If the current pallets $w$ loaded in route $R$ is less than $K_{\max }$ (i.e., $w<K_{\max }$ ), the algorithm searches routes from $I R L$ which can be merged into route $R$ and merges them into route $R$ by following the typical Clark and Wright saving algorithm, until no feasible merge can be found in $I R L$.

If $w>K_{\max }$, (i.e., even the largest truck cannot deliver the demanded materials to the served node with one visit,) the node has to be served by more than one route. In order to simplify the split deliveries policy and make their management easy, $K_{\max }$ pallets of materials will be delivered to the node by the available largest truck with one dedicated 
trip. The remaining $w-K_{\max }$ pallets materials demanded at the node will be delivered by other routes. Correspondingly, route $R$ is split into two routes. One loads $K_{\max }$ pallets of materials, the largest truck is assigned to this route, the truck only visits the node and then return to the depot, and this route is put into $F R L$. The other loads the remaining $w-K_{\max }$ pallets materials, and the route is put back into $I R L$ for further processing.

Once a route is completed with merge or split, it will be assigned to a truck. As pseudocode Assign_Truck ( ) shows, the algorithm first searches for an available truck from the available truck list $L$, whose schedule allows it to serve the current route without violation of the required delivery duration constraint, and whose capacity fits the load on that route. If no truck is available, the algorithm searches for a fitting virtual truck from the Virtual Truck List $(V L)$ with respect to the same constraints. If even a fitting virtual truck cannot be found, then the algorithm finds an appropriate truck type from the truck type list $T L$, creates a virtual truck based on it, assigns this virtual truck to the route and inserts this virtual truck into $V L$ for potential future use. A virtual truck is not a physical truck, and represents a truck shortage. The virtual truck list $V L$ is used to report truck shortages to the decision makers, and suggest the decision makers to add more trucks into the planning and re-solve the VRP. 


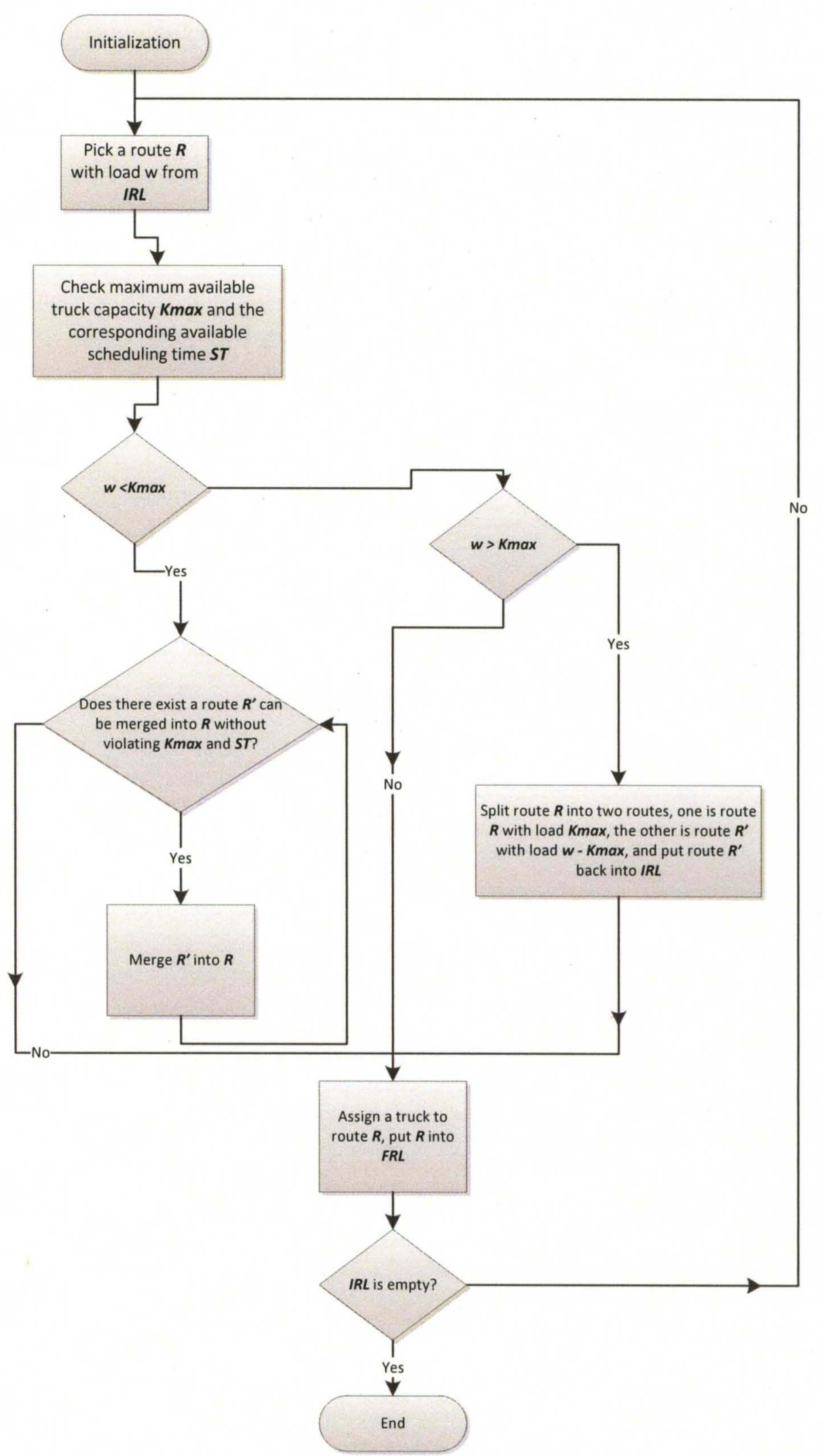

Figure 7. The initial solution algorithm. 
The below is the pseudo-code of the initial solution algorithm:

Algorithm Initial_Solution $\left(o, N_{o}, L, T L, d, L T, U T, B T, D T, V\right)$

$I^{*} d$ : the distance matrix between nodes, $d_{i j}$ is the distance between node $i$ and node $j, i, j \in\{o\} \cup N_{o} * /$

/* the other parameters are interpreted in Section 4.2.1*/

\section{Begin}

Step 1, Initialization:

(1) Compute the distance saving matrix: $s_{u v}=d_{u o}+d_{o v}-d_{u v}$ for each $u, v \in N_{o}$, and $u \neq v$;

(2) Create a route $R_{u}=\left(\emptyset, \emptyset, \emptyset, t_{u}, R D_{u},\langle o, u, o\rangle\right)$ for each $u \in N_{o}$, where $t_{u}=$ $L T+U T+\frac{d_{o u}+d_{u o}}{V}$, and form an initial route list denoted as $I R L=\left\{R_{u} \mid u \in N_{o}\right\}$;

(3) Order $s_{u v}$ in a non-increasing fashion, and form a sequenced list;

Step 2, Split or merge routes, and assign a truck to routes or report a truck shortage by creating a virtual truck for a route:

Construct a finished route list denoted as $F R L=\emptyset$;

While (IRL is not empty) Do

Pick a route $R=(\emptyset, \emptyset, \emptyset, t, w,\langle o, i, \cdots, j, o\rangle)$ from $I R L$;

$\left(K_{\max }, S T\right)=$ Max_Available_TruckCapacity $(R, L, V L, T L, D T, B T) ; / *$ Serach for the largest truck. The found truck has capacity of $K_{\max }$ pallets, and its corresponding available scheduling time is $S T$ */

If $\left(w>K_{\max }\right)$ Do $/ *$ Split*/

(1) Split $R$ as two routes $R_{1}=\left(\emptyset, \emptyset, \emptyset, t, K_{\max },\langle o, i, \cdots, j, o\rangle\right)$ and $R_{2}=\left(\emptyset, \emptyset, \emptyset, t, w-K_{\max },\langle o, i, \cdots, j, o)\right)$

(2) Assign_Truck $\left(R_{1}, L, V L, T L, B T, D T\right)$; /*Assign a truck for route $R_{1} * /$

(3) Put $R_{1}$ into $F R L$;

(4) Put $R_{2}$ back into $I R L$;

End If.

If $\left(w=K_{\max }\right)$ Do $\quad / * J u s t$ assign a truck $* /$

(1) Assign_Truck $(R, L, V L, T L, B T, D T)$; /*Assign a truck for route $R * /$

End If.

(2) Put $R$ into $F R L$;

If $\left(w<K_{\max }\right) \quad / *$ Merge $* /$ 
(1) Search for the first saving value $s_{u i}$ or $s_{j v}$ in the saving list such that there exists route $R_{1}=\left(\emptyset, \emptyset, \emptyset, t_{1}, w_{1},\langle o, \cdots, u, o\rangle\right)$ in $I R L$ which ends with $\langle u, o\rangle$ and satisfies $t+t_{1}-\frac{s_{u i}}{V}-L T \leq S T$ and $w+w_{1} \leq K_{\max }$, or there exists route $R_{2}=\left(\emptyset, \emptyset, \emptyset, t_{2}, w_{2},\langle o, v, \cdots, o\rangle\right)$ in $I R L$ which starts with $\langle o, v\rangle$ and satisfies $t+t_{2}-\frac{s_{j v}}{v}-L T \leq S T$ and $w+w_{2} \leq K_{\max }$;

(2) In the former case, merge $R_{1}$ into $R$, update $R=\left(\emptyset, \emptyset, \emptyset, t+t_{1}-\right.$ $\left.\frac{s_{u i}}{V}-L T, w+w_{1},\langle o, \cdots, u, i, \cdots, j, o\rangle\right)$, and remove $R_{1}$ from $I R L$; in the latter case, merge $R_{2}$ into $R$, update $R=\left(\emptyset, \emptyset, \emptyset, t+t_{2}-\right.$ $\left.\frac{s_{j v}}{V}-L T, w+w_{2},\langle o, i, \cdots, j, v, \cdots, o\rangle\right)$, and remove $R_{2}$ from $I R L ;$

End If.

(3) Implement operations (1) and (2) to the current route $R$ until no feasible merge exists;

(4) Assign_Truck $(R, L, V L, T L, B T, D T)$;

(5) Put $R$ into $F R L$;

End While.

Return FRL;

End.

Procedure Max_Available_TruckCapacity $(R, L, V L, T L, D T, B T)$

$I^{*} R$ : the current route to be processed */

$I^{*}$ suppose $R=(\emptyset, \emptyset, \emptyset, t, w,\langle o, \cdots, o\rangle) * I$

\section{Begin Procedure}

Step 1, find a truck with maximum loading capacity from truck list $L$ :

(1) Solve the following problem:

$\max _{l \in L} K_{l}$

Subject to

Finish_Time $(l)+B T+t \leq D T$ for $l \in$

$L$ and if truck $l$ has already been assigned to at least one route;

(2) If there is feasible solution $l$, do the following:

If truck $l$ has not been assigned to any route yet, $K_{\max }=K_{l}, S T=D T$; 
If truck $l$ has already been assigned to at least one route, $K_{\max }=K_{l}$, $S T=D T-($ Finish_Time $(l)+B T) ; \operatorname{Return}\left(K_{\max }, S T\right)$;

(3) If there is no feasible solution, go to Step 2;

Step 2, find a virtual truck with maximum loading capacity from virtual truck list $V L$ :

(1) Solve the following problem:

$\max _{l \in V L} K_{l}$

Subject to

Finish_Time $(l)+B T+t \leq D T$ for $l \in$

$V L$ and if truck $l$ has already been assigned to at least one route;

(2) If there is a feasible solution $l$, do the following:

If virtual truck $l$ has not been assigned to any route yet, $K_{\max }=K_{l}$,

$S T=D T$

If virtual truck has already been assigned to at least one route, $K_{\max }=$ $K_{l}, S T=D T-($ Finish_Time $(l)+B T)$;

Return $\left(K_{\max }, S T\right)$;

(3) If there is no feasible solution, go to Step 3;

Step 3, find a truck type with maximum loading capacity from truck type list $T L$ :

Find the truck type $l$ with maximum loading capacity in $T L, K_{\max }=K_{l}$, $S T=D T$, then Return $\left(K_{\max }, S T\right)$.

\section{End Procedure}

Procedure Assign_Truck $(R, L, V L, T L, B T, D T)$

I*R: the current route to be processed */

$I^{*}$ suppose $R=(\emptyset, \emptyset, \emptyset, t, w,\langle o, \cdots, o\rangle) * /$

\section{Begin Procedure}

Step 1, find a truck from truck list $L$ :

(1) Solve the following problem:

$\min _{l \in L} K_{l}-w / *$ use the trucks in a saving way by selecting the capable truck with the smallest available capacity */

Subject to

$K_{l}-w \geq 0$;

Finish_Time $(l)+B T+t \leq D T$ for $l \in$

$L$ and if truck $l$ has already been assigned to at least one route;

(2) If there is a feasible solution $l$, assign truck $l$ to route $R$ : 
If truck $l$ has not been assigned to any route yet, update

$R=(l, 0, t, t, w,\langle o, \cdots, o\rangle)$;

If truck $l$ has already been assigned to at least one route, update $R=$ $(l$, Finish_Time $(l)+B T$, Finish_Time $(l)+B T+t, t, w,\langle o, \cdots, o\rangle)$;

Return;

(3) If there is no feasible solution, go to Step 2;

Step 2, find a virtual truck from virtual truck list $V L$ :

(1) Solve the following problem:

$\min _{l \in V L} K_{l}-w / *$ use the virtual trucks in a saving way by selecting the capable truck with the smallest available capacity */

Subject to

$K_{l}-w \geq 0$;

Finish_Time $(l)+B T+t \leq D T$ for $l \in$

$V L$ and if truck $l$ has already been assigned to at least one route;

(2) If there is a feasible solution $l$, assign virtual truck $l$ to route $R$ :

If virtual truck $l$ has not been assigned to any route yet, update $R=$ $(l, 0, t, t, w,\langle o, \cdots, o\rangle)$;

If truck has already been assigned to at least one route, update $R=(l$, Finish_Time $(l)+B T$, Finish_Time $(l)+B T+t, t, w,\langle o, \cdots, o\rangle)$;

Return;

(3) If there is no feasible solution, go to Step 3;

Step 3, create a new virtual truck for reporting a truck shortage:

(1) Solve the following problem:

$$
\begin{aligned}
& \min _{l \in T L} K_{l}-w \\
& \text { Subject to } \\
& K_{l}-w \geq 0 \text { for } l \in T L ;
\end{aligned}
$$

(2) With the solution $l$ obtained above, create a new virtual truck $v l$ belonging to truck type $l$, assign virtual truck $v l$ to route $R$, update $R=(v l, 0, t, t, w,\langle o, \cdots, o\rangle)$

End Procedure , and insert $v l$ into $V L$.

\subsubsection{Improvement Algorithm}

A Simulated Annealing (SA) algorithm is developed to improve the initial solution.

\section{Neighborhood of a Solution}


There are two types of operations to alter a solution $S$ to a neighboring solution $S^{\prime}$ in our SA algorithm design: Shift and Exchange. Randomly select two routes $R_{1}$ and $R_{2}$ from solution $S$, first try to apply Shift operation on these two routes; if there is no feasible Shift operation, then apply Exchange operation on these two routes. In the following, the two types of operations are explained:

1. Shift: A shift operation shifts one node from one route to another route. As shown in Figure 8, node $i$ is removed from the route it belongs to, and is inserted before node $j$ in another route.
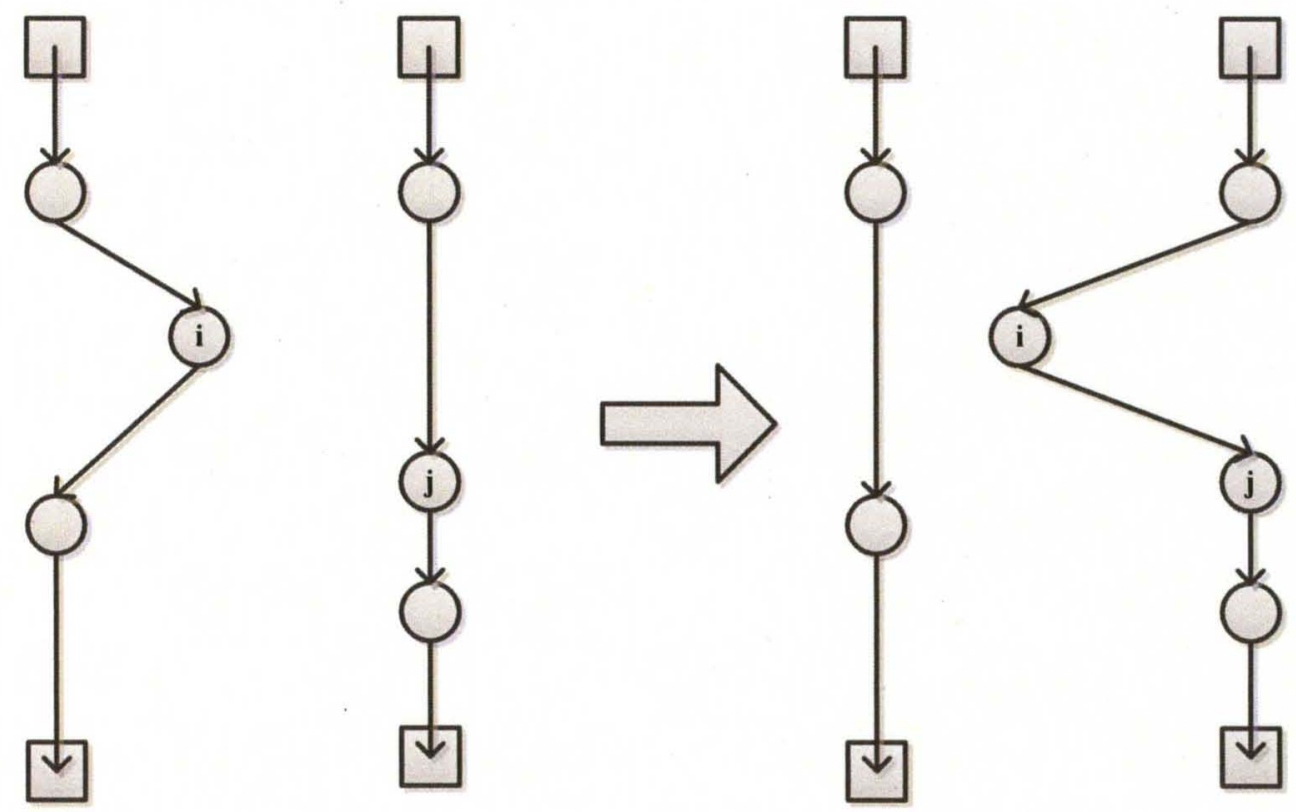

Figure 8. Shift operation.

Suppose

$$
R_{1}=\left(l_{1}, a_{1}, b_{1}, t_{1}, w_{1},\langle o, \cdots, i-1, i, i+1, \cdots, o\rangle\right)
$$

$R_{2}=\left(l_{2}, a_{2}, b_{2}, t_{2}, w_{2},\langle o, \cdots, j-1, j, \cdots, o\rangle\right)$, and suppose node $i$ is removed from $R_{1}$ and inserted before node $j$ in $R_{2}$, thus solution $S$ is transformed into solution $S^{\prime}$. The change of travel distance of $R_{1}$ is $\Delta_{1}=d_{i-1, i+1}-\left(d_{i-1, i}+d_{i, i+1}\right)$, the change of travel 
distance of $R_{2}$ is $\Delta_{2}=d_{j-1, i}+d_{i, j}-d_{j-1, j}$, therefore the change of the total distance caused by this shift operation is $\Delta=f\left(S^{\prime}\right)-f(S)=\Delta_{1}+\Delta_{2}$. Now the problem is to determine node $i$ and node $j$ to minimize $\Delta$ in order to obtain a neighboring solution $S^{\prime}$ with a lower total distance subjecting to the following two constraints: (1) the shift operation does not violate the capacity constraint of truck $l_{2}$, i.e., $w_{2}+D Q_{i} \leq K_{l_{2}}$, where $D Q_{i}$ is the quantity of materials delivered to node $i$ originally in route $R_{1} ;(2)$ the shift operation does not violate the duration constraint of truck $l_{2}$, i.e., Finish_Time $\left(l_{2}\right)+\frac{\Delta_{2}}{V}+$ $U T \leq D T$. Because the number of nodes in the two routes is limited, the problem can be solved by enumeration. The selection of nodes $i$ and $j$ determines a node shift operation from $R_{1}$ to $R_{2}$. In the same way, a possible node shift operation from $R_{2}$ to $R_{1}$ can also be found. Finally, the shift operation which results in the least total travel distance is chosen to be applied to transform the current solution $S$ to a neighboring solution $S^{\prime}$ by doing the following operations (in case that the shift operation from $R_{1}$ to $R_{2}$ is applied):

(1) Remove node $i$, insert it before node $j$, update $R_{1}=\left(l_{1}, a_{1}, b_{1}+\frac{\Delta_{1}}{V}-\right.$

$$
\begin{aligned}
& \left.U T, t_{1}+\frac{\Delta_{1}}{V}-U T, w_{1}-D Q_{i},\langle o, \cdots, i-1, i+1, \cdots, o\rangle\right) \quad \text { and } \quad R_{2}= \\
& \left(l_{2}, a_{2}, b_{2}+\frac{\Delta_{2}}{V}+U T, t_{2}+\frac{\Delta_{2}}{V}+U T, w_{2}+D Q_{i},\langle o, \cdots, j-1, i, j, \cdots, o\rangle\right)
\end{aligned}
$$

(2) Adjust the schedule of truck $l_{1}$ by shifting its route schedules from the completion time of serving $R_{1}$ with a period of $\frac{\Delta_{1}}{V}-U T$;

(3) Adjust the schedules of truck $l_{2}$ by shifting its route schedules from the completion time of serving $R_{2}$ with a period of $\frac{\Delta_{2}}{V}+U T$. 
2. Exchange: For two selected routes, an exchange operation moves a node from each route to the other route. As shown in Figure 9, node $i$ is moved from the left route to the right route, and node $j$ is moved from the right route to the left route.
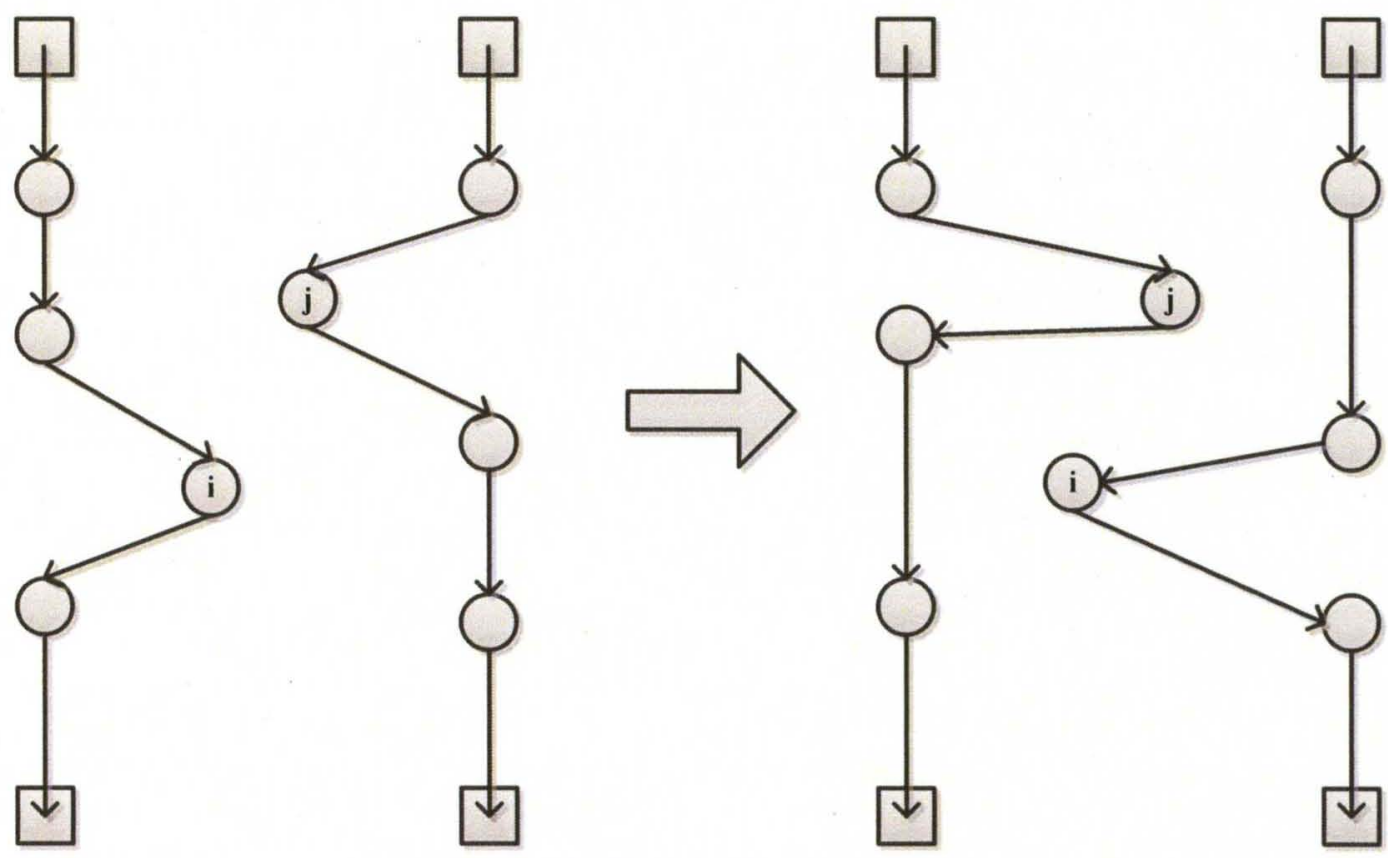

Figure 9. Exchange operation.

Suppose $\quad R_{1}=\left(l_{1}, a_{1}, b_{1}, t_{1}, w_{1},\langle o, \cdots, i-1, i, i+1, \cdots, n-1, n, \cdots, o\rangle\right) \quad, \quad R_{2}=$ $\left(l_{2}, a_{2}, b_{2}, t_{2}, w_{2},\langle o, \cdots, m-1, m, \cdots, j-1, j, j+1, \cdots, o\rangle\right)$, suppose that node $i$ is removed from $R_{1}$ and inserted before node $m$ in $R_{2}$, and node $j$ is removed from $R_{2}$ and inserted before node $n$ in $R_{1}$, thus solution $\mathrm{S}$ is transformed into solution $\mathrm{S}$ '. The change of travel distance of $R_{1}$ is $\Delta_{1}=d_{i-1, i+1}-d_{i-1, i}-d_{i, i+1}+d_{n-1, j}+d_{j n}-d_{n-1, n}$, the change of travel distance of $R_{2}$ is $\Delta_{2}=d_{j-1, j+1}-d_{j-1, j}-d_{j, j+1}+d_{m-1, i}+d_{i m}-$ $d_{m-1, m}$, therefore the change of the total travel distance caused by the exchange operation is $\Delta=f\left(S^{\prime}\right)-f(S)=\Delta_{1}+\Delta_{2}$. The problem is to determine node $i, j, m$ and $n$ to minimize $\Delta$ in order to obtain a neighboring solution $S^{\prime}$ with a lower total travel 
distance by applying an exchange operation. The selection of node $i, j, m$ and $n$ must satisfy the following constraints: (1) The exchange operation cannot violate the capacity constraints of truck $l_{1}$ and $l_{2}$, i.e., $w_{1}-D Q_{i}+D Q_{j} \leq K_{l_{1}}$ and $w_{2}-D Q_{j}+D Q_{i} \leq K_{l_{2}}$; (2) The exchange operation cannot violate the duration constraints of truck $l_{1}$ and $l_{2}$, i.e., Finish_Time $\left(l_{1}\right)+\frac{\Delta_{1}}{V} \leq D T$ and Finish_Time $\left(l_{2}\right)+\frac{\Delta_{2}}{V} \leq D T$. Once the nodes $i, j, m$ and $n$ are determined by enumeration, the exchange operation is determined to transit solution $S$ to $S^{\prime}$ by executing the following operations:

(1) Remove node $i$ from $R_{1}$, and insert it before node $m$ in $R_{2}$;

(2) Remove node $j$ from $R_{2}$, and insert it before node $n$ in $R_{1}$;

(3) Update $\quad R_{1}=\left(l_{1}, a_{1}, b_{1}+\frac{\Delta_{1}}{V}, t_{1}+\frac{\Delta_{1}}{V}, w_{1}-D Q_{i}+D Q_{j},\langle o, \cdots, i-1, i+\right.$ $1, \cdots, n-1, j, n, \cdots, o\rangle)$

(4) Update $R_{2}=\left(l_{2}, a_{2}, b_{2}+\frac{\Delta_{2}}{V}, t_{2}+\frac{\Delta_{2}}{V}, w_{2}-D Q_{j}+D Q_{i},\langle o, \cdots, m-\right.$ $1, i, m, \cdots, j-1, j+1, \cdots, o\rangle)$

(5) Adjust the schedule of truck $l_{1}$ by shifting its route schedules from the completion time of serving $R_{1}$ with a period of $\frac{\Delta_{\mathbf{1}}}{V}$;

(6) Adjust the schedules of truck $l_{2}$ by shifting its route schedules from the completion time of serving $R_{2}$ with a period of $\frac{\Delta_{2}}{V}$.

The pseudo-code for determining a neighbor solution of solution $S$ is provided below:

Procedure Neighbor_Solution(S) 
$1 * S$ is the current solution*/

\section{Begin Procedure}

Step 1 , randomly select two different routes $R_{1}$ and $R_{2}$ from solution $S$;

Step 2, shift operation:

(1) Find a shift operation which can be applied on the two routes feasibly;

(2) If a feasible shift operation can be found, transit solution $S$ to a neighboring solution $S^{\prime}$ by applying the shift operation, then return $S^{\prime}$; otherwise, go to step 3; Step 3, exchange operation:

(1) Find an exchange operation which can be applied on the two routes feasibly;

(2) If a feasible exchange operation can be found, transit solution $S$ to a neighboring solution $S^{\prime}$ by applying the exchange operation, then return $S^{\prime}$; otherwise, go to step 1;

End Procedure

\section{The Simulated Annealing Algorithm and the Cooling Schedule}

The effectiveness of a SA algorithm is affected by its cooling schedule. In our algorithm, the cooling schedule is determined by five parameters: the initial temperature $T_{0}$, the cooling ratio of temperature $\alpha$, the declining ratio of epoch length $\beta$, the initial epoch length and the maximum number of epochs $N_{\max }$. According to [87], the initial temperature $T_{0}$ should be sufficiently large. In our algorithm, the maximum difference in cost between any two neighboring solutions is chosen as its value. In our design, $T_{0}$ is set as the objective value of the initial solution $S_{0} . \alpha$ can be a value between 0.8 and $0.99 . \beta$ can be a value between 0.8 and $1 . N_{\max }$ is set as 200 . In addition, the initial epoch length is the number of possible neighborhood solutions that can be transited from the initial solution, which is $M_{s_{0}} \times\left(M_{s_{0}}-1\right)$ according to our neighborhood solution algorithm, where $M_{s_{0}}$ is the number of routes in the initial solution. The pseudo-code of the simulated annealing algorithm is shown below: 
Algorithm SimulatedAnnealing $\left(S_{0}, T_{0}, \alpha, \beta, N_{\max }\right)$

$/ * S_{0}$ : the initial solution obtained from the Initial_Solution algorithm;*/

$/ * T_{0}$ : the initial temperature; $* /$

$I^{*} \alpha$ : the cooling ratio of temperature;*/

$I^{*} \beta$ : the declining ratio of epoch length;*/

$/ * N_{\max }:$ the maximum number of epochs; $* /$

\section{Begin}

$\operatorname{curr} S=S_{0} ; /^{*} \operatorname{curr} S$ is the current solution $* /$

currCost $=f\left(S_{0}\right) ; I^{*} \operatorname{currCost}$ is the objective value of the current solution*/

best $=\operatorname{curr} S ; /^{*}$ best $S$ is the best solution seen so far*/

bestCost $=\operatorname{curr} \operatorname{Cost} ; \mathrm{I}^{*}$ bestCost is the objective value of the best solution */

count $=0$

epochLen $=M_{S_{0}} \times\left(M_{s_{0}}-1\right) ; /^{*}$ epochLen is the epoch length, $M_{S_{0}}$ is the number of routes in solution $S_{0} *$ /

While (count $\leq N_{\max }$ ) Do

$$
\begin{aligned}
& \text { For (int } i=0 ; i<\text { epochLen; } i++ \text { ) Do } \\
& \text { newS }=\text { Neighbor_Solution(currS }) \text {; } \\
& \text { newCost }=f(\text { new } S) \text {; } \\
& \Delta \text { Cost }=\text { newCost }- \text { currCost; } \\
& \text { If }(\Delta \operatorname{Cos} t \leq 0) \text { Do } \\
& \text { currs }=\text { news; } \\
& \text { currCost }=\text { newCost; } \\
& \text { If (currCost < bestCost) Do } \\
& \text { bestS = currs; } \\
& \text { bestCost }=\text { currCost; }
\end{aligned}
$$




\section{End If.}

Else Do

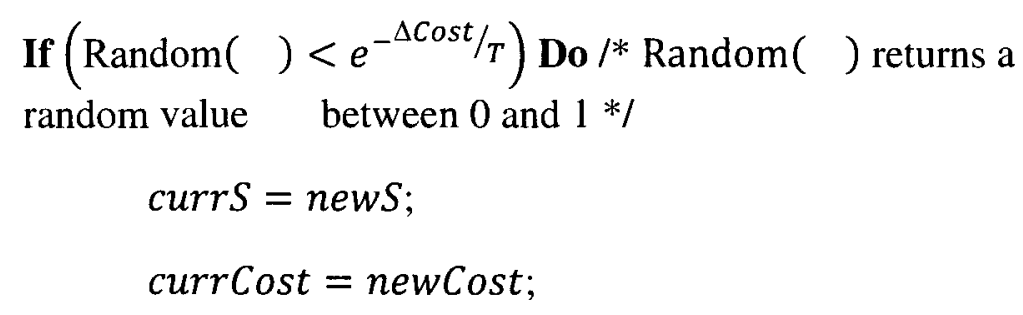

\section{End If.}

End If.

\section{End For.}

count ++

$T=T \times \alpha ;$

epochLen $=$ epochLen $\times \beta ;$

\section{End While.}

Return bestS;

End.

\subsection{Experiments and Result Analysis}

The SNS VRP solution is implemented in Microsoft C\#. The implementation is compared to the best known algorithms. Because our SNS VRP solution is the only solution for solving single-depot multiple-vehicle VRP allowing split deliveries and more than one trip per vehicle with duration constraints, there is no test instance specifically for its benchmarking. Therefore, the SNS VRP has to be altered to a capacity constrained VRP by disallowing split deliveries and more than one trip per vehicle and relaxing the duration constraints. Table 9 in Appendix $\mathbf{C}$ shows the results of running our solution on 
a set of instances for testing capacity constrained VRP solutions [125]. Table 6 summarizes the information of Table 9. The average distance reduction shows how much our solution outperforms (specified by the positive percentage) or underperforms (specified by the negative percentage) the best practice solution in terms of the total traveling distance.

Table 6 Summary of Capacity Constrained VRP Test Instances

\begin{tabular}{|c|c|c|}
\hline Test Instance Group & Average Execution Time (seconds) & $\begin{array}{c}\text { Average Distance } \\
\text { Reduction }\end{array}$ \\
\hline Augerat, et al. Set A & 2.41 & $12.19 \%$ \\
\hline Augerat, et al. Set B & 3.80 & $1.40 \%$ \\
\hline Augerat, et al. Set P & 6.62 & $-5.90 \%$ \\
\hline Christofides and Eilon & 10.32 & $-5.87 \%$ \\
\hline Fisher & 12.43 & $-9.28 \%$ \\
\hline Gillet and Johnson & 72.00 & $39.21 \%$ \\
\hline Christofides, Mingozzi, and Toth & 61.51 & $-12.75 \%$ \\
\hline
\end{tabular}

Tables 10, 11 and 12 show the results of running our solution on Solomon test instances for testing capacity constrained VRPs with time windows respectively as there are 25,50 and 100 visited nodes [126]. Table 7 summarizes the results of Tables 10,11 and 12. The time window constraints in these test cases are specified as the required delivery duration constraints in our model. Therefore, the comparison between our solution and the best practice solution in terms of the total travel distance gives us some hints on how to improve our solution for further research.

Table $7 \underline{\text { Summary of Solomon Test Instances }}$ 


\begin{tabular}{|c|c|c|c|c|c|c|}
\hline \multirow[b]{2}{*}{$\begin{array}{l}\text { Test Instance } \\
\text { Group }\end{array}$} & \multicolumn{2}{|c|}{$\begin{array}{c}\text { Best Practice } \\
\text { Solution }\end{array}$} & \multicolumn{3}{|c|}{ Our Solution } & \multirow[b]{2}{*}{$\begin{array}{l}\text { Average } \\
\text { Distance } \\
\text { Reduction }\end{array}$} \\
\hline & $\begin{array}{l}\text { Averag } \\
\text { e \# of } \\
\text { Trucks }\end{array}$ & $\begin{array}{c}\text { Average } \\
\text { Distanc } \\
\text { e }\end{array}$ & $\begin{array}{c}\text { Averag } \\
\text { e \# of } \\
\text { Trucks }\end{array}$ & $\begin{array}{c}\text { Averag } \\
\text { e } \\
\text { Distanc } \\
\text { e }\end{array}$ & $\begin{array}{l}\text { Average Execution } \\
\text { Time (seconds) }\end{array}$ & \\
\hline Solomon_25_C1 & 3 & 190.6 & 3 & 193.42 & 0.87 & $-1.49 \%$ \\
\hline Solomon_25_R1 & 5 & 463.4 & 4.1 & 386.95 & 1.04 & $15.05 \%$ \\
\hline $\begin{array}{l}\text { Solomon_25_RC } \\
1\end{array}$ & 3.3 & 358.2 & 3.1 & 316.48 & 2.97 & $10.68 \%$ \\
\hline Solomon_25_C2 & 1.9 & 214.45 & 1 & 215.91 & 0.04 & $-0.68 \%$ \\
\hline Solomon_25_R2 & 2.7 & 382.1 & 1 & 358.2 & 0.05 & $5.52 \%$ \\
\hline $\begin{array}{l}\text { Solomon_25_RC } \\
2\end{array}$ & 3 & 326.4 & 1 & 233.42 & 0.03 & $28.21 \%$ \\
\hline Solomon_50_C1 & 4.9 & 361.8 & 5 & 369.94 & 5.75 & $-2.25 \%$ \\
\hline Solomon_50_R1 & 8.4 & 778.24 & 6.9 & 618.25 & 12.46 & $18.91 \%$ \\
\hline $\begin{array}{l}\text { Solomon_50_RC } \\
1\end{array}$ & 7 & 750.6 & 7.3 & 739.53 & 17.15 & $-1.25 \%$ \\
\hline Solomon_50_C2 & 2.8 & 357.91 & 2 & 370.84 & 3.19 & $-3.62 \%$ \\
\hline Solomon_50_R2 & 4.2 & 624.2 & 2 & 532.08 & 0.85 & $13.03 \%$ \\
\hline $\begin{array}{l}\text { Solomon_50_RC } \\
2\end{array}$ & 4.4 & 585.4 & 1.3 & 425.55 & 0.17 & $26.46 \%$ \\
\hline $\begin{array}{l}\text { Solomon_100_C } \\
1\end{array}$ & 10 & 828.38 & 10 & 978.13 & 36.03 & $-18.08 \%$ \\
\hline $\begin{array}{l}\text { Solomon_100_R } \\
1\end{array}$ & 11.9 & 1209.9 & 10.8 & 977.1 & 66.9 & $17.12 \%$ \\
\hline $\begin{array}{l}\text { Solomon_100_R } \\
\text { C1 }\end{array}$ & 11.5 & 1384.16 & 11 & 1143.92 & 64.85 & $15.54 \%$ \\
\hline $\begin{array}{l}\text { Solomon_100_C } \\
2\end{array}$ & 3 & 589.86 & 3.4 & 697.56 & 28.18 & $-18.26 \%$ \\
\hline $\begin{array}{l}\text { Solomon_100_R } \\
2\end{array}$ & 2.7 & 951.91 & 2 & 746.56 & 20.74 & $19.90 \%$ \\
\hline $\begin{array}{l}\text { Solomon_100_R } \\
\text { C2 }\end{array}$ & 3.3 & 1119.35 & 2 & 785.19 & 20.90 & $27.08 \%$ \\
\hline
\end{tabular}

From the results, the following points can be summarized:

(1) The execution time of our solution satisfies the requirement of web-based decision support system in terms of response time. 
(2) From Table 6, it can be seen that our solution outperforms or underperforms around $10 \%$ compared to the best practice solution for the chosen problems, thus the solution can be considered acceptable.

(3) From Table 7, our solution is relatively weak to deal with the test instances in which the visited nodes are clustered compactly within several sparse geographical areas. Although the nodes are distributed relatively evenly over a geographical area in our problems, this weakness needs further investigation and should be improved. 


\section{CHAPTER 5 LOCATION-ROUTING ANALYSIS OF EMERGENCY SCENARIO}

\subsection{Introduction}

Usually the effectiveness of a relief operations plan is evaluated by drills or computer simulations. However, it is very difficult to apply the same evaluation approaches to the relief operations plans for responding to large-scale emergencies. For example, it is very costly to perform a drill exercise, because a large number of resources including staff, trucks and other necessary resources are required to perform a drill. Due to the lack of historical data, it is very difficult to simulate and analyze the relief operations plans for responding to large-scale emergencies with computer simulation. Large-scale emergencies are unpredictable low-frequency events, thus little data has been collected for computer simulations. Moreover, the data set for simulating large-scale emergencies could be very large and hard to be created accurately by mathematical models.

In this chapter, a binary facility location model and the SNS VRP solution algorithm are integrated and used to evaluate the effectiveness of alternate operational plans relevant to location decisions and transportation decisions of the trucks under an assumed large-scale emergency scenario, as shown in Figure 10. The location solution algorithm and the 
outing solution algorithm are integrated as one module. The information associated with RSSs, RDNs and PODs including their locations, capacity and demand, and the list of optional truck types are inputs to the module. The output of the module includes the open RSSs, RDNs and the corresponding assignment between these sites, the number of trucks of various types to be selected for the best performance, and the corresponding routing schedule of each truck.

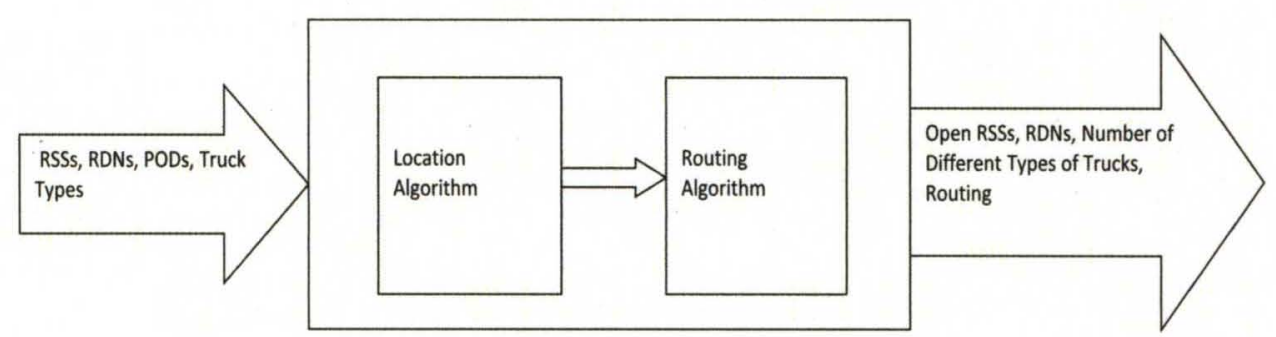

Figure 10. The location-routing analysis of large-scale emergency scenarios.
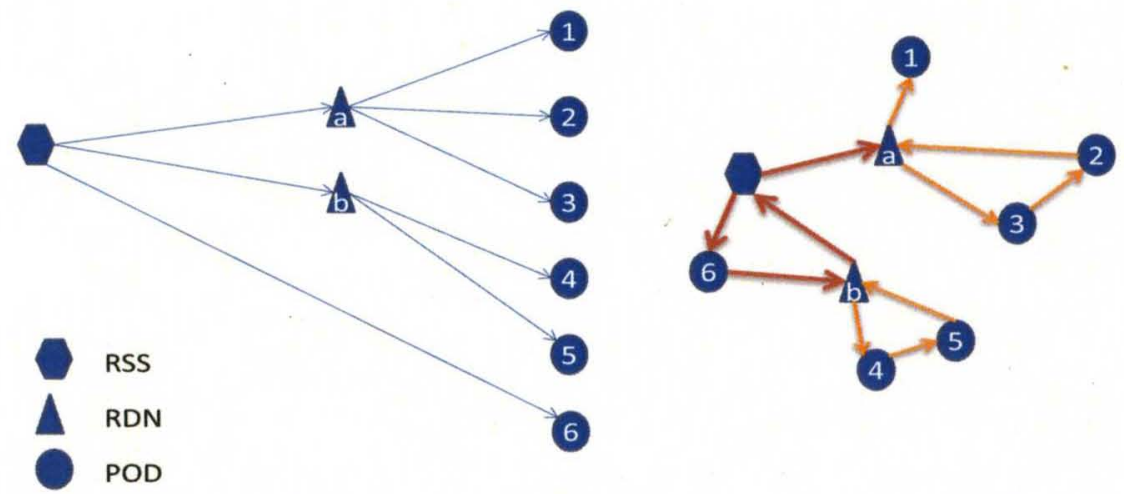

Figure 11. The relationship between location-assignment solution and VRPs.

The location solution is taken as the input to the routing algorithm. Based on the obtained location solution, a set of similar VRPs are created. Figure 11 shows a simple example. In the left, a location solution is shown: PODs 1, 2 and 3 are assigned to RDN a; PODs 4 
and 5 are assigned to RDN b; POD 6 and RDNs a, b are assigned to the only open RSS. In the right, three VRPs are created: the first one has RDN a as the depot, and PODs 1,2 and 3 as the served nodes; the second one has RDN b as the depot, and POD 4 and 5 as the served nodes; the third one has the RSS as the depot, RDN a, b and POD 6 as the served nodes. The routing solution algorithm solves them individually, and summarizes all the solutions of location and routing as the output of location-routing analysis.

\subsection{Models and Solution Algorithm}

A 0-1 integer mathematical model is formulated to determine open RSSs, open RDNs and assignment between RSSs, RDNs and PODs. In this model, instead of minimizing the total operational cost, the objective is to minimize the total linked distance from each open RSS or RDN to its assigned nodes. In addition, we use parameters $S_{1}$ and $S_{2}$ to limit the distance between each RSS and its assigned RDNs, between each RSS or RDN and its assigned PODs. The solution of this model will be fed into the SNS VRP solution algorithm presented in Chapter 4 . The parameters $S_{1}$ and $S_{2}$ could be used to control the closeness between each depot and its served nodes, thus allowing the VRP solution to give feedback control to the location solution.

Sets:

I: set of available RSSs;

$J$ : set of available RDNs;

$K:$ set of open PODs;

Parameter:

$D_{k}:$ number of pallets demanded at POD $k, k \in K$; 
$S_{1}$ : maximum allowable distance between RSSs and the assigned RDNs;

$S_{2}$ : maximum allowable distance between RDNs and the assigned PODs, or RSSs and the assigned PODs;

$C_{j}$ : maximum number of pallets that can be handled at $\operatorname{RDN} j, j \in J$;

$p$ : the required number of open RSSs;

$a_{i j}$ : distance from RSS $i$ to $\mathrm{RDN} j$;

$b_{j k}:$ distance from $\operatorname{RDN} j$ to $\operatorname{POD} k$;

$c_{i k}:$ distance from RSS $i$ to POD $k$;

Decision Variables:

$U_{i}=\left\{\begin{array}{lr}1 & \text { if RSS } i \text { is open; } \\ 0 & \text { otherwise }\end{array}\right.$

$V_{j}=\left\{\begin{array}{cr}1 & \text { if } \mathrm{RDN} j \text { is open; } \\ 0 & \text { otherwise; }\end{array}\right.$

$X_{i j}=\left\{\begin{array}{rr}1 & \text { if RDN } j \text { is assigned to RSS } i ; \\ 0 & \text { otherwise; }\end{array}\right.$

$Y_{j k}= \begin{cases}1 & \text { if POD } k \text { is assigned to } \operatorname{RDN} j ; \\ 0 & ;\end{cases}$

otherwise;

$Z_{i k}=\left\{\begin{array}{lr}1 & \text { if POD } k \text { is assigned to RSS } i ; \\ 0 & \text { otherwise; }\end{array}\right.$

Models:

$\min \sum_{i \in I} \sum_{j \in J} a_{i j} * X_{i j}+\sum_{j \in J} \sum_{k \in K} b_{j k} * Y_{j k}+\sum_{i \in I} \sum_{k \in K} c_{i k} * Z_{i k}$

Subject to:

$\sum_{i \in I} X_{i j}=V_{j} \quad \forall j \in J$ 


$$
\begin{aligned}
& \sum_{i \in I} Z_{i k}+\sum_{j \in J} Y_{j k}=1 \quad \forall k \in K \\
& \sum_{i \in I} U_{i}=p \\
& a_{i j} * X_{i j} \leq S_{1} \quad \forall i \in I, j \in J \\
& b_{j k} * Y_{j k} \leq S_{2} \quad \forall j \in J, k \in K \\
& c_{i k} * Z_{i k} \leq S_{2} \quad \forall i \in I, k \in K \\
& \sum_{k \in K} Y_{j k} * D_{k} \leq C_{j} \quad \forall j \in J \\
& X_{i j} \leq U_{i} \quad \forall i \in I, j \in J \\
& X_{i j} \leq V_{j} \quad \forall i \in I, j \in J \\
& Y_{j k} \leq V_{j} \quad \forall k \in K, j \in J \\
& Z_{i k} \leq U_{i} \quad \forall k \in K, i \in I \\
& X_{i j}=1 \text { or } 0 \quad \forall i \in I, j \in J \\
& Y_{j k}=1 \text { or } 0 \quad \forall j \in J, k \in K \\
& Z_{i k}=1 \text { or } 0 \quad \forall i \in I, k \in K \\
& U_{i}=1 \text { or } 0 \quad \forall i \in I \\
& V_{j}=1 \text { or } 0 \quad \forall j \in J
\end{aligned}
$$

The objective (40) minimizes the total linked distance of the SNS logistics network. Constraints (41) assure that each open RDN must be served by exactly one RSS. Constraints (42) assure that each open POD must be served by exactly one RDN or one RSS. Constraints (43) enforce that only a required number of RSSs can be open. Constraints (44), (45) and (46) enforce that only the nodes within a specified distance away from a RSS or RDN can be assigned to it. Constraints (47) are throughput capacity constraint at RDNs. Constraints (48), (49), (50) and (51) enforce that the served nodes 
can only be assigned to open RSSs or RDNs. Constraints (52), (53), (54), (55) and (56) are binary variable constraints.

Given a specific problem, the location solution is fed into the SNS VRP solution algorithm. For each open RSS or RDN, a VRP is formed. Each open RSS or RDN is considered as the depot, and the nodes assigned to it are the served nodes to be visited by the trucks departing from the depot. The demand at each RDN is the sum of the demands at the PODs assigned to it. The control parameters of VRPs including the required maximum delivery duration, break time, load time and unload time could be different depending on the requirements at each depot. Instead of a list of physical trucks, a list of optional truck types is input, since this module is used to investigate the best preparedness planning policies for trucks. Besides the number of various types of trucks, the output also includes the routing schedules of each truck, the number of late deliveries and the average lateness.

\subsection{Scenario Analysis}

Our models and solutions are applied to an assumed large-scale emergency scenario. A number of people infected by a virulent strand of a pandemic influenza virus are detected across Kentucky, which could cause a state-wide outbreak within a short duration. After Kentucky state authorities and the federal authorities evaluate the situation together, the federal authorities decide to deliver vaccines to the entire state within a specified time period. 
Kentucky state authorities must make plans to receive the vaccine packages and distribute them to the affected population across the entire state. Table 13 displays the population of all counties in Kentucky obtained from 2010 census [62] and the corresponding vaccine demands. Two demand modes are estimated: the light demand mode assumes that every 5,000 persons need one pallet of vaccine; whereas the heavy demand mode assumes that every 1000 persons need one pallet of vaccine. The allocation of vaccine to a county is proportional to the population of that county with respect to one of the above two demand modes.

The locations of candidate RSS sites, candidate RDN sites and POD sites are provided by Kentucky state government. Under this scenario, all the PODs across the entire state are supposed to be open. The vaccine allocated to a county is evenly allocated to the open PODs within that county. The routing distance between any two locations is calculated by a program using Microsoft Bing Map APIs to form a distance matrix.

The optional trucks include 13 different types of trucks with $2,4,6,8,10,12,14,16,18$, $20,22,24$ and 26 pallets loading capacities respectively. In the entire logistics system, the transportation consists of two stages. In the first stage, the trucks begin from RSSs and deliver the vaccine from RSSs to their assigned RDNs or PODs. In the second stage, the trucks begin from RDNs and deliver the vaccine from RDNs to their assigned PODs. Sufficient number of trucks must be prepared and pre-positioned at each open RSS or RDN before the transportation. The required maximum delivery duration for the first stage is denoted as $D T 1$, whereas the required maximum delivery duration for the second stage is denoted as $D T 2$. The break time in both stages $B T$ is set as 1 hour by default. 
Given different $D T 1$ and $D T 2$, performance measures such as number of late trips, average lateness, trucks resource requirements, total travel distance and total load capacity can be used to evaluate alternate solutions.

Based on the experiments with different DT1 and DT2 under this scenario, the following issues will be discussed: (1) The Feasible DT1 and DT2; (2) Trucks Resource Planning Policies; (3) Indirect Shipment vs Direct Shipment.

\subsubsection{The Feasible $D T 1$ and $D T 2$}

With respect to the requirement that the vaccine must be delivered to all the PODs across the entire state of Kentucky within the required duration, what would be the feasible DT1 and DT2 in terms of the acceptable number of late trips and the acceptable average lateness? Figures $12-19$ displays the number of late trips and the average lateness of each transportation stage under both demand modes.

Figures 12 and 13 indicate that there is no late trips in the first stage transportation under the heavy demand mode if the delivery duration constraint is 18 hours. Actually depending on the extent of relaxation of the duration requirements, any duration constraint from 14 hours to 18 hours could be acceptable. From Figures 14 and 15, similar results can be obtained under the light demand mode. Therefore, it can be concluded that given sufficient number of trucks, the effect of duration constraint on the number of late trips and the average lateness are not affected by the demand mode in the first stage transportation. 
Figure 16 and 17 indicate that a transportation plan with a duration constraint from 6 hours to 10 hours can be acceptable for the second stage transportation under the heavy demand mode in terms of the number of late trips and the average lateness. Figure 18 and 19 shows the same results under the light demand. Therefore, it can be concluded that the effect of duration constraint on the number of late trips and the average lateness does not matter with the demand mode in the second stage transportation, given enough trucks.

Generally, based on the above observations, the following pattern relevant to feasibility of SNS operations within a specific area can be concluded:

Given sufficient number of trucks, how soon to complete the deliveries is determined not by the demand at nodes, but by the locations of sites and the corresponding geographic structure. 


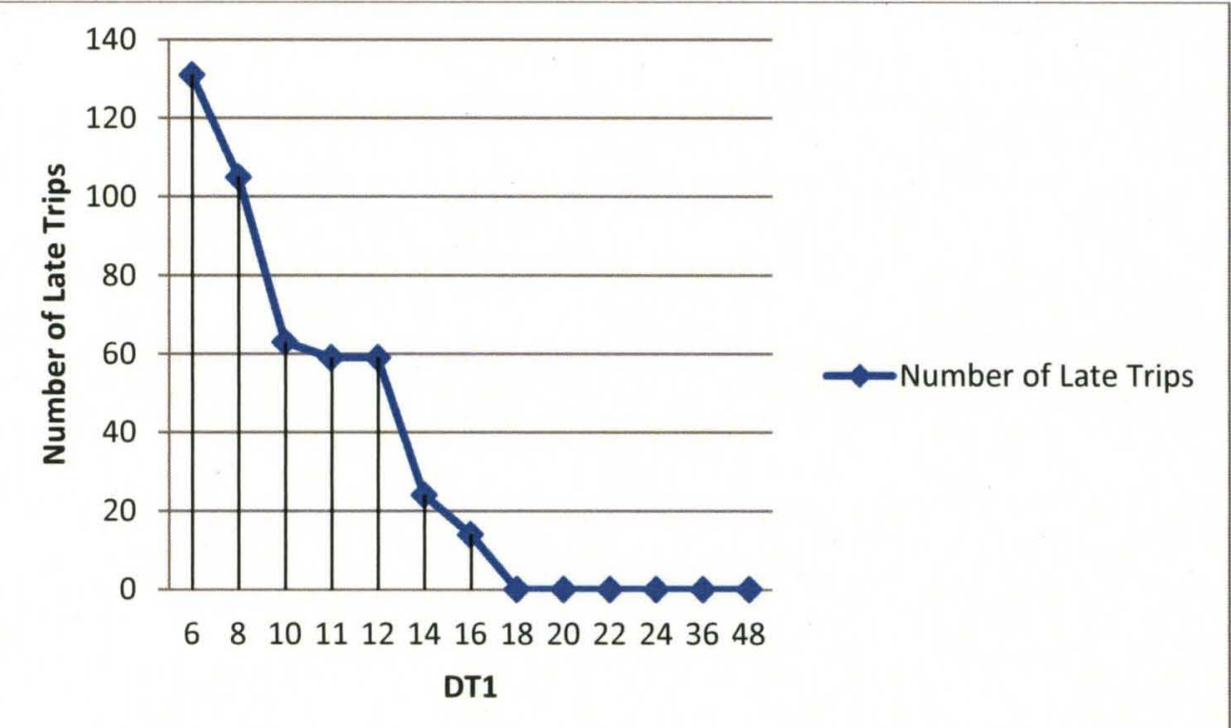

Figure 12. The number of late trips of $1^{\text {st }}$ stage transportation under heavy demand.

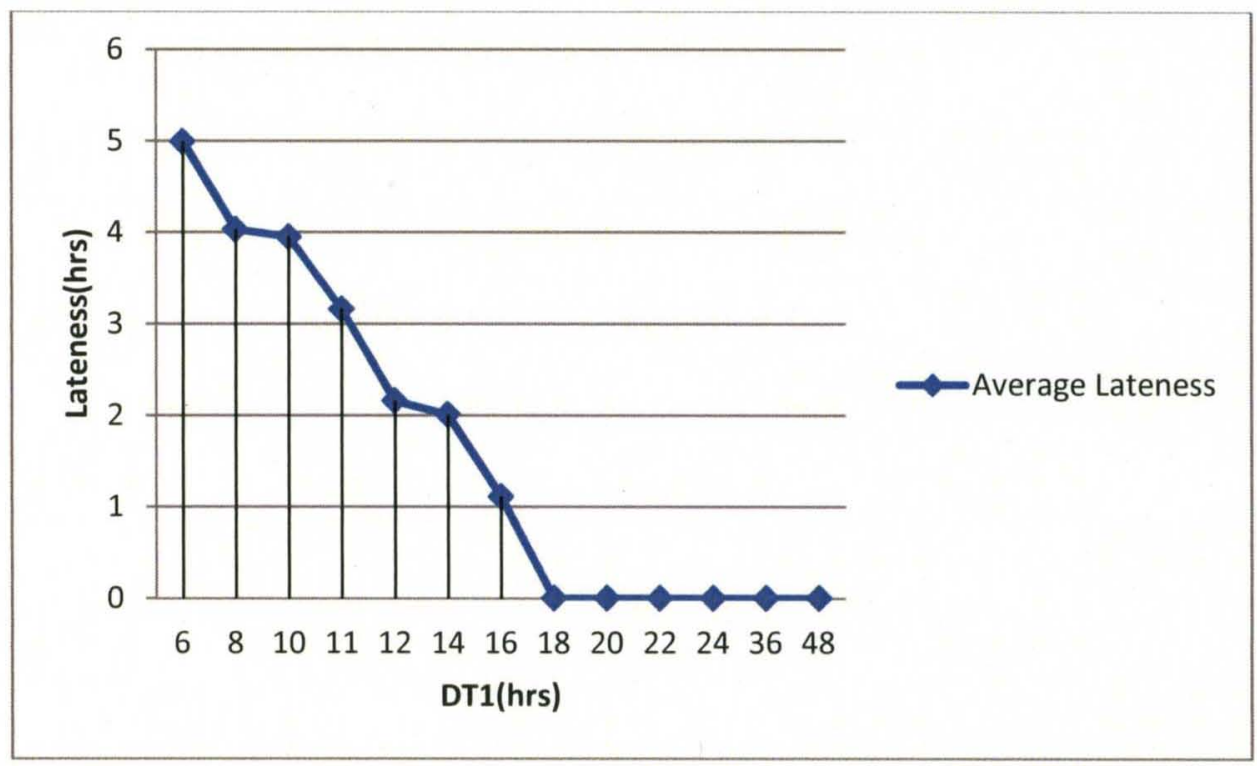

Figure 13. The average lateness of $1^{\text {st }}$ stage transportation under heavy demand. 


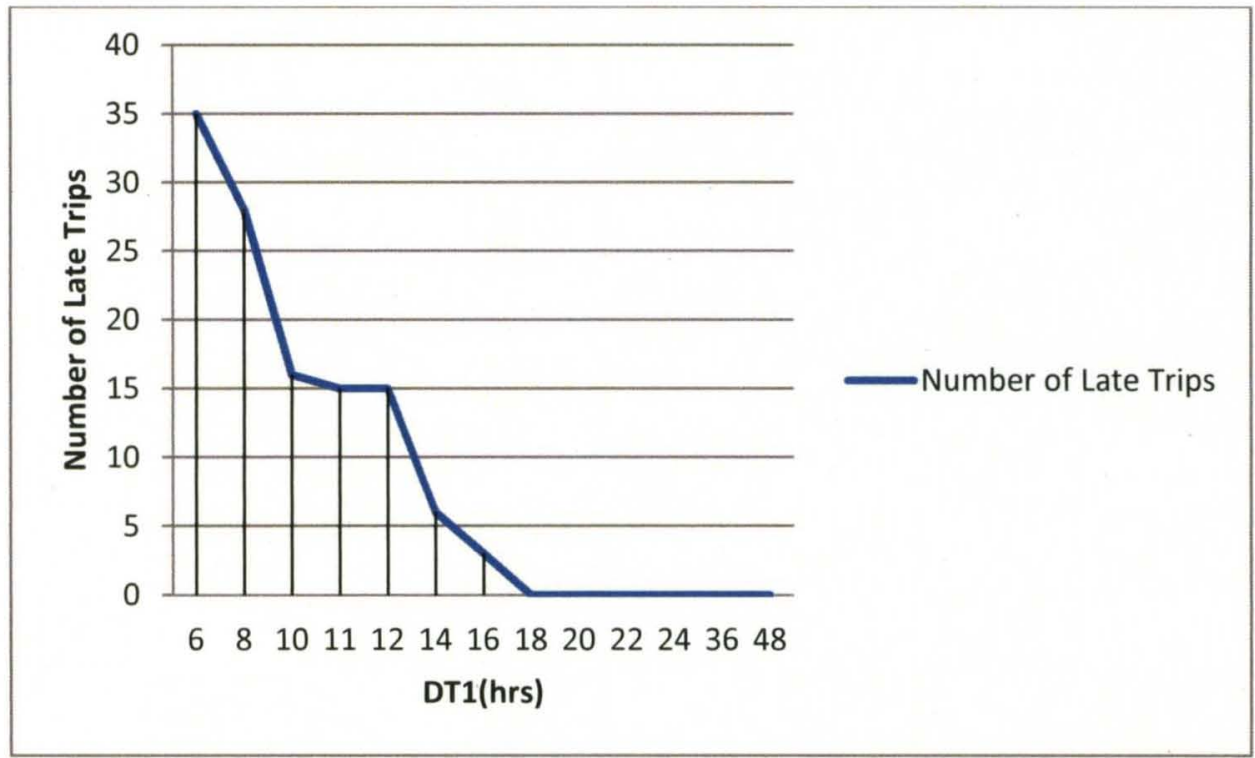

Figure 14. The number of late trips of $1^{\text {st }}$ stage transportation under light demand.

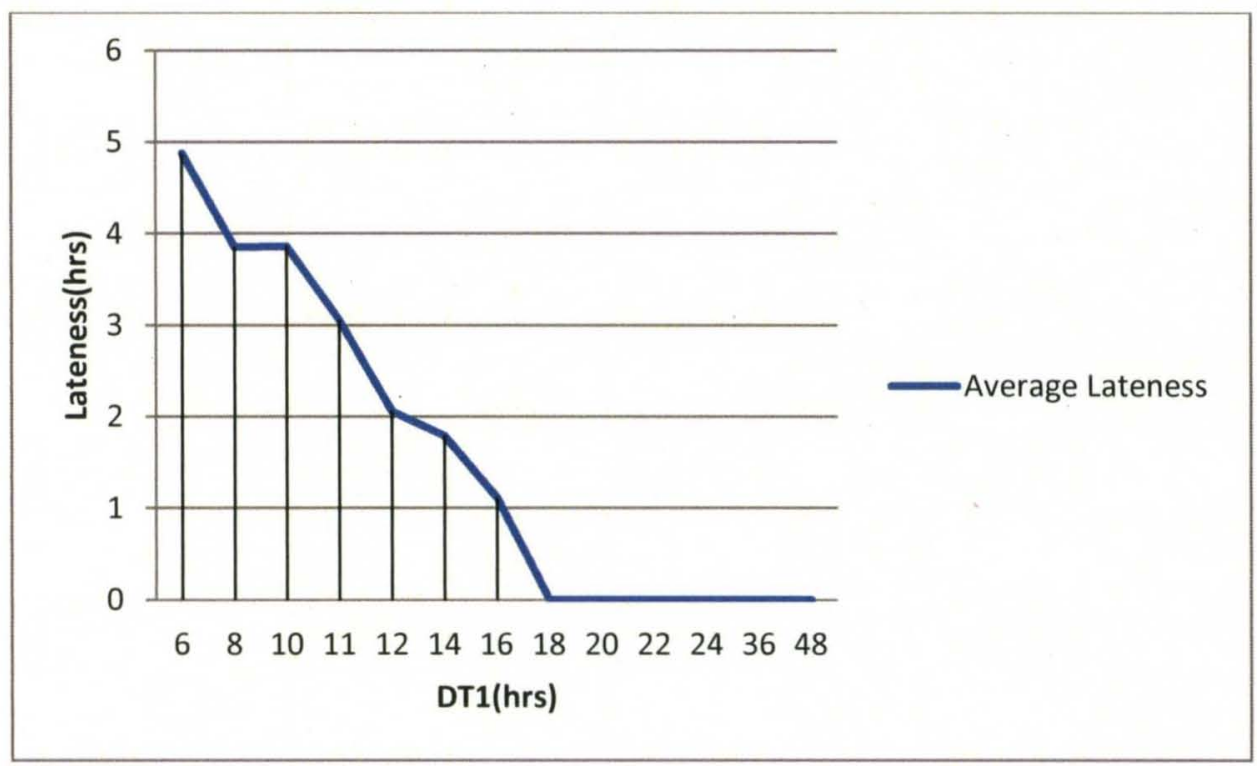

Figure 15. The average lateness of $1^{\text {st }}$ stage transportation under light demand. 


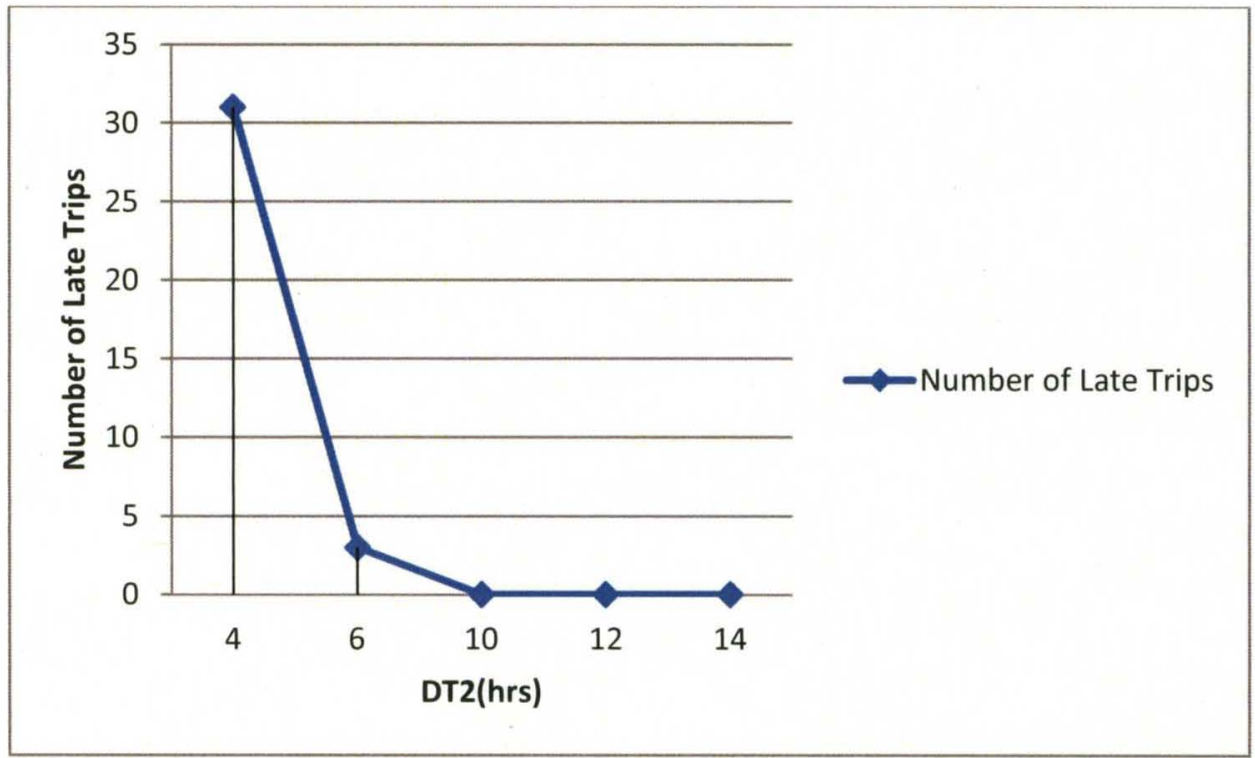

Figure 16. The number of late trips of $2^{\text {nd }}$ stage transportation under heavy demand.

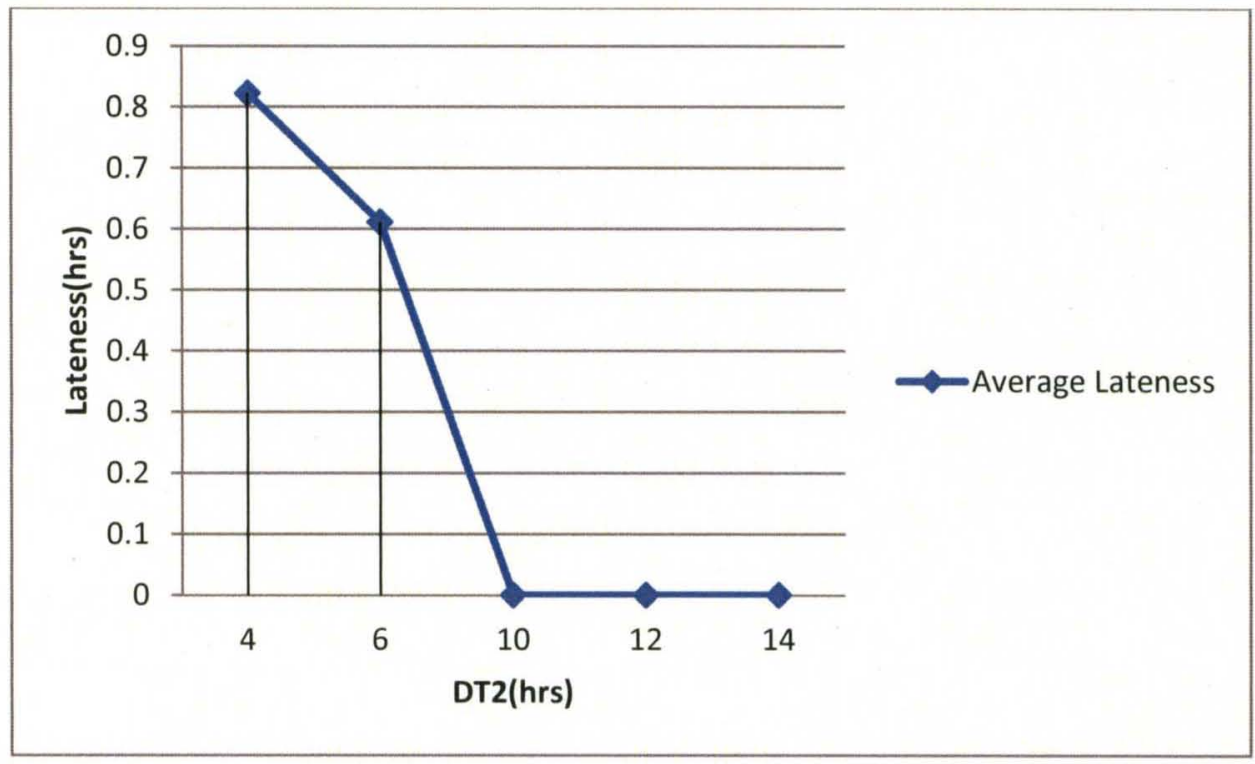

Figure 17. The average lateness of $2^{\text {nd }}$ stage transportation under heavy demand. 


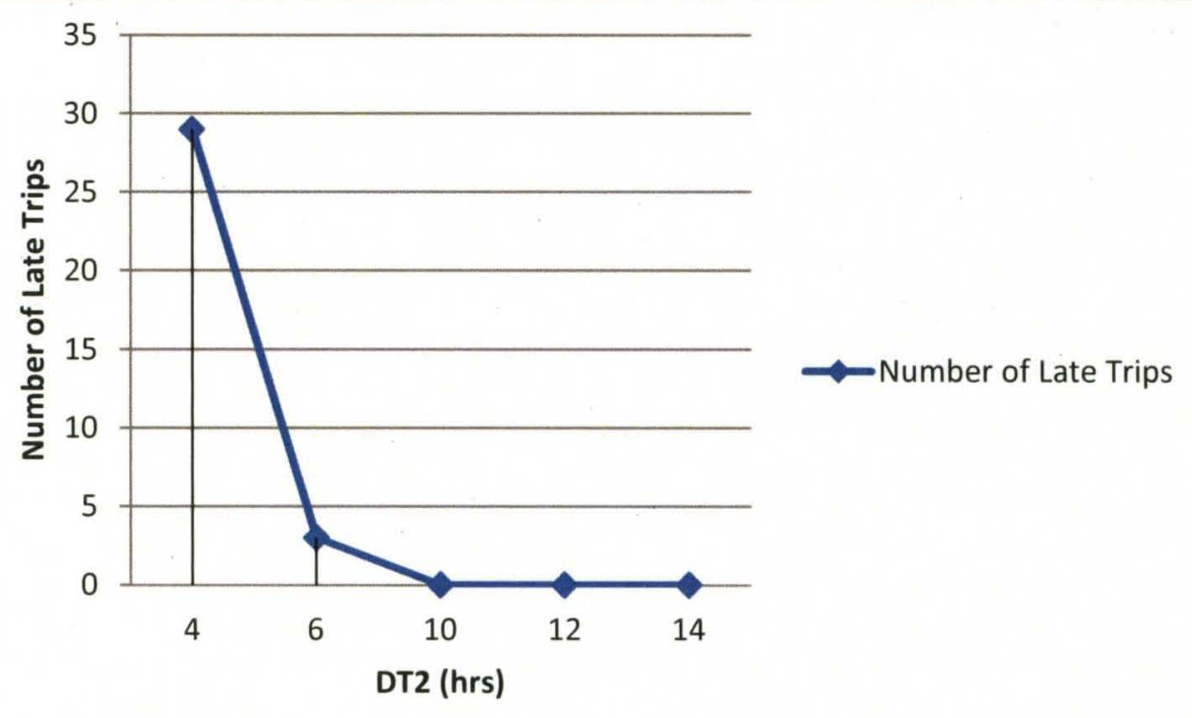

Figure 18. The number of late trips of $2^{\text {nd }}$ stage transportation under light demand.

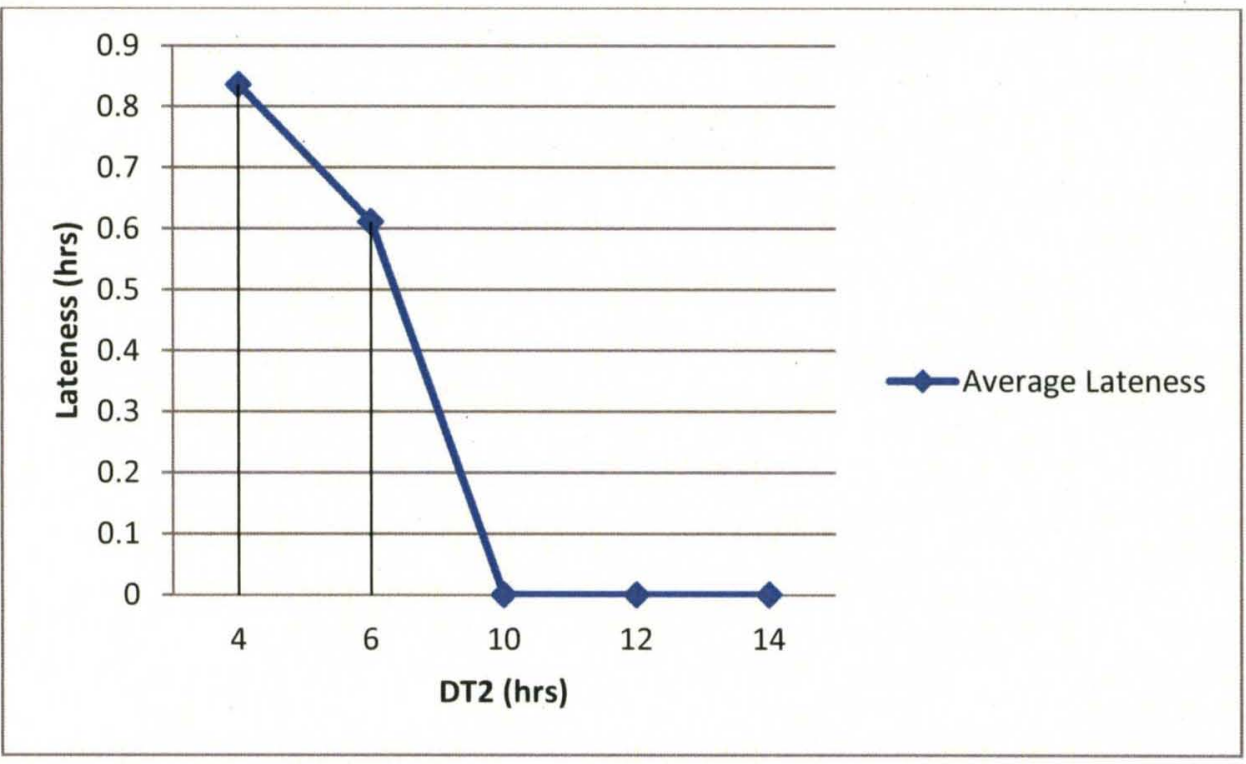

Figure 19. The average lateness of $2^{\text {nd }}$ stage transportation under light demand. 


\subsubsection{Truck Resource Planning Policies}

Adopting the feasible operations plans in terms of DT1 and DT2 obtained in Section 5.3.1, Figures $20-23$ display a set of optimal truck resource preparedness plans for each stage of transportation under the heavy demand mode and the light demand mode. The $\mathrm{x}$ axis lists the truck types in terms of their loading capacity measured in pallets; the $y$-axis displays the corresponding number of each type of trucks to be selected in the optimal plan. Figure 20, 21 and 22 indicates that big trucks are preferred for the first stage feasible transportation plans under each demand mode and the second stage transportation plans under the heavy demand mode. Figure 23 indicates that the feasible operation plans for the second stage transportation under the light demand mode requires more small trucks for short distance deliveries compared to the previous cases, especially if the duration constraint is short.

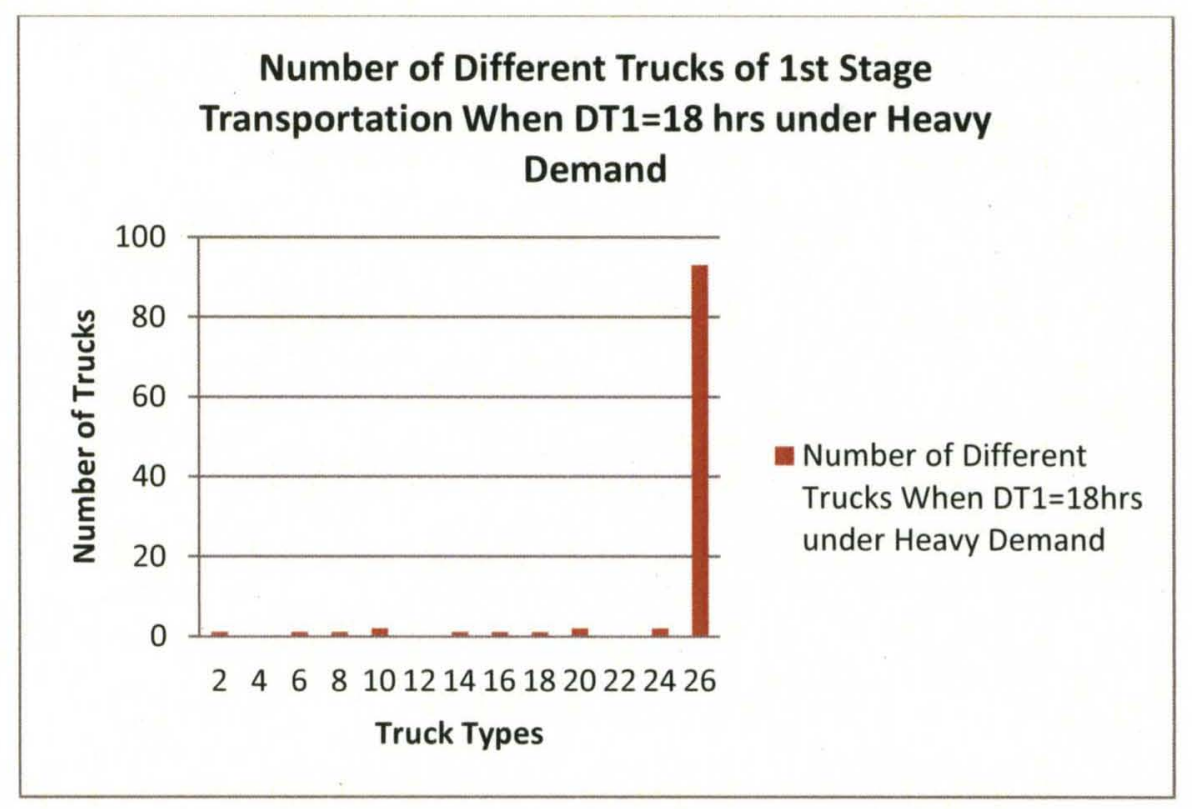

Figure 20. The number of different trucks of $1^{\text {st }}$ stage transportation when DT1=18 hrs under heavy demand. 


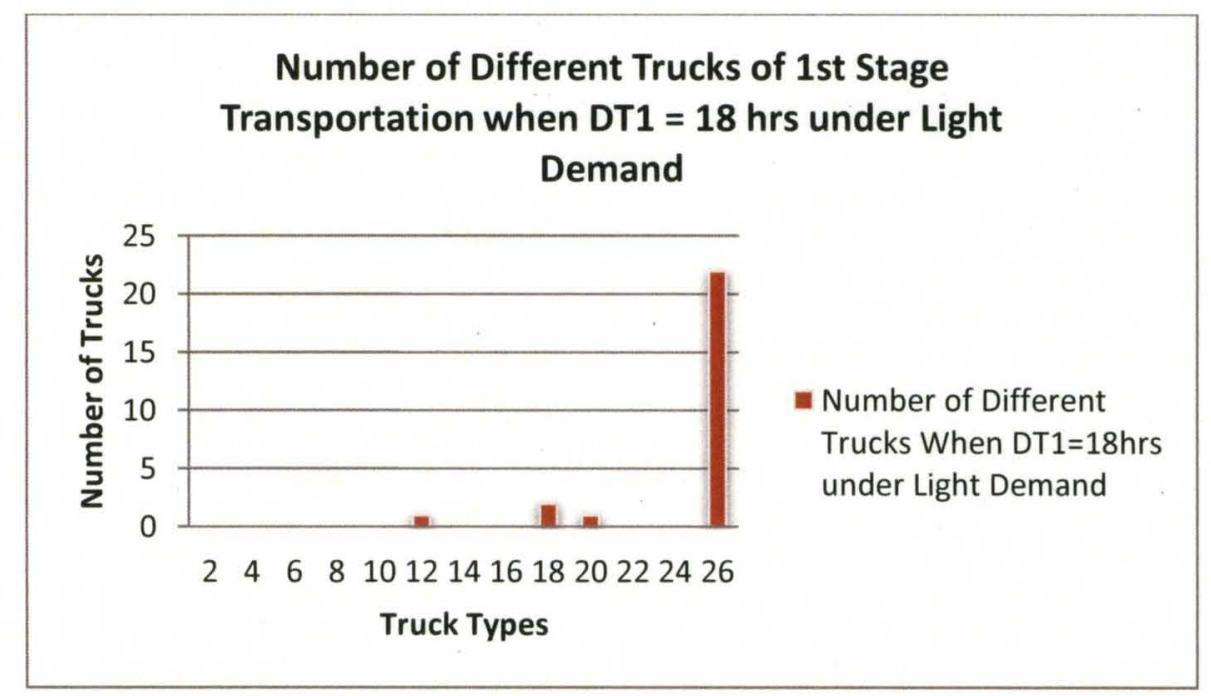

Figure 21. The number of different trucks of $1^{\text {st }}$ stage transportation when DT $1=18 \mathrm{hrs}$ under light demand.

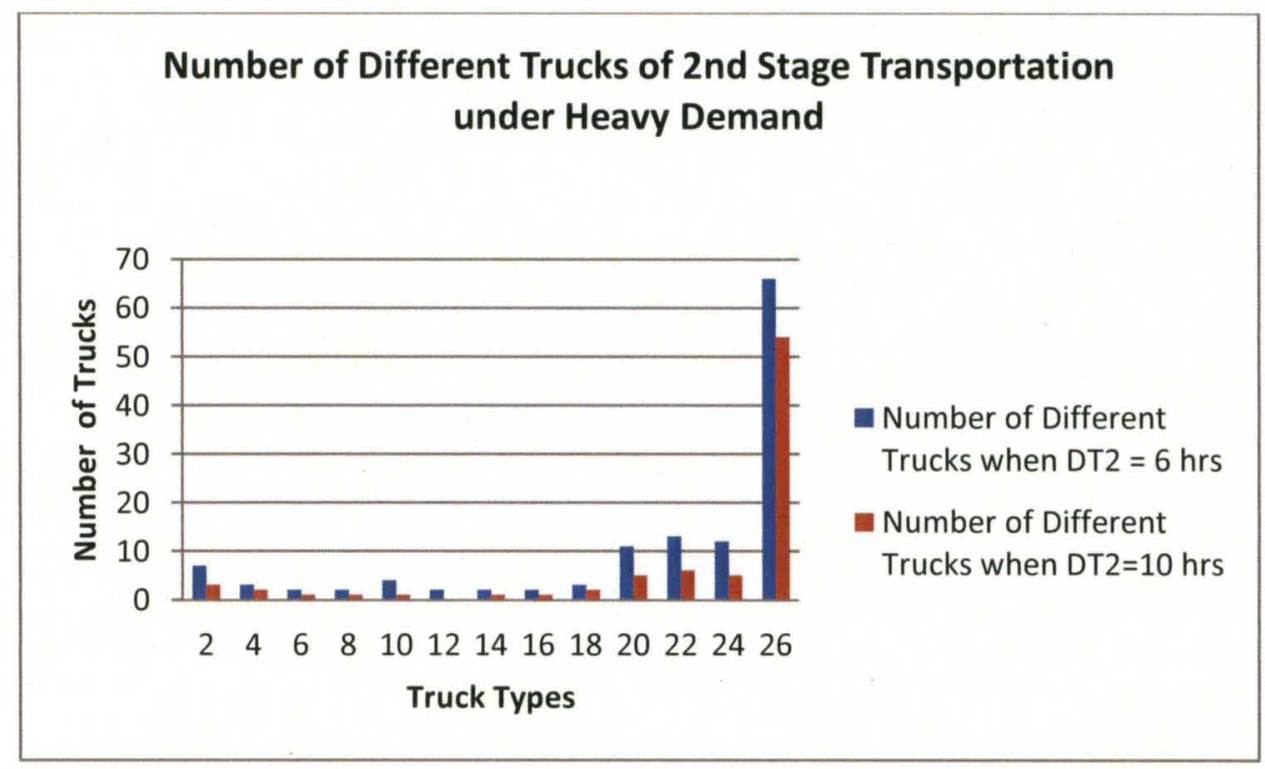

Figure 22. The number of different trucks of $2^{\text {nd }}$ stage transportation under heavy demand. 


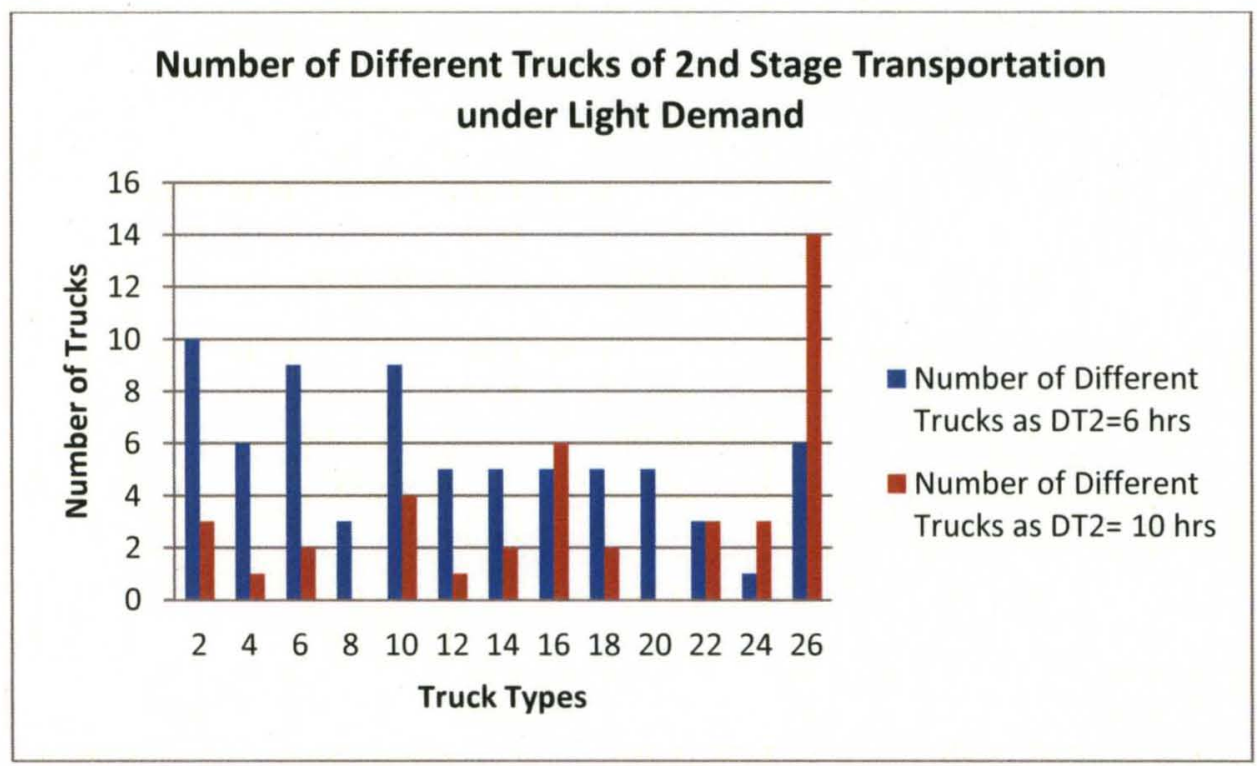

Figure 23. The number of different trucks of $2^{\text {nd }}$ stage transportation under light demand.

\subsubsection{Indirect Shipment vs Direct Shipment}

In our solutions, there are two ways to transport the relief materials from RSSs to PODs.

One is two-stage indirect shipment, by which the materials are shipped from RSSs to PODs via RDNs. The other is single-stage direct shipment, by which the materials are shipped from RSS to PODs directly. Using our software module, we can compare the performance of these two ways. Table 8 lists eight candidate solutions. Solution A, B, C and $\mathrm{C}$ are indirect shipment plans following the feasible duration constraints DT1 and DT2 obtained from the previous experiments, but the number of open RDNs is reduced stepwise by 5 from solution A to D. Solution E, F, G and H are direct shipment plans, in which there is no RDNs to be open. The required maximum delivery duration indicated by DT 1 is reduced stepwise by 2 from solution $\mathrm{E}$ to $\mathrm{H}$. The performance of the above 
solutions is compared in terms of the total travel distance, the total load capacity, the number of late trips and the average lateness under both demand modes in Figures 24 31. The total load capacity is calculated by $\sum_{k} C_{k} N_{k}$, where $k$ denotes the type of trucks, $C_{k}$ denotes the loading capacity of truck type $k$, and $N_{k}$ denotes the number of trucks of type $k$ in the corresponding solution.

Table 8 The Candidate Shipment Solutions

\begin{tabular}{|c|c|c|c|}
\hline Solution & DT1 & DT2 & \# of open RDNs \\
\hline A & 18 & 6 & 20 \\
\hline B & 18 & 6 & 15 \\
\hline C & 18 & 6 & 10 \\
\hline D & 18 & 6 & 5 \\
\hline E & 24 & 0 & 0 \\
\hline F & 22 & 0 & 0 \\
\hline G & 20 & 0 & 0 \\
\hline H & 18 & 0 & 0 \\
\hline
\end{tabular}

Under the heavy demand mode, Figure 24 shows that direct shipment solution E, F and G outperform all the indirect solutions in terms of the total travel distance. Solution F and G also outperform all the indirect shipment solutions in terms of responsiveness (i.e. shorter delivery duration). Figure 25 shows that all the direct shipment solutions require less total load capacity than all the indirect solutions, thus the direct shipment solutions use fewer trucks than the indirect shipment solutions to accomplish all the delivery tasks. Figures 26 and 27 shows that direct shipment solutions $\mathrm{E}$ and $\mathrm{F}$ have no late trips, and direct shipment solution $\mathrm{G}$ is acceptable in terms of lateness. 
Figures 28-31 show that the results under the light demand mode have the similar pattern as under the heavy demand mode.

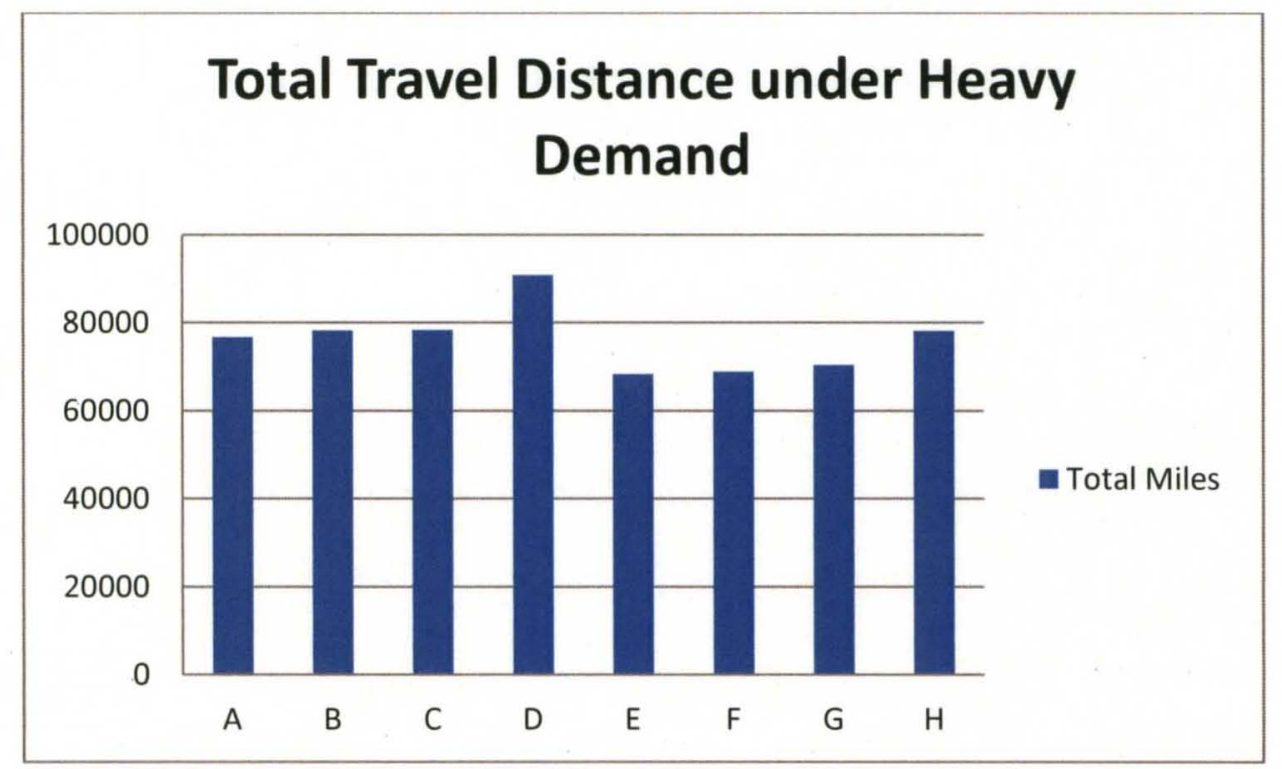

Figure 24. Comparison of total travel distance among the candidate solutions under heavy demand.

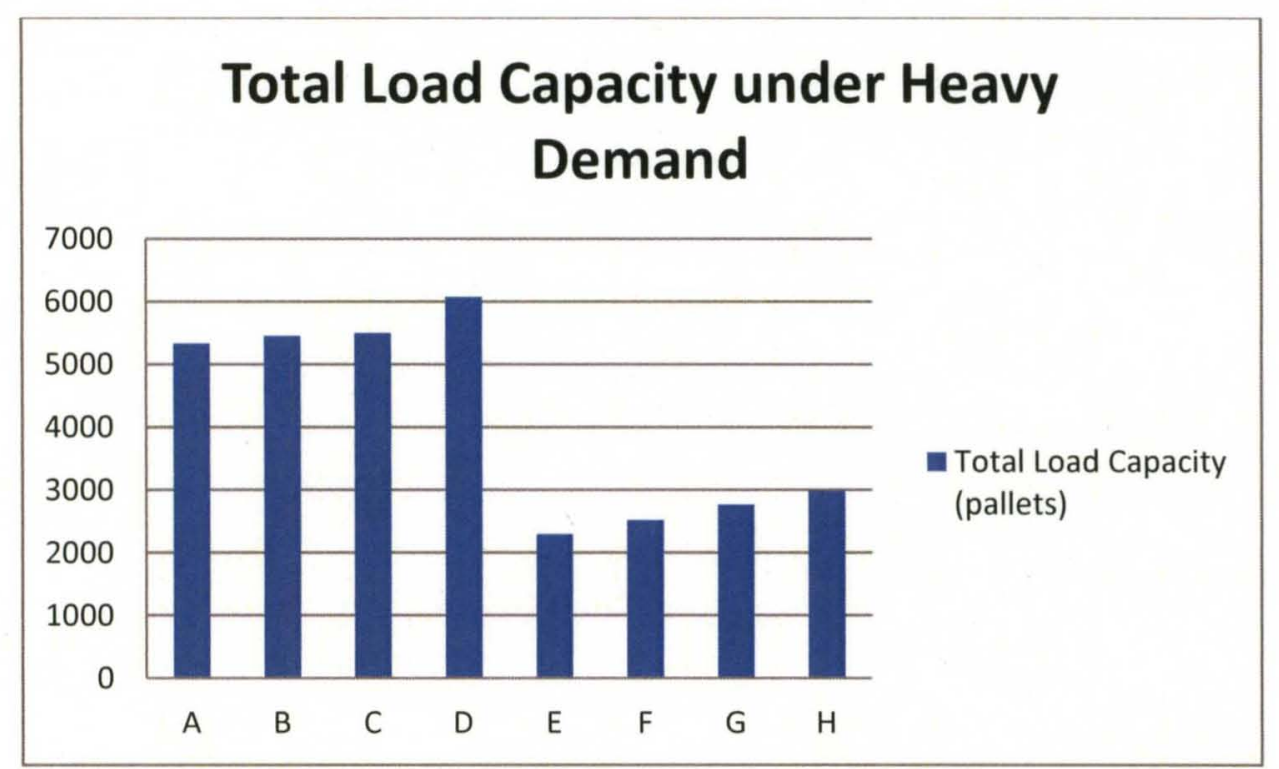

Figure 25. Comparison of total load capacity among the candidate solutions under heavy demand. 


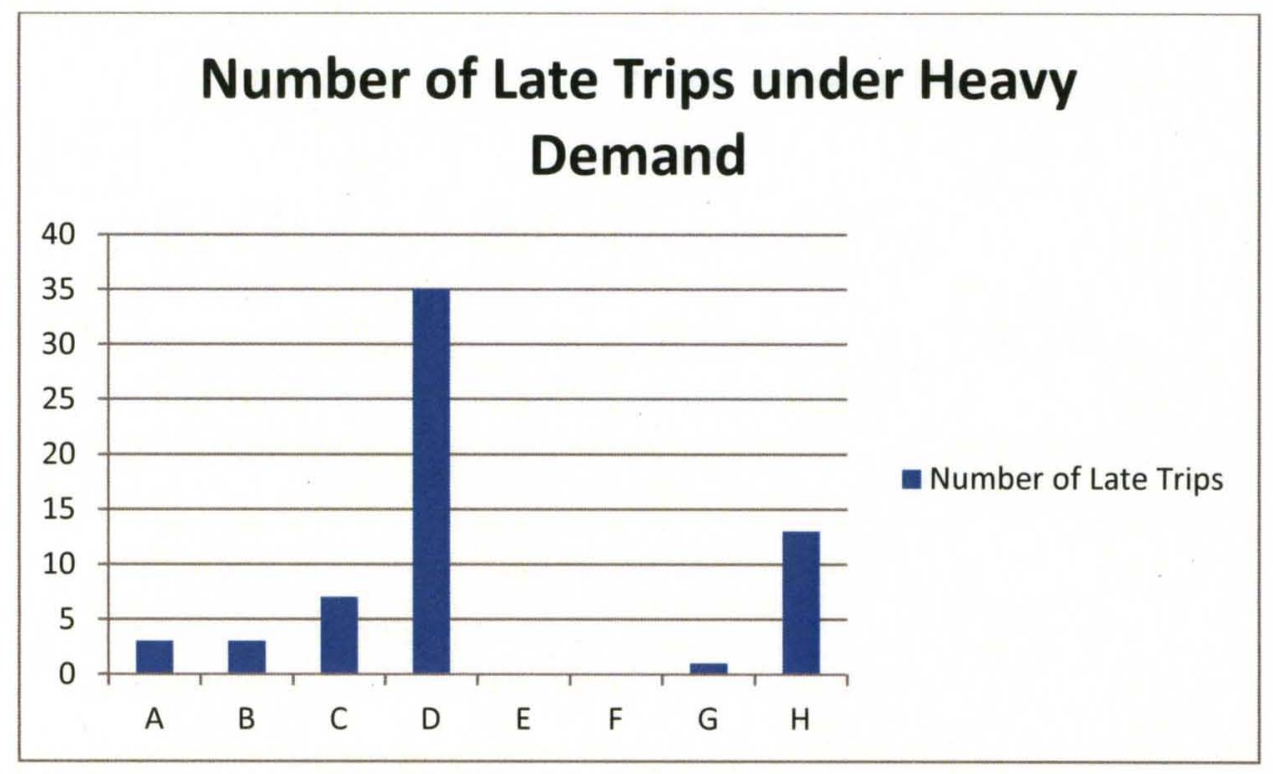

Figure 26. Comparison of number of late trips among the candidate solutions under heavy demand.

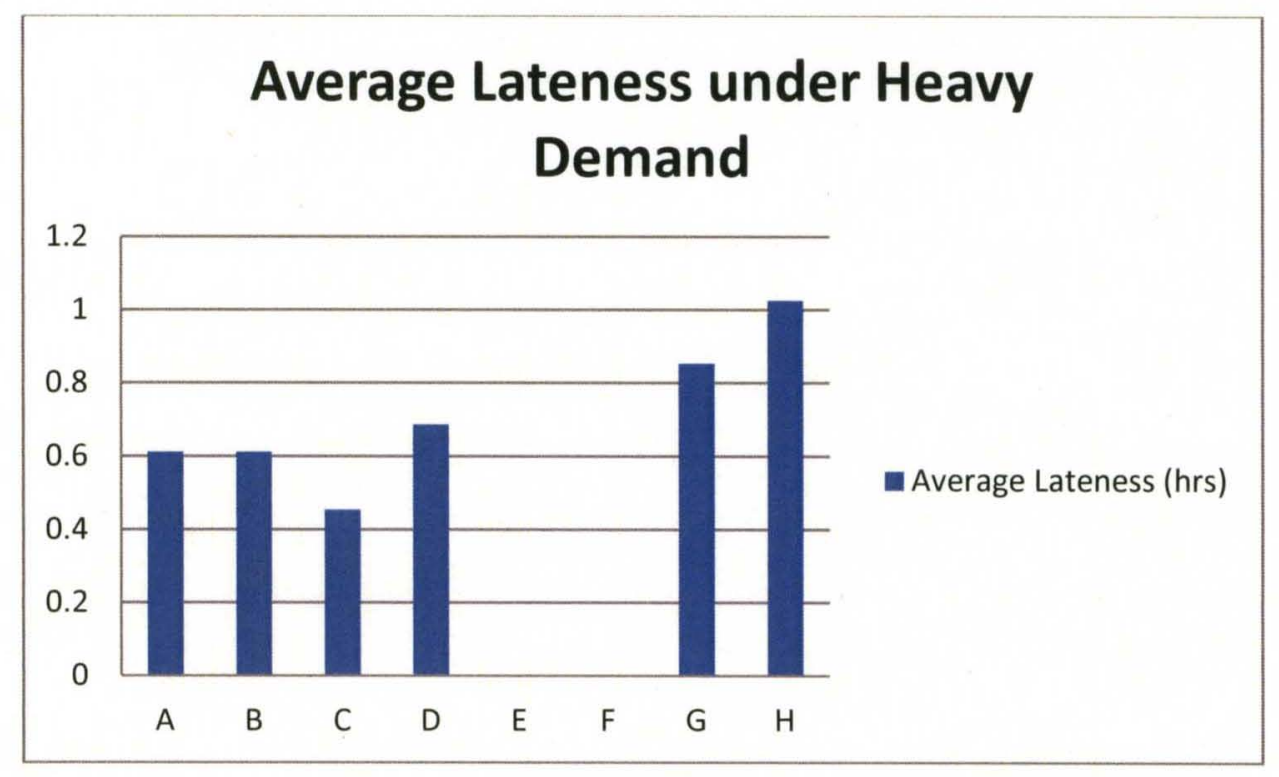

Figure 27. Comparison of average lateness among the candidate solutions under heavy demand. 


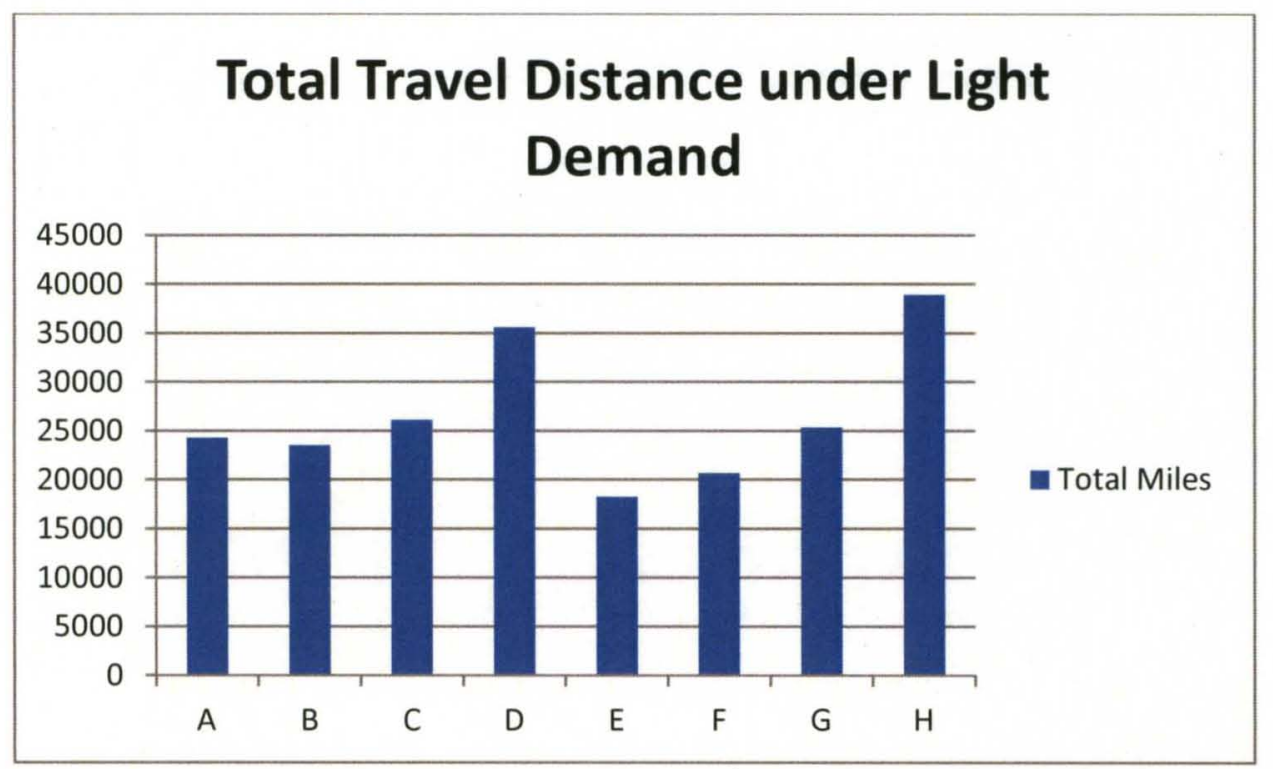

Figure 28. Comparison of total travel distance among the candidate solutions under light demand.

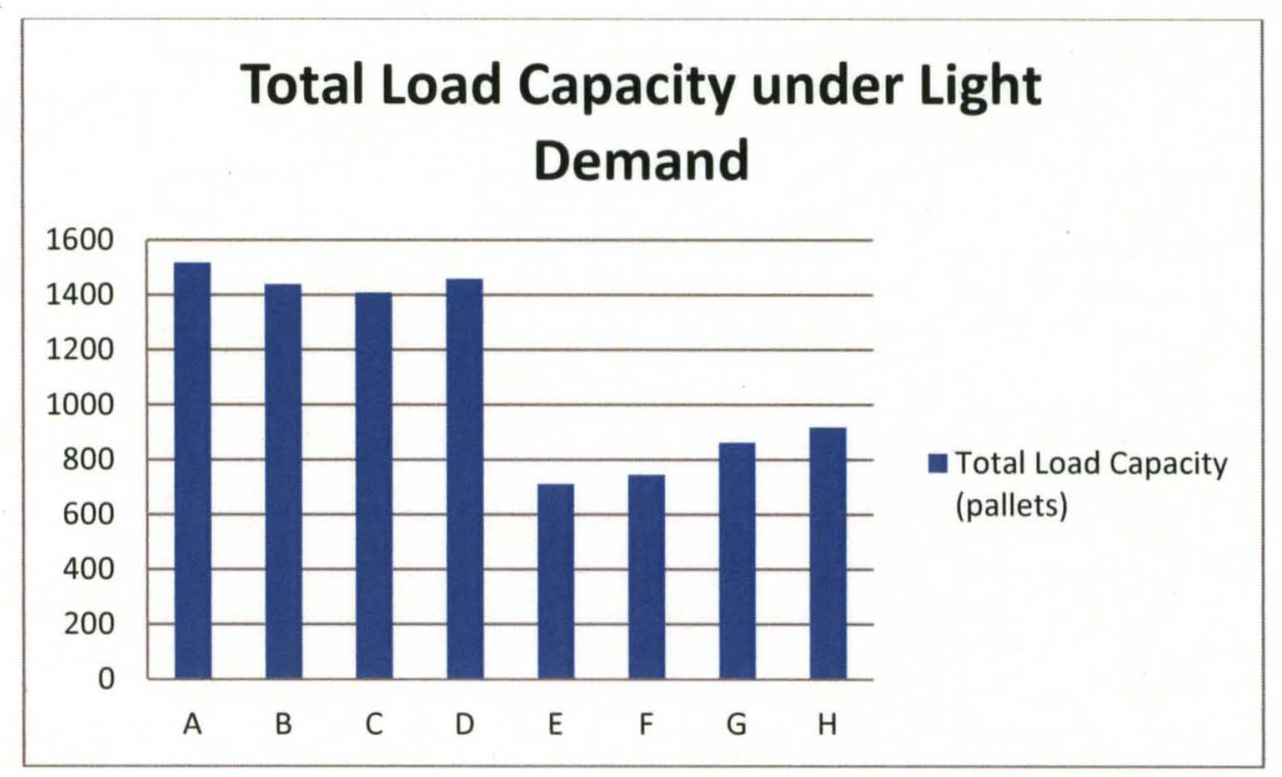

Figure 29. Comparison of total load capacity among the candidate solutions under light demand. 


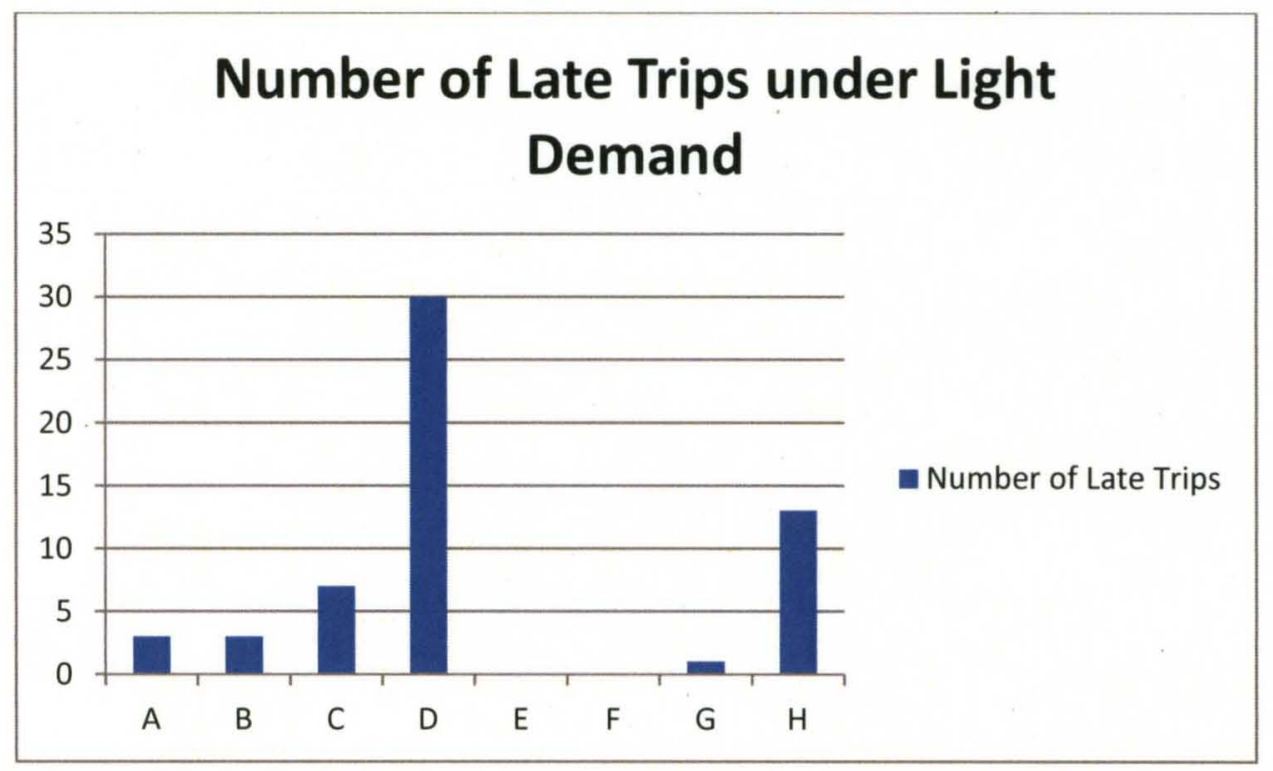

Figure 30. Comparison of number of late trips among the candidate solutions under light demand.

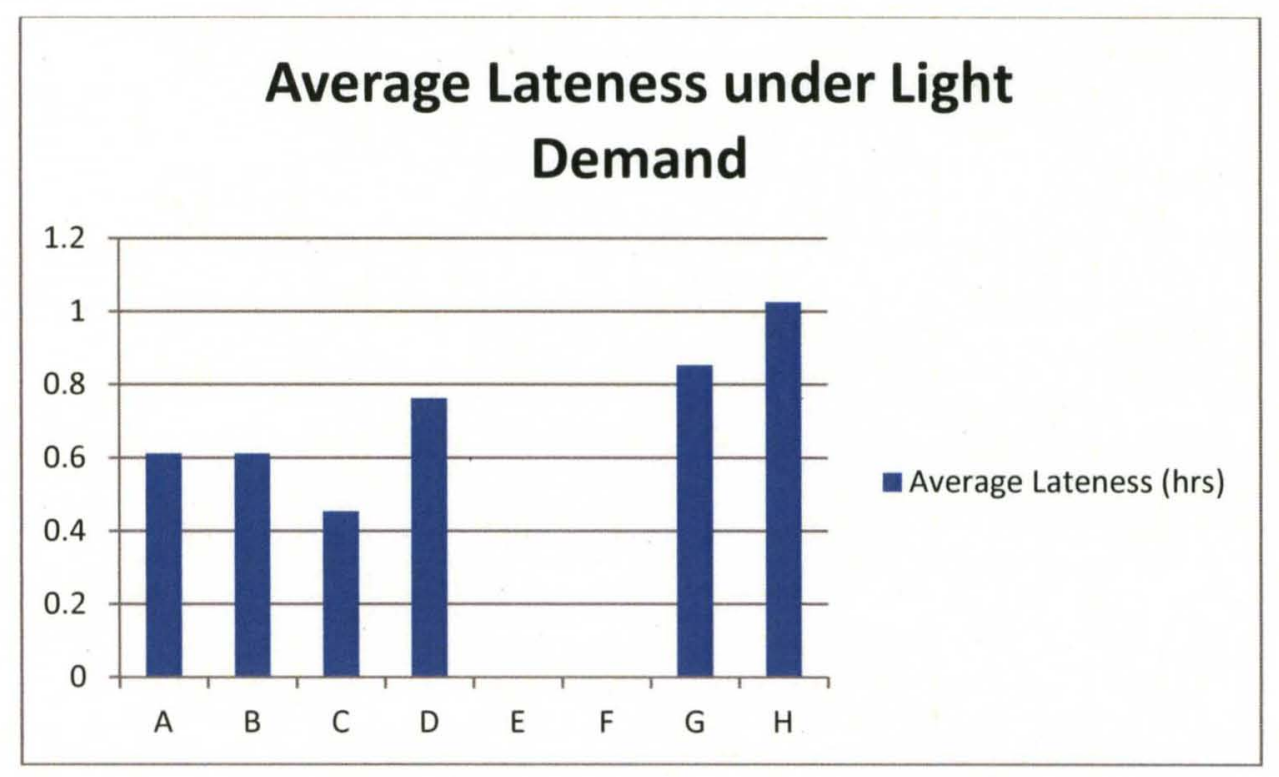

Figure 31. Comparison of average lateness among the candidate solutions under light demand.

In general, the direct shipment solutions outperform the indirect shipment solutions. Therefore, we suggest that removing the middle level warehouse RDNs and adopting direct shipment from RSSs to PODs could improve the total performances as well as 
reduce the total cost. However, the following issues relevant to the above suggestions have to be discussed:

(1) There is an assumption behind the above suggestions, that our model and the corresponding solution algorithm always can provide optimal or near-optimal solutions. However, there could be alternative models or solution algorithms which could provide better solutions than that proposed in this dissertation. Moreover, the effectiveness of our solutions must be demonstrated via practical drills, simulation or other analytical approaches.

(2) In a direct shipment plan, a truck has to be driven continuously for longer time than in an indirect shipment plan. However, a driver is only allowed to drive for a specified period in one day. According to the law, legal driving time is 11 hours of driving with 10 hours of break thereafter [127]. Therefore, an optimal practical shipment solution should be constrained by the drivers' legal driving time. Moreover, a driver scheduling algorithm should be developed, or the middle level warehouse RDNs should be changed as a set of relay points for drivers switching in the direct shipment solutions. 


\section{CHAPTER 6 CONCLUSION}

In this chapter, the contributions of this research are outlined, and several potential ideas for future research are discussed.

\subsection{Contributions}

This research gives the following two contributions:

(1) It provides a practical solution for the SNS distribution planning within a state. In this research, a transshipment and location model is formulated to determine the open facilities and the transshipment quantity of materials between facilities. A model for VRP and a corresponding solution algorithm is developed to determine the routing of trucks for deliveries. We believe that it is the first multiple-vehicle routing model with duration constraint and capacity constraint and allowing split deliveries as well as multiple trips per vehicle. Based on the two models and solutions, a web-based SNS planning tool is developed to assist SNS staff to make decisions.

(2) A binary location model is formulated to determine the open facilities and their assignment relationship in Chapter 5 , and the corresponding solution algorithm is integrated with the previous solution algorithm for the SNS VRP as a large-scale emergency scenario analysis module. Given the real data of Kentucky fed into 
the analysis module, three issues are discussed for better logistics planning: the feasible operation plans in terms of duration constraint, the truck resource preparedness planning in terms of truck capacities, and the comparison between direct shipment and indirect shipment.

\subsection{Further Work}

Based on the current research, we can extend this work in three specific directions, and we can also solve the similar problems with a more creative approach.

\subsubsection{The Practical Extensions of the Current Work}

(1) Develop a fast solution algorithm for solving the SNS transshipment and location model presented in Section 3.3

Currently the solution of the SNS transshipment and location model is exact, thus as the size of the problem becomes larger (i.e., the number of RSSs, RDNs and PODs is increased), the execution of the solution could become much slower. Therefore, it is very necessary to develop a fast solution for solving the model. The fast solution could be implemented by a bender decomposition algorithm or a heuristic algorithm.

(2) Develop a "routing-first, location-second" heuristic algorithm for solving twolevel SNS location problem

Some states adopt a three-level of logistics network design presented in this dissertation as in Kentucky, whereas other states adopt a two-level SNS logistics 
network design as in Texas. In the latter, the logistics network only consists of RSSs and PODs, more than one RSSs could be open, and the relief materials are shipped from RSSs to PODs directly. This simpler structure allows a "routingfirst, location-second" approach to combine location and routing decisions. With this approach, more effective operations plans can be made to distribute the relief materials faster. First all the open PODs are divided into a set of clusters based on their geographic closeness, a route is formed for each cluster. Second each route is assigned to its closest available RSS.

(3) Develop location model and vehicle routing model of SNS logistics network for vendor managed inventory

Federal SNS authorities prepare two types of stockpiles. One is a 12-hour push package, which is shipped from federal warehouse to the affected state directly as the first batch relief materials within 12 hours. The other is vendor managed inventory, which is shipped from the vendors to the affected area as more specific additional materials are required. Evidently the models and solutions in this dissertation focus on solving the problems relevant to the former case. However, in the latter case, more issues such as vendor selection, the transportation from vendors to the affected area and so on need to be considered, thus a set of new models and solutions need to be developed. 


\subsubsection{Intelligent Agent-based Transportation Planning and Directing System for Large-scale Emergency Relief Operations}

Our current models and solutions assume that all the demand information is revealed and all the resources are ready before the operations begin, there is no change during the operations and thus the decisions in the beginning are committed until the end of operations. However, that usually is not the real case. During a large-scale emergency, the situation is full of uncertainties, especially as the emergency can destroy or disturb the resources such as trucks, highway, truck drivers and so on. Moreover, most probably the demand information could be revealed incrementally over time. Thus, it is necessary to develop a flexible decision support system which can capture the real-time information of changing situation including demands and available resources, and dynamically assign and deliver those resources to the demanding sites.

Inspired by the agent-based scheduling system for real-time transportation problems introduced in [128], we can develop a vehicle-based distribution planning system deployed for a large-scale emergency. One of the aims of this research is to use agentbased simulation to explore the essential techniques for developing such a system in practice, and investigate the feasibility or effectiveness of developing or deploying such systems.

In this system, a control center, warehouses, PODs, trucks and drivers are regarded as agents. All of them are connected with some wireless communication technologies, thus they can send data message to each other. All of them are equipped with a computer with 
specific computation capabilities, thus the data can be processed. Once a POD sends out a demand request to the control center, the control center broadcasts this request to all the warehouses and trucks in the system. Then warehouses and trucks bind each other by negotiation, form bids, and send the bids to the control center. Each bid represents an operation plan corresponding to the demand request. The control center selects the best bid to execute in terms of the performance requirements of different agents and the entire system. This system is agent-based multiple-goal decision support system based on auction mechanism. The research will focus on exploring the best rules or protocols to implement the system by simulation. 


\section{REFERENCES}

1. CDC. Strategic National Stockpile. 2010 [cited 2010; Available from: http://www.bt.cdc.gov/stockpile/.

2. Banner, G., The Rhode Island Medical Emergency Distribution System (MEDS). Disaster Management \& Response. 2(2): p. 53-57.

3. CDC, Receiving, Distributing, and Dispensing Strategic National Stockpile Assets--A Guide for Preparedness, CDC, Editor. 2005.

4. CDC, Strategic National Stockpile Operation Plan. 2008.

5. Real Time Decision Support System for Health Care and Public Health Sector Protection Project. 2010; Available from: http://rtdss.louisville.edu/.

6. Owen, S.H. and M.S. Daskin, Strategic facility location: A review. European Journal of Operational Research, 1998. 111(3): p. 423-447.

7. Brandeau, M.L. and S.S. Chiu, An Overview of Representative Problems in Location Research. Management Science, 1989. 35(6): p. 645-674. 
8. Hamacher, H.W. and S. Nickel, Classification of location models. Location Science. 6(1-4): p. 229-242.

9. Klose, A. and A. Drexl, Facility location models for distribution system design. European Journal of Operational Research, 2005. 162(1): p. 4-29.

10. Snyder, L.V., Facility location under uncertainty: a review. IIE Transactions, 2006. $38(7):$ p. $547-564$.

11. Current, J., H. Min, and D. Schilling, Multiobjective analysis of facility location decisions. European Journal of Operational Research, 1990. 49(3): p. 295-307.

12. Drezner, T., Optimal continuous location of a retail facility, facility attractiveness, and market share: An interactive model. Journal of Retailing, 1994. 70(1): p. 49-64.

13. Alumur, S. and B.Y. Kara, Network hub location problems: The state of the art. European Journal of Operational Research, 2008. 190(1): p. 1-21.

14. Current, J., M. Daskin, and D. Schilling, Discrete Network Location Models, in Facility Location: Applications and Theory, H.H. Zvi Drezner, Editor. 2001, SpringerVerlag.

15. Hakimi, S.L., Optimum Locations of Switching Centers and the Absolute Centers and Medians of a Graph. OPERATIONS RESEARCH, 1964. 12(3): p. 450-459. 
16. Balinski, M.L., Integer Programming: Methods, Uses, Computations. Management Science, 1965. 12(3): p. 253-313.

17. Mladenovic, N., et al., The p-median problem: A survey of metaheuristic approaches. European Journal of Operational Research, 2007. 179(3): p. 927-939.

18. Chung, C.-H., Recent Applications of the Maximal Covering Location Planning (M.C.L.P.) Model. The Journal of the Operational Research Society, 1986. 37(8): p. 735746.

19. Church, R. and $\mathrm{C}$. ReVelle, The maximal covering location problem. Papers in Regional Science, 1974. 32(1): p. 101-118.

20. Toregas, C. and C. ReVelle, Optimal location under time or distance constraints. Papers in Regional Science, 1972. 28(1): p. 131-143.

21. Chen, R. and Y. Handler, The conditional $\langle I>p</ I>$-center problem in the plane. Naval Research Logistics, 1993. 40(1): p. 117-127.

22. Erkut, E., The discrete p-dispersion problem. European Journal of Operational Research, 1990. 46(1): p. 48-60.

23. Zhang, F.G. and E. Melachrinoudis, The Maximin-Maxisum Network Location Problem. Computational Optimization and Applications, 2001. 19(2): p. 209-234. 
24. Pirkul, H. and D.A. Schilling, The Maximal Covering Location Problem with Capacities on Total Workload. Management Science, 1991. 37(2): p. 233-248.

25. Esbitt, D., The strategic national stockpile: roles and responsibilities of health care professionals for receiving the stockpile assets. Disaster Management \& Response. 1(3): p. 68-70.

26. Syarif, A., Y. Yun, and M. Gen, Study on multi-stage logistic chain network: a spanning tree-based genetic algorithm approach. Computers \& Industrial Engineering, 2002. 43(1-2): p. 299-314.

27. Wesolowsky, G.O., Dynamic Facility Location. Management Science, 1973. 19(11): p. 1241-1248.

28. Roy, T.J.V. and D. Erlenkotter, A Dual-Based Procedure for Dynamic Facility Location. Management Science, 1982. 28(10): p. 1091-1105.

29. Saldanha da Gama, F. and M.E. Captivo, A heuristic approach for the discrete dynamic location problem. Location Science. 6(1-4): p. 211-223.

30. Marianov, V. and $\mathrm{C}$. ReVelle, The capacitated standard response fire protection siting problem: Deterministic and probabilistic models. Annals of Operations Research, 1992. 40(1): p. 303-322. 
31. Wang, Q., R. Batta, and C.M. Rump, Algorithms for a Facility Location Problem with Stochastic Customer Demand and Immobile Servers. Annals of Operations Research, 2002. 111(1): p. 17-34.

32. Rosenhead, J., M. Elton, and S.K. Gupta, Robustness and Optimality as Criteria for Strategic Decisions. Operational Research Quarterly (1970-1977), 1972. 23(4): p. 413-431.

33. Ahmadi Javid, A. and N. Azad, Incorporating location, routing and inventory decisions in supply chain network design. Transportation Research Part E: Logistics and Transportation Review, 2010. 46(5): p. 582-597.

34. Klibi, W., et al., The Stochastic Multiperiod Location Transportation Problem. TRANSPORTATION SCIENCE, 2010. 44(2): p. 221-237.

35. ReVelle, C., Review, extension and prediction in emergency service siting models. European Journal of Operational Research, 1989. 40(1): p. 58-69.

36. ReVelle, C., et al., Facility location: a review of context-free and EMS models.

37. Toregas, C., et al., The Location of Emergency Service Facilities. OPERATIONS RESEARCH, 1971. 19(6): p. 1363-1373.

38. Calvo, A.B. and D.H. Marks, Location of health care facilities: An analytical approach. Socio-Economic Planning Sciences, 1973. 7(5): p. 407-422. 
39. Aly, A.A. and J.A. White, Probabilistic Formulation of the Emergency Service Location Problem. The Journal of the Operational Research Society, 1978. 29(12): p. 1167-1179.

40. Schilling, D.A., DYNAMIC LOCATION MODELING FOR PUBLIC-SECTOR FACILITIES: A MULTICRITERIA APPROACH*. Decision Sciences, 1980. 11(4): p. 714-724.

41. Araz, C., H. Selim, and I. Ozkarahan, A fuzzy multi-objective covering-based vehicle location model for emergency services. Computers \& Operations Research, 2007. 34(3): p. 705-726.

42. Daskin, M.S. and E.H. Stern, A Hierarchical Objective Set Covering Model for Emergency Medical Service Vehicle Deployment. TRANSPORTATION SCIENCE, 1981. 15(2): p. 137-152.

43. Repede, J.F. and J.J. Bernardo, Developing and validating a decision support system for locating emergency medical vehicles in Louisville, Kentucky. European Journal of Operational Research, 1994. 75(3): p. 567-581.

44. Daskin, M.S., APPLICATION OF AN EXPECTED COVERING MODEL TO EMERGENCY MEDICAL SERVICE SYSTEM DESIGN*. Decision Sciences, 1982. 13(3): p. $416-439$. 
45. Bianchi, G. and R.L. Church, A hybrid fleet model for emergency medical service system design. Social Science \& Medicine, 1988. 26(1): p. 163-171.

46. Hogan, K. and C. ReVelle, Concepts and Applications of Backup Coverage. Management Science, 1986. 32(11): p. 1434-1444.

47. Pirkul, H. and D.A. Schilling, The Siting of Emergency Service Facilities with Workload Capacities and Backup Service. Management Science, 1988. 34(7): p. 896-908.

48. Eaton, D.J., et al., Determining Emergency Medical Service Vehicle Deployment in Austin, Texas. INTERFACES, 1985. 15(1): p. 96-108.

49. Eaton, D.J., et al., Determining Ambulance Deployment in Santo Domingo, Dominican Republic. The Journal of the Operational Research Society, 1986. 37(2): p. 113-126.

50. Goldberg, J. and L. Paz, Locating Emergency Vehicle Bases When Service Time Depends on Call Location. TRANSPORTATION SCIENCE, 1991. 25(4): p. 264-280.

51. Ball, M.O. and F.L. Lin, A reliability model applied to emergency service vehicle location. Oper. Res., 1993. 41(1): p. 18-36.

52. Marianov, V. and C. ReVelle, The Queueing Maximal availability location problem: A model for the siting of emergency vehicles. European Journal of Operational Research, 1996. 93(1): p. 110-120. 
53. Lee, E.K., et al., Modeling and Optimizing the Public-Health Infrastructure for Emergency Response. INTERFACES, 2009. 39(5): p. 476-490.

54. Tech, C.f.o.r.i.m.a.h.---G. RealOpt user manual-- software for public health and medical preparedness, version 5. 2010; Available from: http://www2.isye.gatech.edu/medicalor/research.htm\#realopt.

55. Jia, H., et al., A modeling framework for facility location of medical services for large-scale emergencies. IIE Transactions, 2007. 39: p. 41-55.

56. Balcik, B. and B.M. Beamon, Facility location in humanitarian relief. International Journal of Logistics Research and Applications: A Leading Journal of Supply Chain Management, 2008. 11(2): p. 101 - 121.

57. Rawls, C.G. and M.A. Turnquist, Pre-positioning of emergency supplies for disaster response. Transportation Research Part B: Methodological, 2010. 44(4): p. 521534.

58. Mete, H.O. and Z.B. Zabinsky, Stochastic optimization of medical supply location and distribution in disaster management. International Journal of Production Economics, 2010. 126(1): p. 76-84.

59. Brandeau, M.L., et al., Recommendations for Modeling Disaster Responses in Public Health and Medicine: A Position Paper of the Society for Medical Decision Making. Medical Decision Making, 2009. 29(4): p. 438-460. 
60. Lee, E.K., et al., Large-Scale Dispensing for Emergency Response to Bioterrorism and Infectious-Disease Outbreak. INTERFACES, 2006. 36(6): p. 591-607.

61. Hupert, N., A.I. Mushlin, and M.A. Callahan, Modeling the Public Health Response to Bioterrorism: Using Discrete Event Simulation to Design Antibiotic Distribution Centers. Medical Decision Making, 2002. 22(5 suppl): p. S17-S25.

62. Automation, R. Arena Simulation Software. 2012; Available from: http://www.arenasimulation.com/arena Home.aspx.

63. Giovachino, M., et al., Optimizing a District of Columbia Strategic National Stockpile Dispensing Center. Journal of Public Health Management and Practice, 2005. 11(4): p. 282-290.

64. Whitworth, M.H., Designing the Response to an Anthrax Attack. INTERFACES, 2006. 36(6): p. 562-568.

65. Washington, M.L., Evaluating the Capability and Cost of a Mass Influenza and Pneumococcal Vaccination Clinic via Computer Simulation. Medical Decision Making, 2009. 29(4): p. 414-423.

66. Ding, H., L. Benyoucef, and X. Xie, Stochastic multi-objective productiondistribution network design using simulation-based optimization. International Journal of Production Research, 2009. 47(2): p. 479 - 505. 
67. Hidaka, K. and H. Okano, Simulation-based approach to the warehouse location problem for a large-scale real instance, in Proceedings of the 29th conference on Winter simulation. 1997, IEEE Computer Society: Atlanta, Georgia, United States. p. 1214-1221.

68. Bruno, G., A. Genovese, and A. Sgalambro, An Agent-Based framework for modeling and solving location problems. TOP, 2010. 18(1): p. 81-96.

69. Toth, P. and D. Vigo, The vehicle routing problem. 2002.

70. Gilbert, L., The vehicle routing problem: An overview of exact and approximate algorithms. European Journal of Operational Research, 1992. 59(3): p. 345-358.

71. Desrochers, M., J.K. Lenstra, and M.W.P. Savelsbergh, A classification scheme for vehicle routing and scheduling problems. European Journal of Operational Research, 1990. 46(3): p. 322-332.

72. Dror, M., G. Laporte, and P. Trudeau, Vehicle routing with split deliveries. Discrete Applied Mathematics, 1994. 50(3): p. 239-254.

73. Ho, S.C. and D. Haugland, A tabu search heuristic for the vehicle routing problem with time windows and split deliveries. Computers \&amp; Operations Research, 2004. 31(12): p. 1947-1964. 
74. Archetti, C., M.G. Speranza, and M.W.P. Savelsbergh, An Optimization-Based Heuristic for the Split Delivery Vehicle Routing Problem. TRANSPORTATION SCIENCE, 2008. 42(1): p. 22-31.

75. Chen, S., B. Golden, and E. Wasil, The split delivery vehicle routing problem: Applications, algorithms, test problems, and computational results. Networks, 2007. 49(4): p. 318-329.

76. Ghiani, G., et al., Real-time vehicle routing: Solution concepts, algorithms and parallel computing strategies. European Journal of Operational Research, 2003. 151(1): p. 1-11.

77. Özdamar, L., E. Ekinci, and B. Küçükyazici, Emergency Logistics Planning in Natural Disasters. Annals of Operations Research, 2004. 129(1): p. 217-245.

78. Yi, W. and A. Kumar, Ant Colony Optimization for Disaster Relief Operations. Transportation Research Part E: Logistics and Transportation Review, 2007. 43(6): p. $660-672$.

79. Belson, D., Storage, Distribution, and Dispensing of Medical Supplies. 2005, Center for Risk and Economic Analysis of Terrorism Events.

80. Degang Liu, J.H., Jianming Zhu, Vehicle Routing for Medical Supplies in LargeScale Emergencies, in The First International Symposium, OSB'07, L.C. Xiang-Sun Zhang, Ling-Yun Wu and Yong Wang, Editor. 2007: Beijing, China. 
81. Luo, J.Y., J.Y. Wang, and H. Yu. A dynamic vehicle routing problem for medical supplies in large-scale emergencies. in Information Technology and Artificial Intelligence Conference (ITAIC), 2011 6th IEEE Joint International. 2011.

82. Campbell, A.M., D. Vandenbussche, and W. Hermann, Routing for Relief Efforts. TRANSPORTATION SCIENCE, 2008. 42(2): p. 127-145.

83. Shen, Z., M.M. Dessouky, and F. Ordóñez, A two-stage vehicle routing model for large-scale bioterrorism emergencies. Networks, 2009. 54(4): p. 255-269.

84. Clarke, G. and J.W. Wright, Scheduling of Vehicles from a Central Depot to a Number of Delivery Points. OPERATIONS RESEARCH, 1964. 12(4): p. 568-581.

85. Bruce, H. A tutorial survey of theory and applications of simulated annealing. in Decision and Control, 1985 24th IEEE Conference on. 1985.

86. Bertsimas, D. and J. Tsitsiklis, Simulated Annealing. Statistical Science, 1993. $8(1):$ p. $10-15$.

87. Aarts, E., J. Korst, and W. Michiels, Simulated Annealing

Search Methodologies, E.K. Burke and G. Kendall, Editors. 2005, Springer US. p. 187210. 
88. Youssef, H., S. M. Sait, and H. Adiche, Evolutionary algorithms, simulated annealing and tabu search: a comparative study. Engineering Applications of Artificial Intelligence, 2001. 14(2): p. 167-181.

89. Chiang, W.-C. and R. Russell, Simulated annealing metaheuristics for the vehicle routing problem with time windows. Annals of Operations Research, 1996. 63(1): p. 3-27.

90. Min, H., V. Jayaraman, and R. Srivastava, Combined location-routing problems: A synthesis and future research directions. European Journal of Operational Research, 1998. 108(1): p. 1-15.

91. Nagy, G. and S. Salhi, Location-routing: Issues, models and methods. European Journal of Operational Research, 2007. 177(2): p. 649-672.

92. Salhi, S. and G.K. Rand, The effect of ignoring routes when locating depots. European Journal of Operational Research, 1989. 39(2): p. 150-156.

93. Salhi, S. and G. Nagy, Consistency and Robustness in Location-Routing. Studies in Locational Analysis, 1999. 13: p. 3-19.

94. Barreto, S., et al., Using clustering analysis in a capacitated location-routing problem. European Journal of Operational Research, 2007. 179(3): p. 968-977.

95. Christofides, N. and S. Eilon, Expected Distances in Distribution Problems. OR, 1969. 20(4): p. 437-443. 
96. Chien, T.W., Heuristic Procedures for Practical-Sized Uncapacitated LocationCapacitated Routing Problems*. Decision Sciences, 1993. 24(5): p. 995-1021.

97. Burness, R.C. and J.A. White, The Traveling Salesman Location Problem. TRANSPORTATION SCIENCE, 1976. 10(4): p. 348-360.

98. Laporte, G. and Y. Nobert, An exact algorithm for minimizing routing and operating costs in depot location. European Journal of Operational Research, 1981. 6(2): p. 224-226.

99. Laporte, G., Y. Nobert, and D. Arpin, An exact algorithm for solving a capacitated location-routing problem. Annals of Operations Research, 1986. 6(9): p. 291-310.

100. Laporte, G., Y. Nobert, and S. Taillefer, Solving a Family of Multi-Depot Vehicle Routing and Location-Routing Problems. TRANSPORTATION SCIENCE, 1988. 22(3): p. 161-172.

101. Bookbinder, J.H. and K.E. Reece, Vehicle routing considerations in distribution system design. European Journal of Operational Research, 1988. 37(2): p. 204-213.

102. Or, I. and W.P. Pierskalla, A Transportation Location-Allocation Model for Regional Blood Banking. AIIE Transactions, 1979. 11(2): p. 86 - 95. 
103. MIN, H., CONSOLIDATION TERMINAL LOCATION-ALLOCATION AND CONSOLIDATED ROUTING PROBLEMS. JOURNAL OF BUSINESS LOGISTICS, 1996. V. 17( NO. 2 (1996)): p. 235-263: ILL.

104. Murty, K.G. and P.A. Djang, The U.S. Army National Guard's Mobile Training Simulators Location and Routing Problem. OPERATIONS RESEARCH, 1999. 47(2): p. 175-182.

105. Wu, T.-H., C. Low, and J.-W. Bai, Heuristic solutions to multi-depot locationrouting problems. Computers \&amp; Operations Research, 2002. 29(10): p. 1393-1415.

106. Lin, C.K.Y., C.K. Chow, and A. Chen, A location-routing-loading problem for bill delivery services. Comput. Ind. Eng., 2002. 43(1-2): p. 5-25.

107. Jacobsen, S.K. and O.B.G. Madsen, A comparative study of heuristics for a twolevel routing-location problem. European Journal of Operational Research, 1980. 5(6): p. 378-387.

108. Madsen, O.B.G., Methods for solving combined two level location-routing problems of realistic dimensions. European Journal of Operational Research, 1983. 12(3): p. 295-301.

109. Ambrosino, D. and M. Grazia Scutellà, Distribution network design: New problems and related models. European Journal of Operational Research, 2005. 165(3): p. 610-624. 
110. Lee, J.-H., I.-K. Moon, and J.-H. Park, Multi-level supply chain network design with routing. International Journal of Production Research, 2009. 48(13): p. 3957-3976.

111. Laporte, G., Y. Nobert, and P. Pelletier, Hamiltonian location problems. European Journal of Operational Research, 1983. 12(1): p. 82-89.

112. Branco, I.M. and J.D. Coelho, The hamiltonian p-median problem. European Journal of Operational Research, 1990. 47(1): p. 86-95.

113. Perl, J. and M.S. Daskin, A warehouse location-routing problem. Transportation Research Part B: Methodological, 1985. 19(5): p. 381-396.

114. Liu, S.C. and S.B. Lee, A two-phase heuristic method for the multi-depot location routing problem taking inventory control decisions into consideration. The International Journal of Advanced Manufacturing Technology, 2003. 22(11): p. 941-950.

115. Tuzun, D. and L.I. Burke, A two-phase tabu search approach to the location routing problem. European Journal of Operational Research, 1999. 116(1): p. 87-99.

116. Wasner, M. and G. Zäpfel, An integrated multi-depot hub-location vehicle routing model for network planning of parcel service. International Journal of Production Economics, 2004. 90(3): p. 403-419.

117. Melechovsk\, J., et al., A Metaheuristic to Solve a Location-Routing Problem with Non-Linear Costs. Journal of Heuristics, 2005. 11(5-6): p. 375-391. 
118. Albareda-Sambola, M., J.A. Díaz, and E. Fernández, A compact model and tight bounds for a combined location-routing problem. Computers \&amp; Operations Research, 2005. 32(3): p. 407-428.

119. Salhi, S. and G. Nagy, Local improvement in planar facility location using vehicle routing. Annals of Operations Research, 2009. 167(1): p. 287-296.

120. Srivastava, R., Alternate solution procedures for the location-routing problem. Omega, 1993. 21(4): p. 497-506.

121. Nagy, G. and S. Salhi, Nested Heuristic Methods for the Location-Routeing Problem. The Journal of the Operational Research Society, 1996. 47(9): p. 1166-1174.

122. LAPORTE, et al., Models and exact solutions for a class of stochastic locationrouting problems. Vol. 39. 1989, Amsterdam, PAYS-BAS: Elsevier.

123. Albareda-Sambola, M., E. Fernández, and G. Laporte, Heuristic and lower bound for a stochastic location-routing problem. European Journal of Operational Research, 2007. 179(3): p. 940-955.

124. Microsoft, Microsoft Solver Foundation. 2008. p. Solver Foundation is a .Net runtime for mathematical programming, modeling, and optimization. .

125. Ralphs, T. Vehicle Routing Data Sets. October 3, 2003; Available from: http://branchandcut.org/VRP/data/. 
126. Auren, N.a.E.O. The VRP Web. March, 2007; Available from: http://neo.lcc.uma.es/radi-aeb/WebVRP/.

127. Truck Driver Facts. 2011; Available from: http://www.thetruckersreport.com/truck-driver-facts/.

128. Mes, M., M. van der Heijden, and A. van Harten, Comparison of agent-based scheduling to look-ahead heuristics for real-time transportation problems. European Journal of Operational Research, 2007. 181(1): p. 59-75.

129. Rochat, Y. and É. Taillard, Probabilistic diversification and intensification in local search for vehicle routing. Journal of Heuristics, 1995. 1(1): p. 147-167.

130. Homberger, J., Verteilt-parallele Metaheuristiken zur Tourenplanung : Lösungsverfahren für das Standardproblem mit Zeitfensterrestriktionen. 2000, Dt. Univ.Verl. [u.a.]: Wiesbaden.

131. Li, H. and A. Lim, Local search with annealing-like restarts to solve the vehicle routing problem with time windows, in Proceedings of the 2002 ACM symposium on Applied computing. 2002, ACM: Madrid, Spain. p. 560-565.

132. Mester, D., et al., Active guided evolution strategies for large-scale vehicle routing problems with time windows. Comput. Oper. Res., 2005. 32(6): p. 1593-1614. 
133. Shaw, P., A New Local Search Algorithm Providing High Quality Solutions to Vehicle Routing Problems. 1997.

134. Berger, J. and M. Barkaoui, A parallel hybrid genetic algorithm for the vehicle routing problem with time windows. Computers \&amp; Operations Research, 2004. 31(12): p. 2037-2053.

135. Homberger, J. and H. Gehring, A two-phase hybrid metaheuristic for the vehicle routing problem with time windows. European Journal of Operational Research, 2005. 162(1): p. $220-238$.

136. Rousseau, L.-M., M. Gendreau, and G. Pesant, Using Constraint-Based Operators to Solve the Vehicle Routing Problem with Time Windows. Journal of Heuristics, 2002. 8(1): p. 43-58.

137. Gambardella, L.M., et al., MACS-VRPTW: a multiple ant colony system for vehicle routing problems with time windows, in New ideas in optimization. 1999, McGraw-Hill Ltd., UK. p. 63-76.

138. TAILLARD, et al., A tabu search heuristic for the vehicle routing problem with soft time windows. Vol. 31. 1997, Linthicum, MD, ETATS-UNIS: Institute for Operations Research and the Management Sciences. 
139. Shaw, P., Using Constraint Programming and Local Search Methods to Solve Vehicle Routing Problems, in Proceedings of the 4th International Conference on Principles and Practice of Constraint Programming. 1998, Springer-Verlag. p. 417-431.

140. CORDEAU, et al., A unified tabu search heuristic for vehicle routing problems with time windows. 2001, Basingstoke, ROYAUME-UNI: Palgrave Macmillan.

141. BENT, et al., A two-stage hybrid local search for the vehicle routing problem with time windows. Vol. 38. 2004, Linthicum, MD, ETATS-UNIS: Institute for Operations Research and the Management Sciences. 16.

142. Schrimpf, G., et al., Record breaking optimization results using the ruin and recreate principle. J. Comput. Phys., 2000. 159(2): p. 139-171.

143. Czech, Z.J. and P. Czarnas. Parallel simulated annealing for the vehicle routing problem with time windows. in Parallel, Distributed and Network-based Processing, 2002. Proceedings. 10th Euromicro Workshop on. 2002.

144. T., I., Effective local search algorithms for the vehicle routing problem with general time window constraints. Proc. of MIC'2001, 2001: p. 293-297. 


\section{APPENDIX A THE LINGO FILE OF MATHEMATICAL}

\section{MODEL 1}

model :

sets :

RSSs/RSS1, RSS2/: rssOpened, rssFixedCost ;

RDNs/RDN1 . RDN10/: opened, RDNFixedCost;

PODs / POD1 . POD20/;

LnkRSSRDN (RSSS, RDNs): timeRSSRDN, distanceRSSRDN ;

LnkRDNPOD (RDNs, PODs): timeRDNPOD, distanceRDNPOD;

Lnk3 (RSSs, RDNs, PODs): path;

LnkRSSPOD (RSSs, PODs);

endsets

data :

RDNFixedCost $=@ O L E($ 'cover3.xlsx', 'FixedCost') ;

timeRSSRDN = @OLE ('cover3.xlsx', 'timeRSSRDN');

timeRDNPOD = @OLE ('cover3.xlsx', 'timeRDNPOD');

distanceRSSRDN = @OLE('Cover3.xlsx', 'distanceRSSRDN');

distanceRDNPOD = @OLE ('cover3.xlsx',

'distanceRDNPOD' );

rssFixedCost = @OLE ('Cover3.xlsx', 'RSSFixedCost') ;

$@ O L E($ 'Cover3.xlsx', 'opened') = opened;

@OLE ('Cover3.xlsx', 'RSSOpened') = rssOpened;

enddata

$\min =@ \operatorname{Sum}(\operatorname{RSSs}(i)$ :rssFixedCost $(i)$ *rssopened (i)) +

$@ \operatorname{Sum}(\operatorname{RDNs}(j)$ : RDNFixedCost $(j)$ *opened $(j))+$

$@ \operatorname{Sum}(\operatorname{Lnk} 3(i, j, k)$ :

$2 * 2 * \operatorname{path}(i, j, k) *($ distanceRSSRDN $(i, j)+$ distanceRDNPOD $(j, k))$

) $;$

@For (RDNs $(j)$ : @bin (opened $(j)))$;

@For $(\operatorname{Lnk} 3(i, j, k): @ b i n(\operatorname{path}(i, j, k)))$;

!@For (RDNs $(j)$ : @Sum(LnkRSSPOD $(i, k): \operatorname{path}(i, j, k))<=$ 999*opened (j)) ; 


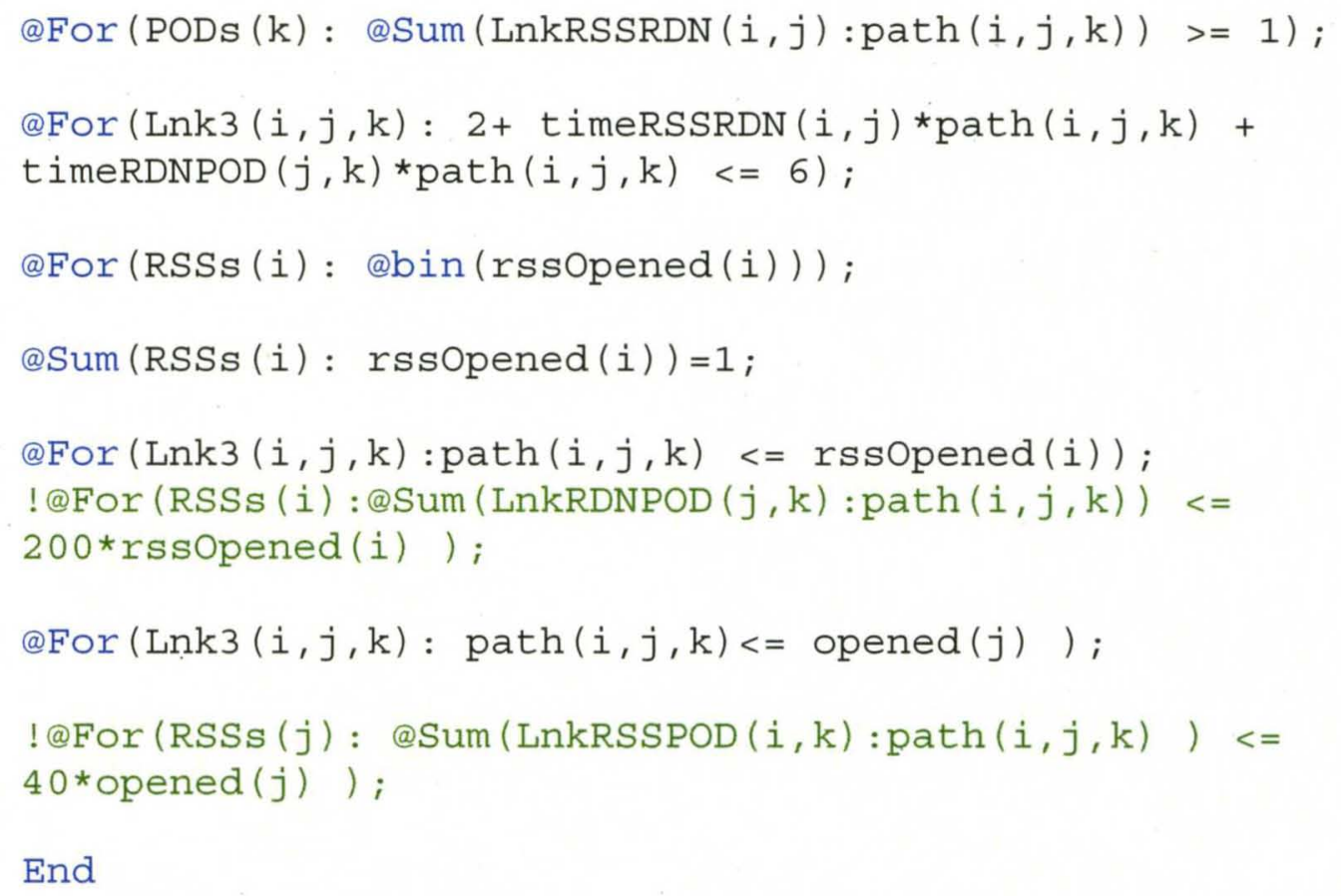

End 


\section{APPENDIX B THE LINGO FILE OF MATHEMATICAL}

\section{MODEL 2}

model :

sets :

RSSs/RSS1, RSS2/: rssopened, rssFixedCost ;

RDNs/RDN1 . RDN10/: opened, RDNFixedCost;

PODs / POD1 . POD20/;

LnkRSSRDN(RSSS, RDNs): timeRSSRDN, distanceRSSRDN;

LnkRDNPOD (RDNs, PODs) : timeRDNPOD, distanceRDNPOD;

Lnk3 (RSSs, RDNs, PODs): path;

LnkRSSPOD (RSSs, PODs): timeRSSPOD, distanceRSSPOD,

directPath;

endsets

data:

RDNFixedCost $=$ @OLE ('Cover3.xlsx', 'FixedCost' $)$;

timeRSSRDN = @OLE $(' \operatorname{cover} 3 . x \mathrm{sx}$ ', 'timeRSSRDN');

timeRDNPOD = @OLE ('COver3.xlsx', 'timeRDNPOD');

distanceRSSRDN = @OLE('Cover3.xlsx', 'distanceRSSRDN');

distanceRDNPOD = @OLE ('cover3.xlsx',

'distanceRDNPOD' ) ;

timeRSSPOD = @OLE ('cover3.xlsx', 'timeMatrixRSSPOD');

distanceRSSPOD = @OLE ('Cover3.xlsx',

'distMatrixRSSPOD' );

rssFixedCost = @OLE ('Cover3.xlsx', 'RSSFixedCost');

@OLE ('Cover3.xlsx', 'opened') = opened;

$@ O L E(' \operatorname{cover} 3 . \mathrm{xlsx}$ ', 'RSSOpened') = rssopened;

enddata

$\min =@ \operatorname{Sum}(\operatorname{RSSs}(i)$ :rssFixedCost $(i)$ *rssopened(i)) +

$@ \operatorname{Sum}(\operatorname{RDNs}(j): \operatorname{RDNFixedCost}(j)$ *opened $(j))$

$+@ \operatorname{Sum}(\operatorname{Lnk} 3(i, j, k)$ :

$2 * 2 * \operatorname{path}(i, j, k) *($ distanceRSSRDN $(i, j)+\operatorname{distanceRDNPOD}(j, k)))$

+ @Sum (LnkRSSPOD $(i, k)$ :

4 *directPath $(i, k)$ *distanceRSSPOD $(i, k))$; 


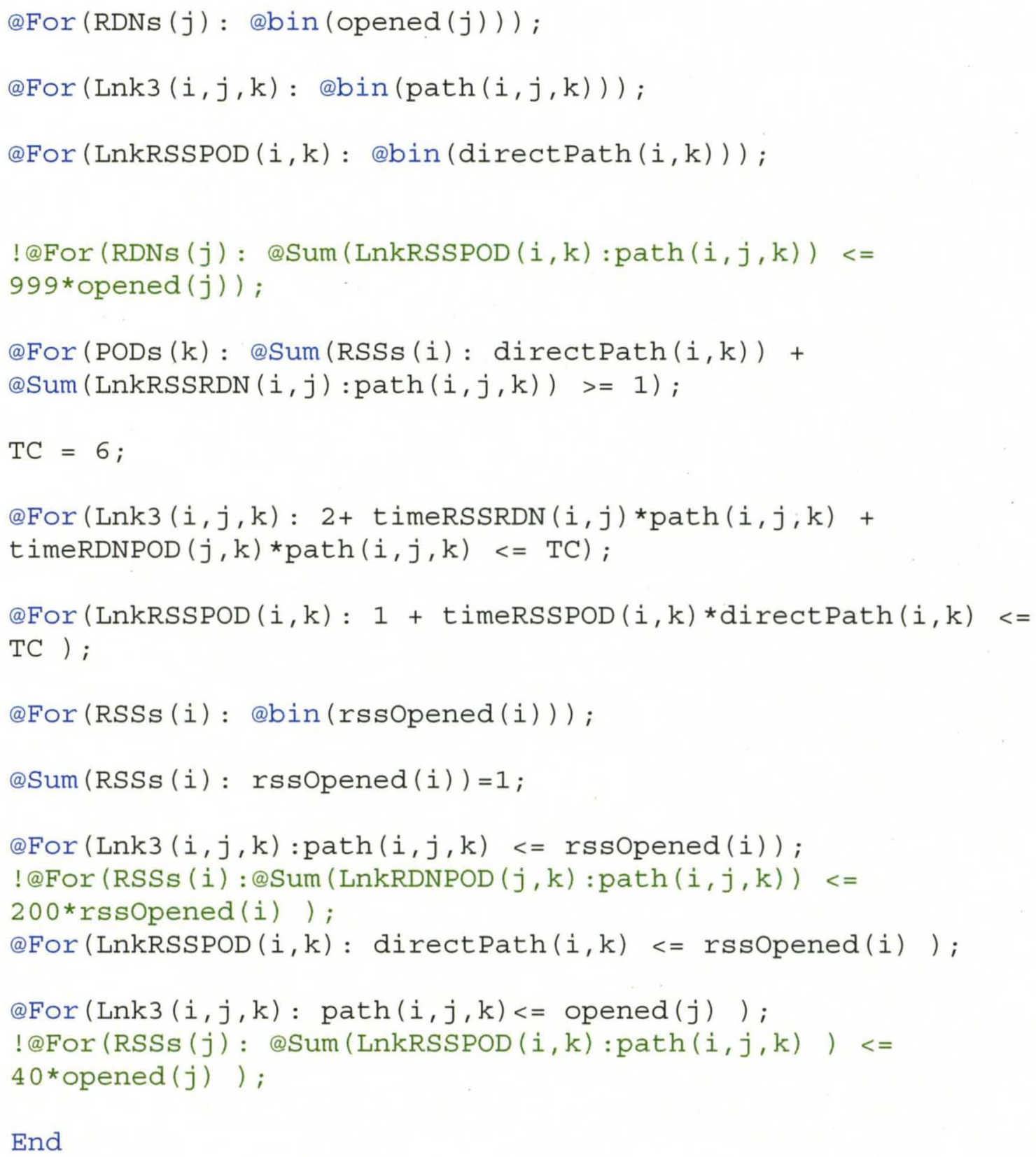

End 


\section{APPENDIX C BENCHMARKING SNS VRP SOLUTION}

In the following tables, "\# of Trucks" is the number of trucks used in the solution; "Distance" is the total traveling distance in the solution; "Initial Distance" is the total traveling distance in the initial solution constructed by the variant of Clark and Wright saving algorithm; "Improved Distance" is the total traveling distance in the final solution after improvement by SA; "Improvement Rate" is the percentage of traveling distance reduced by the SA improvement algorithm compared to the initial solution; "Execution Time" is the time of running our solution on a test instance; "Comparison" is the percentage of our solution outperforms (displayed by positive percentage) or underperforms (displayed by negative percentage) the best practice solution in terms of the total traveling distance. In Table 11, "Authors" refer to the publication where the best practice solution is introduced. 
Table 9 Results of Capacity Constrained Test Instances

\begin{tabular}{|c|c|c|c|c|c|c|c|c|}
\hline \multirow[b]{2}{*}{$\begin{array}{l}\text { Instan } \\
\text { ce }\end{array}$} & \multicolumn{2}{|c|}{$\begin{array}{c}\text { Best Practice } \\
\text { Solution }\end{array}$} & \multicolumn{5}{|c|}{ Our Solution } & \multirow[b]{2}{*}{$\begin{array}{l}\text { Comp } \\
\text { arison }\end{array}$} \\
\hline & $\begin{array}{c}\text { \# of } \\
\text { Truck } \\
\text { S } \\
\end{array}$ & $\begin{array}{l}\text { Dist } \\
\text { ance }\end{array}$ & $\begin{array}{c}\begin{array}{c}\text { of } \\
\text { Truck } \\
\text { s }\end{array} \\
\end{array}$ & $\begin{array}{c}\text { Initial } \\
\text { Distanc } \\
\mathbf{e} \\
\end{array}$ & $\begin{array}{l}\text { Improved } \\
\text { Distance }\end{array}$ & $\begin{array}{l}\text { Improve } \\
\text { ment Rate }\end{array}$ & $\begin{array}{c}\text { Execution } \\
\text { Time(seconds } \\
\text { ) } \\
\end{array}$ & \\
\hline \multicolumn{9}{|c|}{ Augerat, et al. Set A : } \\
\hline $\begin{array}{c}\text { A- } \\
\text { n32- } \\
\text { k5 }\end{array}$ & 5 & 784 & 5 & 635.37 & 545.98 & $14.07 \%$ & 0.69 & $\begin{array}{c}30.36 \\
\%\end{array}$ \\
\hline $\begin{array}{c}\text { A- } \\
\text { n33- } \\
\text { k5 }\end{array}$ & 5 & 661 & 5 & 585.36 & 433.94 & $25.87 \%$ & 0.64 & $\begin{array}{c}34.35 \\
\%\end{array}$ \\
\hline $\begin{array}{c}\text { A- } \\
\text { n33- } \\
\text { k6 }\end{array}$ & 6 & 742 & 6 & 703.53 & 541.27 & $23.06 \%$ & 0.58 & $\begin{array}{c}27.05 \\
\%\end{array}$ \\
\hline $\begin{array}{c}\text { A- } \\
\text { n34- } \\
\text { k5 }\end{array}$ & 5 & 778 & 5 & 644.56 & 552.12 & $14.34 \%$ & 0.55 & $\begin{array}{c}29.03 \\
\%\end{array}$ \\
\hline $\begin{array}{c}\text { A- } \\
\text { n36- } \\
\text { k5 }\end{array}$ & 5 & 799 & 5 & 644.78 & 572.06 & $11.28 \%$ & 0.72 & $\begin{array}{c}28.40 \\
\%\end{array}$ \\
\hline $\begin{array}{c}\text { A- } \\
\text { n37- } \\
\text { k5 }\end{array}$ & 5 & 669 & 5 & 641.54 & 517.27 & $19.37 \%$ & 0.95 & $\begin{array}{c}22.68 \\
\%\end{array}$ \\
\hline $\begin{array}{c}\text { A- } \\
\text { n37- } \\
\text { k6 } \\
\end{array}$ & 6 & 949 & 6 & 929.32 & 781.31 & $15.93 \%$ & 0.61 & $\begin{array}{c}17.67 \\
\%\end{array}$ \\
\hline $\begin{array}{c}\mathrm{A}- \\
\mathrm{n} 38- \\
\mathrm{k} 5\end{array}$ & 5 & 730 & 5 & 766.51 & 585.06 & $23.67 \%$ & 0.59 & $\begin{array}{c}19.85 \\
\%\end{array}$ \\
\hline $\begin{array}{c}\mathrm{A}- \\
\mathrm{n} 39- \\
\mathrm{k} 5\end{array}$ & 5 & 822 & 5 & 782.32 & 732.48 & $6.37 \%$ & 0.66 & $\begin{array}{c}10.89 \\
\%\end{array}$ \\
\hline $\begin{array}{c}\mathrm{A}- \\
\mathrm{n} 39- \\
\mathrm{k} 6 \\
\end{array}$ & 6 & 831 & 6 & 758.34 & 569.6 & $24.89 \%$ & 1.12 & $\begin{array}{c}31.46 \\
\%\end{array}$ \\
\hline $\begin{array}{c}\mathrm{A}- \\
\mathrm{n} 44- \\
\mathrm{k} 6\end{array}$ & 6 & 937 & 6 & 850.65 & 801.63 & $5.76 \%$ & 1.05 & $\begin{array}{c}14.45 \\
\%\end{array}$ \\
\hline $\begin{array}{c}\mathrm{A}- \\
\mathrm{n} 45- \\
\mathrm{k} 6 \\
\end{array}$ & 6 & 944 & 6 & 859.97 & 824.67 & $4.10 \%$ & 1.19 & $\begin{array}{c}12.64 \\
\%\end{array}$ \\
\hline $\begin{array}{c}\mathrm{A}- \\
\mathrm{n} 45- \\
\mathrm{k} 7\end{array}$ & 7 & 1146 & 7 & 877.02 & 744.11 & $15.15 \%$ & 1.14 & $\begin{array}{c}35.07 \\
\%\end{array}$ \\
\hline $\begin{array}{c}\text { A- } \\
n 46-\end{array}$ & 7 & 914 & 7 & 970.95 & 849.17 & $12.54 \%$ & 1.37 & $7.09 \%$ \\
\hline
\end{tabular}




\begin{tabular}{|c|c|c|c|c|c|c|c|c|}
\hline \multicolumn{9}{|l|}{ k7 } \\
\hline $\begin{array}{c}\mathrm{A}- \\
\mathrm{n} 48- \\
\mathrm{k} 7\end{array}$ & 7 & 1073 & 7 & 913.16 & 822.91 & $9.88 \%$ & 1.47 & $\begin{array}{c}23.31 \\
\%\end{array}$ \\
\hline $\begin{array}{c}\text { A- } \\
\text { n53- } \\
\text { k7 } \\
\end{array}$ & 7 & 1010 & 7 & 1124.26 & 940.69 & $16.33 \%$ & 1.37 & $6.86 \%$ \\
\hline $\begin{array}{c}\text { A- } \\
\text { n54- } \\
\text { k7 }\end{array}$ & 7 & 1167 & 7 & 944.99 & 912.6 & $3.43 \%$ & 1.33 & $\begin{array}{c}21.80 \\
\%\end{array}$ \\
\hline $\begin{array}{c}\mathrm{A}- \\
\mathrm{n} 55- \\
\mathrm{k} 9\end{array}$ & 9 & 1073 & 9 & 1206.57 & 1158.8 & $3.96 \%$ & 2.34 & $8.00 \%$ \\
\hline $\begin{array}{c}\mathrm{A}- \\
\mathrm{n} 60- \\
\mathrm{k} 9\end{array}$ & 9 & 1354 & 9 & 1468.2 & 1266.95 & $13.71 \%$ & 2.16 & $6.43 \%$ \\
\hline $\begin{array}{c}\mathrm{A}- \\
\mathrm{n} 61- \\
\mathrm{k} 9\end{array}$ & 9 & 1034 & 9 & 1377.55 & 1252.01 & $9.11 \%$ & 5.17 & $\begin{array}{c}- \\
21.08 \\
\%\end{array}$ \\
\hline $\begin{array}{c}\text { A- } \\
\mathrm{n} 62- \\
\mathrm{k} 8 \\
\end{array}$ & 8 & 1288 & 8 & 1491.71 & 1334.02 & $10.57 \%$ & 2.41 & $\begin{array}{c}- \\
3.57 \%\end{array}$ \\
\hline $\begin{array}{c}\text { A- } \\
\text { n63- } \\
\text { k9 } \\
\end{array}$ & 9 & 1616 & 9 & 1666.14 & 1606.6 & $3.57 \%$ & 2.03 & $0.58 \%$ \\
\hline $\begin{array}{c}\text { A- } \\
\text { n63- } \\
\text { k10 } \\
\end{array}$ & 10 & 1314 & 10 & 1593.03 & 1343.86 & $15.64 \%$ & 5.76 & $2.27 \%$ \\
\hline $\begin{array}{c}\text { A- } \\
\text { n64- } \\
\text { k9 }\end{array}$ & 9 & 1401 & 9 & 1665.76 & 1466.55 & $11.96 \%$ & 5.97 & $4.68 \%$ \\
\hline $\begin{array}{c}\text { A- } \\
\text { n65- } \\
\text { k9 }\end{array}$ & 9 & 1174 & 9 & 1477.74 & 1265.67 & $14.35 \%$ & 6.11 & $7.81 \%$ \\
\hline $\begin{array}{c}\mathrm{A}- \\
\mathrm{n} 69- \\
\mathrm{k} 9\end{array}$ & 9 & 1159 & 9 & 1485.97 & 1268.08 & $14.66 \%$ & 6.53 & $9 . \overline{41 \%}$ \\
\hline $\begin{array}{c}\mathrm{A}- \\
\mathrm{n} 80- \\
\mathrm{k} 10 \\
\end{array}$ & 10 & 1763 & 10 & 1945.87 & 1659.7 & $14.71 \%$ & 10.69 & $5.86 \%$ \\
\hline & & & & & Average & $13.27 \%$ & 2.41 & $\begin{array}{c}12.19 \\
\%\end{array}$ \\
\hline \multicolumn{9}{|c|}{ Augerat, et al. Set B : } \\
\hline $\begin{array}{c}\text { B- } \\
\text { n31- } \\
\text { k5 }\end{array}$ & 5 & 672 & 5 & 448.13 & 399.27 & $10.90 \%$ & 0.61 & $\begin{array}{c}40.58 \\
\%\end{array}$ \\
\hline $\begin{array}{c}\text { B- } \\
\text { n34- } \\
\text { k5 }\end{array}$ & 5 & 788 & 5 & 763.4 & 681.87 & $10.68 \%$ & 0.61 & $\begin{array}{c}13.47 \\
\%\end{array}$ \\
\hline
\end{tabular}




\begin{tabular}{|c|c|c|c|c|c|c|c|c|}
\hline $\begin{array}{c}\text { B- } \\
\text { n35- } \\
\text { k5 }\end{array}$ & 5 & 955 & 5 & 873.61 & 700.56 & $19.81 \%$ & 0.72 & $\begin{array}{c}26.64 \\
\%\end{array}$ \\
\hline $\begin{array}{c}\text { B- } \\
\text { n38- } \\
\text { k6 }\end{array}$ & 6 & 805 & 6 & 697.55 & 636.91 & $8.69 \%$ & 0.91 & $\begin{array}{c}20.88 \\
\%\end{array}$ \\
\hline $\begin{array}{c}\text { B- } \\
\text { n39- } \\
\text { k5 }\end{array}$ & 5 & 549 & 5 & 821.06 & 575.4 & $29.92 \%$ & 0.94 & $4 . \overline{81 \%}$ \\
\hline $\begin{array}{c}\text { B- } \\
\text { n41- } \\
\text { k6 }\end{array}$ & 6 & 829 & 6 & 865.73 & 771.07 & $10.93 \%$ & 1.23 & $6.99 \%$ \\
\hline $\begin{array}{c}\text { B- } \\
\text { n43- } \\
\text { k6 }\end{array}$ & 6 & 742 & 6 & 811.94 & 759.5 & $6.46 \%$ & 1.2 & $2.36 \%$ \\
\hline $\begin{array}{c}\text { B- } \\
\text { n44- } \\
\text { k7 }\end{array}$ & 7 & 909 & 7 & 945.28 & 862.68 & $8.74 \%$ & 1.08 & $5.10 \%$ \\
\hline $\begin{array}{c}\text { B- } \\
\mathrm{n} 45- \\
\mathrm{k} 5 \\
\end{array}$ & 4 & 751 & 5 & 848.56 & 725.21 & $14.54 \%$ & 0.67 & $3.43 \%$ \\
\hline $\begin{array}{c}\text { B- } \\
\text { n45- } \\
\text { k6 }\end{array}$ & 6 & 678 & 6 & 954.44 & 761.74 & $20.19 \%$ & 2.7 & $\begin{array}{c}- \\
12.35 \\
\%\end{array}$ \\
\hline $\begin{array}{c}\text { B- } \\
\text { n50- } \\
\text { k7 }\end{array}$ & 7 & 741 & 7 & 1013.97 & 777.56 & $23.32 \%$ & 1.8 & $4 . \overline{93 \%}$ \\
\hline $\begin{array}{c}\text { B- } \\
\text { n50- } \\
\text { k8 } \\
\end{array}$ & 8 & 1312 & 8 & 1420.73 & 1225.96 & $13.71 \%$ & 1.39 & $6.56 \%$ \\
\hline $\begin{array}{c}\text { B- } \\
\text { n51- } \\
\text { k7 }\end{array}$ & 7 & 1032 & 7 & 1079.21 & 979.48 & $9.24 \%$ & 4.7 & $5.09 \%$ \\
\hline $\begin{array}{c}\text { B- } \\
\text { n52- } \\
\text { k7 }\end{array}$ & 7 & 747 & 7 & 981.63 & 795.4 & $18.97 \%$ & 4.61 & $6 . \overline{-}$ \\
\hline $\begin{array}{c}\text { B- } \\
\text { n56- } \\
\text { k7 }\end{array}$ & 7 & 707 & 7 & 955.04 & 869.13 & $9.00 \%$ & 5.44 & $\begin{array}{c}- \\
22.93 \\
\%\end{array}$ \\
\hline $\begin{array}{c}\text { B- } \\
\text { n57- } \\
\text { k7 }\end{array}$ & 7 & 1153 & 8 & 1184.92 & 1043.33 & $11.95 \%$ & 5.28 & $9.51 \%$ \\
\hline $\begin{array}{c}\text { B- } \\
\text { n57- } \\
\text { k9 }\end{array}$ & 9 & 1598 & 9 & 1409.89 & 1275.52 & $9.53 \%$ & 5.67 & $\begin{array}{c}20.18 \\
\%\end{array}$ \\
\hline $\begin{array}{c}\text { B- } \\
\text { n63- } \\
\text { k10 }\end{array}$ & 10 & 1496 & 10 & 1666.68 & 1420.49 & $14.77 \%$ & 6.97 & $5.05 \%$ \\
\hline $\begin{array}{c}\text { B- } \\
\text { n64- }\end{array}$ & 9 & 861 & 9 & 1293.96 & 1135.23 & $12.27 \%$ & 6.12 & $\begin{array}{c}- \\
31.85\end{array}$ \\
\hline
\end{tabular}




\begin{tabular}{|c|c|c|c|c|c|c|c|c|}
\hline $\mathrm{k} 9$ & & & & & & & & $\%$ \\
\hline $\begin{array}{c}\text { B- } \\
\text { n66- } \\
\text { k9 }\end{array}$ & 9 & 1316 & 9 & 1537.06 & 1279.18 & $16.78 \%$ & 6.56 & $2.80 \%$ \\
\hline $\begin{array}{c}\text { B- } \\
\text { n67- } \\
\text { k10 }\end{array}$ & 10 & 1032 & 10 & 1417.25 & 1251.46 & $11.70 \%$ & 8.47 & $\begin{array}{c}- \\
21.27 \\
\%\end{array}$ \\
\hline $\begin{array}{c}\text { B- } \\
\text { n68- } \\
\text { k9 }\end{array}$ & 9 & 1272 & 9 & 1619.12 & 1450.14 & $10.44 \%$ & 7.44 & $\begin{array}{c}- \\
14.00 \\
\%\end{array}$ \\
\hline $\begin{array}{c}\text { B- } \\
\text { n78- } \\
\text { k10 }\end{array}$ & 10 & 1221 & 10 & 1604.11 & 1381.35 & $13.89 \%$ & 12.3 & $\begin{array}{c}- \\
13.13 \\
\% \\
\end{array}$ \\
\hline & & & & & Average & $13.76 \%$ & 3.80 & $1.40 \%$ \\
\hline \multicolumn{9}{|c|}{ Augerat, et al. Set P : } \\
\hline $\begin{array}{c}\text { P-n 16- } \\
\text { k8 }\end{array}$ & 8 & 450 & 8 & 478.67 & 451.34 & $5.71 \%$ & 0.47 & $\begin{array}{c}- \\
0.30 \% \\
\end{array}$ \\
\hline $\begin{array}{c}\text { P-n19- } \\
\text { k2 }\end{array}$ & 2 & 212 & 2 & 270.14 & 240.19 & $11.09 \%$ & 0.11 & $\begin{array}{c}- \\
13.30 \\
\%\end{array}$ \\
\hline $\begin{array}{c}\text { P-n20- } \\
\text { k2 }\end{array}$ & 2 & 216 & 2 & 266.38 & 250.68 & $5.89 \%$ & 0.13 & $\begin{array}{c}- \\
16.06 \\
\%\end{array}$ \\
\hline $\begin{array}{c}\text { P-n21- } \\
\text { k2 }\end{array}$ & 2 & 211 & 2 & 237.09 & 225.75 & $4.78 \%$ & 0.27 & $\begin{array}{c}- \\
6.99 \% \\
\end{array}$ \\
\hline $\begin{array}{c}\text { P-n22- } \\
\text { k2 }\end{array}$ & 2 & 216 & 2 & 240.51 & 230.42 & $4.20 \%$ & 0.16 & 6. \\
\hline $\begin{array}{c}\text { P-n22- } \\
\text { k8 }\end{array}$ & 8 & 603 & 9 & 724.87 & 634.51 & $12.47 \%$ & 0.39 & $5 . \overline{23 \%}$ \\
\hline $\begin{array}{c}\text { P-n23- } \\
\text { k8 }\end{array}$ & 8 & 529 & 9 & 589.06 & 559.17 & $5.07 \%$ & 0.45 & $\begin{array}{c}- \\
5.70 \% \\
\end{array}$ \\
\hline $\begin{array}{c}\text { P-n40- } \\
\text { k5 }\end{array}$ & 5 & 458 & 5 & 544.69 & 462.93 & $15.01 \%$ & 2.73 & $\begin{array}{c}- \\
1.08 \%\end{array}$ \\
\hline $\begin{array}{c}\text { P-n } 45- \\
\text { k5 }\end{array}$ & 5 & 510 & 5 & 606.61 & 526.63 & $13.18 \%$ & 3.47 & $\begin{array}{c}- \\
3.26 \% \\
\end{array}$ \\
\hline $\begin{array}{c}\text { P-n50- } \\
\text { k7 }\end{array}$ & 7 & 554 & 7 & 710.92 & 566.24 & $20.35 \%$ & 5.19 & $2 . \overline{21 \%}$ \\
\hline $\begin{array}{c}\text { P-n50- } \\
\text { k8 }\end{array}$ & 8 & 631 & 9 & 739.57 & 653.43 & $11.65 \%$ & 6.06 & $\begin{array}{c}- \\
3.55 \% \\
\end{array}$ \\
\hline $\begin{array}{c}\text { P-n50- } \\
\text { k10 }\end{array}$ & 10 & 696 & 10 & 823.58 & 732.56 & $11.05 \%$ & 6.44 & $\begin{array}{c}- \\
5.25 \% \\
\end{array}$ \\
\hline $\begin{array}{c}\text { P-n51- } \\
\text { k10 }\end{array}$ & 10 & 741 & 10 & 921.13 & 796.72 & $13.51 \%$ & 5.87 & $\begin{array}{c}- \\
7.52 \% \\
\end{array}$ \\
\hline $\begin{array}{c}\text { P-n55- } \\
\text { k7 }\end{array}$ & 7 & 568 & 7 & 743.98 & 589.56 & $20.76 \%$ & 6.86 & $\begin{array}{c}- \\
3.80 \% \\
\end{array}$ \\
\hline $\begin{array}{c}\text { P-n55- } \\
\text { k8 }\end{array}$ & 8 & 588 & 7 & 740.74 & 595.27 & $19.64 \%$ & 6.98 & $1 . \overline{24 \%}$ \\
\hline $\begin{array}{c}\text { P-n55- } \\
\text { k10 }\end{array}$ & 10 & 694 & 10 & 864.6 & 720.55 & $16.66 \%$ & 7.37 & $\begin{array}{c}- \\
3.83 \% \\
\end{array}$ \\
\hline
\end{tabular}




\begin{tabular}{|c|c|c|c|c|c|c|c|c|}
\hline $\begin{array}{c}\text { P-n55- } \\
\text { k15 }\end{array}$ & 15 & 989 & 16 & 1150.59 & 1023.56 & $11.04 \%$ & 8.42 & $3.49 \%$ \\
\hline $\begin{array}{c}\text { P-n60- } \\
\text { k10 }\end{array}$ & 10 & 744 & 10 & 876.1 & 788.49 & $10.00 \%$ & 9.44 & $5 . \overline{-}$ \\
\hline $\begin{array}{c}\text { P-n60- } \\
\text { k15 }\end{array}$ & 15 & 968 & 15 & 1166.58 & 1046.04 & $10.33 \%$ & 9.36 & $\begin{array}{c}- \\
8.06 \% \\
\end{array}$ \\
\hline $\begin{array}{c}\text { P-n65- } \\
\text { k10 }\end{array}$ & 10 & 792 & 10 & 930.39 & 843.46 & $9.34 \%$ & 11.7 & $\begin{array}{c}- \\
6.50 \% \\
\end{array}$ \\
\hline $\begin{array}{c}\text { P-n70- } \\
\text { k10 }\end{array}$ & 10 & 827 & 10 & 983.23 & 902.7 & $8.19 \%$ & 14.14 & $\begin{array}{c}- \\
9.15 \% \\
\end{array}$ \\
\hline $\begin{array}{c}\text { P-n 76- } \\
\text { k4 }\end{array}$ & 4 & 593 & 4 & 756.07 & 637.12 & $15.73 \%$ & 9.11 & $\begin{array}{c}- \\
7.44 \% \\
\end{array}$ \\
\hline $\begin{array}{c}\text { P-n76- } \\
\text { k5 }\end{array}$ & 5 & 627 & 5 & 864.78 & 667.39 & $22.83 \%$ & 10.8 & $\begin{array}{c}- \\
6.44 \% \\
\end{array}$ \\
\hline $\begin{array}{c}\mathrm{P}- \\
\mathrm{n} 101- \\
\mathrm{k} 4\end{array}$ & 4 & 681 & 4 & 892.71 & 739.22 & $17.19 \%$ & 32.86 & $8.55 \%$ \\
\hline & & & & & Average & $12.32 \%$ & 6.62 & $\begin{array}{c}- \\
5.90 \% \\
\end{array}$ \\
\hline \multicolumn{9}{|c|}{ Christofides and Eilon : } \\
\hline $\begin{array}{c}\mathrm{E}- \\
\mathrm{n} 22- \\
\mathrm{k} 4\end{array}$ & 4 & 375 & 4 & 517.75 & 392.9 & $24.11 \%$ & 0.23 & $\begin{array}{c}- \\
4.77 \%\end{array}$ \\
\hline $\begin{array}{c}\text { E- } \\
\text { n23- } \\
\text { k3 }\end{array}$ & 3 & 569 & 3 & 723.71 & 568.56 & $21.44 \%$ & 0.39 & $0.08 \%$ \\
\hline $\begin{array}{c}\text { E- } \\
\text { n30- } \\
\text { k3 }\end{array}$ & 3 & 534 & 3 & 623.66 & 539.84 & $13.44 \%$ & 0.52 & $1.09 \%$ \\
\hline $\begin{array}{c}\text { E- } \\
\text { n33- } \\
\text { k4 } \\
\end{array}$ & 4 & 835 & 4 & 993.02 & 874.32 & $11.95 \%$ & 0.56 & $\begin{array}{c}- \\
4.71 \%\end{array}$ \\
\hline $\begin{array}{c}\text { E- } \\
\text { n51- } \\
\text { k5 } \\
\end{array}$ & 5 & 521 & 5 & 622.81 & 549 & $11.85 \%$ & 4.12 & $5.37 \%$ \\
\hline $\begin{array}{c}\text { E- } \\
\text { n76- } \\
\text { k7 }\end{array}$ & 7 & 682 & 7 & 892.27 & 708.91 & $20.55 \%$ & 15.77 & - \\
\hline $\begin{array}{c}\text { E- } \\
\text { n76- } \\
\text { k8 }\end{array}$ & 8 & 735 & 8 & 921.24 & 765.63 & $16.89 \%$ & 12.55 & $4.17 \%$ \\
\hline $\begin{array}{c}\text { E- } \\
\text { n76- } \\
\text { k10 }\end{array}$ & 10 & 830 & 10 & 1050.02 & 919.36 & $12.44 \%$ & 13.58 & $\begin{array}{c}- \\
10.77 \\
\%\end{array}$ \\
\hline $\begin{array}{c}\text { E- } \\
\text { n76- } \\
\text { k14 }\end{array}$ & 14 & 1021 & 15 & 1213.08 & 1151.31 & $5.09 \%$ & 15.11 & $\begin{array}{c}- \\
12.76 \\
\%\end{array}$ \\
\hline $\begin{array}{c}\text { E- } \\
\text { n101- } \\
\text { k8 }\end{array}$ & 8 & 815 & 8 & 1039.21 & 845.85 & $18.61 \%$ & $\begin{array}{c}29.53 \\
\end{array}$ & $\begin{array}{c}- \\
3.79 \%\end{array}$ \\
\hline
\end{tabular}




\begin{tabular}{|c|c|c|c|c|c|c|c|c|}
\hline $\begin{array}{c}\text { E- } \\
\text { n101- } \\
\text { k14 }\end{array}$ & 14 & 1071 & 14 & 1383.29 & 1213.57 & $12.27 \%$ & 21.2 & $\begin{array}{c}- \\
13.31 \\
\%\end{array}$ \\
\hline & & & & & Average & $15.33 \%$ & 10.32 & $\begin{array}{c}- \\
5.87 \%\end{array}$ \\
\hline \multicolumn{9}{|c|}{ Fisher : } \\
\hline $\begin{array}{c}\text { F-n45- } \\
\text { k4 }\end{array}$ & 4 & 724 & 4 & 1133.09 & 763.69 & $32.60 \%$ & 3.86 & $\begin{array}{c}- \\
5.48 \% \\
\end{array}$ \\
\hline $\begin{array}{c}\text { F-n } 72- \\
\text { k4 }\end{array}$ & 4 & 237 & 4 & 405.65 & 289.11 & $28.73 \%$ & 12.62 & $\begin{array}{c}- \\
21.99 \\
\%\end{array}$ \\
\hline $\begin{array}{c}\mathrm{F}- \\
\mathrm{n} 135- \\
\mathrm{k} 7\end{array}$ & 7 & 1162 & 5 & 1304.27 & 1166.37 & $10.57 \%$ & 20.8 & $\begin{array}{c}- \\
0.38 \%\end{array}$ \\
\hline & & & & & Average & $23.97 \%$ & 12.43 & $9 . \overline{28 \%}$ \\
\hline \multicolumn{9}{|c|}{ Gillet and Johnson : } \\
\hline $\begin{array}{c}\mathrm{G}^{-} \\
\mathrm{n} 262- \\
\mathrm{k} 25 \\
\end{array}$ & 25 & 6119 & 25 & 3719.88 & 3719.88 & $0.00 \%$ & 72 & $\begin{array}{c}39.21 \\
\%\end{array}$ \\
\hline \multicolumn{9}{|c|}{ Christofides, Mingozzi, and Toth : } \\
\hline $\begin{array}{c}\text { M- } \\
\text { n101- } \\
\text { k10 }\end{array}$ & 10 & 820 & 10 & 1032.42 & 878.27 & $14.93 \%$ & 41.26 & 7. \\
\hline $\begin{array}{c}\text { M- } \\
\text { n121- } \\
\text { k7 }\end{array}$ & 7 & 1034 & 7 & 1535.56 & 1232.76 & $19.72 \%$ & 57.12 & $\begin{array}{c}- \\
19.22 \\
\%\end{array}$ \\
\hline $\begin{array}{c}\text { M- } \\
\text { n151- } \\
\text { k12 }\end{array}$ & 12 & 1053 & 12 & 1388.41 & 1125.45 & $18.94 \%$ & 80.67 & $\begin{array}{c}- \\
6.88 \%\end{array}$ \\
\hline $\begin{array}{c}\text { M- } \\
\text { n200- } \\
\text { k17 }\end{array}$ & 17 & 1373 & 17 & 1617.42 & 1617.42 & $0.00 \%$ & 67 & $\begin{array}{c}- \\
17.80 \\
\% \\
\end{array}$ \\
\hline & & & & & Average & $13.40 \%$ & 61.51 & $\begin{array}{c}- \\
12.75 \\
\%\end{array}$ \\
\hline
\end{tabular}

Table 10 Results of Solomon 25 Test Instances

\begin{tabular}{|c|c|c|c|c|c|c|c|c|}
\hline \multirow[b]{2}{*}{$\begin{array}{c}\text { Insta } \\
\text { nce }\end{array}$} & \multicolumn{2}{|c|}{$\begin{array}{l}\text { Best Practice } \\
\text { Solution }\end{array}$} & \multicolumn{5}{|c|}{ Our Solution } & \multirow[b]{2}{*}{$\begin{array}{c}\text { Compa } \\
\text { rison }\end{array}$} \\
\hline & $\begin{array}{c}\text { \# of } \\
\text { Truck } \\
\text { s }\end{array}$ & $\begin{array}{c}\text { Dista } \\
\text { nce }\end{array}$ & $\begin{array}{c}\text { \# of } \\
\text { Truc } \\
\text { ks }\end{array}$ & $\begin{array}{c}\text { Initial } \\
\text { Distance }\end{array}$ & $\begin{array}{l}\text { Improved } \\
\text { Distance }\end{array}$ & $\begin{array}{c}\text { Improveme } \\
\text { nt Rate }\end{array}$ & $\begin{array}{l}\text { Executio } \\
\text { n Time } \\
\text { (seconds) }\end{array}$ & \\
\hline
\end{tabular}




\begin{tabular}{|c|c|c|c|c|c|c|c|c|}
\hline \multicolumn{9}{|c|}{ Solomon_25_C1 : } \\
\hline C101 & 3 & $\begin{array}{c}191 . \\
3\end{array}$ & 3 & 214.88 & 193.77 & $9.82 \%$ & 0.97 & $-1.29 \%$ \\
\hline C102 & 3 & $\begin{array}{c}190 . \\
3\end{array}$ & 3 & 217.95 & 192.98 & $11.46 \%$ & 0.92 & $-1.41 \%$ \\
\hline C103 & 3 & $\begin{array}{c}190 . \\
3\end{array}$ & 3 & 217.95 & 192.98 & $11.46 \%$ & 0.78 & $-1.41 \%$ \\
\hline C104 & 3 & $\begin{array}{c}186 . \\
9\end{array}$ & 3 & 217.95 & 192.98 & $11.46 \%$ & 0.81 & $-3.25 \%$ \\
\hline C105 & 3 & $\begin{array}{c}191 . \\
3\end{array}$ & 3 & 214.88 & 193.77 & $9.82 \%$ & 0.84 & $-1.29 \%$ \\
\hline C106 & 3 & $\begin{array}{c}191 . \\
3\end{array}$ & 3 & 214.88 & 193.77 & $9.82 \%$ & 0.91 & $-1.29 \%$ \\
\hline C107 & 3 & $\begin{array}{c}191 . \\
3\end{array}$ & 3 & 214.88 & 193.77 & $9.82 \%$ & 0.91 & $-1.29 \%$ \\
\hline C108 & 3 & $\begin{array}{c}191 . \\
3\end{array}$ & 3 & 214.88 & 193.77 & $9.82 \%$ & 0.8 & $-1.29 \%$ \\
\hline C109 & 3 & $\begin{array}{c}191 . \\
3\end{array}$ & 3 & 217.95 & 192.98 & $11.46 \%$ & 0.89 & $-0.88 \%$ \\
\hline $\begin{array}{l}\text { Aver } \\
\text { age }\end{array}$ & 3 & $\begin{array}{c}190 . \\
6\end{array}$ & 3 & 216.24 & 193.42 & $10.55 \%$ & 0.87 & $-1.49 \%$ \\
\hline \multicolumn{9}{|c|}{ Solomon_25_R1 : } \\
\hline R101 & 8 & $\begin{array}{c}617 . \\
1\end{array}$ & 4 & 444.65 & 393.41 & $11.52 \%$ & 2 & $36.25 \%$ \\
\hline R102 & 7 & $\begin{array}{c}547 . \\
1\end{array}$ & 4 & 472.8 & 385.82 & $18.40 \%$ & 0.75 & $29.48 \%$ \\
\hline R103 & 5 & $\begin{array}{c}454 . \\
6\end{array}$ & 4 & 472.8 & 390.02 & $17.51 \%$ & 0.78 & $14.21 \%$ \\
\hline R104 & 4 & $\begin{array}{c}416 . \\
9\end{array}$ & 4 & 434.61 & 385.82 & $11.23 \%$ & 0.73 & $7.46 \%$ \\
\hline R105 & 6 & $\begin{array}{c}530 . \\
5\end{array}$ & 5 & 493.26 & 385.82 & $21.78 \%$ & 2.3 & $27.27 \%$ \\
\hline R106 & 5 & $\begin{array}{c}465 \\
4\end{array}$ & 4 & 472.8 & 375.37 & $20.61 \%$ & 0.94 & $19.34 \%$ \\
\hline R107 & 4 & $\begin{array}{c}424 . \\
3\end{array}$ & 4 & 472.8 & 385.82 & $18.40 \%$ & 0.78 & $9.07 \%$ \\
\hline R108 & 4 & $\begin{array}{c}397 . \\
3\end{array}$ & 4 & 434.61 & 385.82 & $11.23 \%$ & 0.77 & $2.89 \%$ \\
\hline R109 & 5 & $\begin{array}{c}441 . \\
3\end{array}$ & 4 & 472.8 & 389.64 & $17.59 \%$ & 0.89 & $11.71 \%$ \\
\hline R110 & 4 & $\begin{array}{c}444 . \\
1\end{array}$ & 4 & 434.61 & 390.02 & $10.26 \%$ & 0.73 & $12.18 \%$ \\
\hline R111 & 4 & $\begin{array}{c}428 . \\
8\end{array}$ & 4 & 472.8 & 385.82 & $18.40 \%$ & 0.95 & $10.02 \%$ \\
\hline R112 & 4 & 393 & 4 & 434.61 & 390.02 & $10.26 \%$ & 0.83 & $0.76 \%$ \\
\hline Aver & 5 & 463. & 4.1 & 459.43 & 386.95 & $15.60 \%$ & 1.04 & $15.05 \%$ \\
\hline
\end{tabular}




\begin{tabular}{|c|c|c|c|c|c|c|c|c|}
\hline age & & 4 & & & & & & \\
\hline \multicolumn{9}{|c|}{ Solomon_25_RC1 : } \\
\hline $\begin{array}{c}\mathrm{RC} 10 \\
1 \\
\end{array}$ & 4 & $\begin{array}{c}461 . \\
1 \\
\end{array}$ & 4 & 402.3 & 396.01 & $1.56 \%$ & 2.55 & $14.12 \%$ \\
\hline $\begin{array}{c}\mathrm{RC} 10 \\
2\end{array}$ & 3 & $\begin{array}{c}351 . \\
8\end{array}$ & 3 & 303.23 & 303.23 & $0.00 \%$ & 3.02 & $13.81 \%$ \\
\hline $\begin{array}{c}\text { RC10 } \\
3\end{array}$ & 3 & $\begin{array}{c}332 . \\
8\end{array}$ & 3 & 303.23 & 303.23 & $0.00 \%$ & 3.14 & $8.89 \%$ \\
\hline $\begin{array}{c}\mathrm{RC} 10 \\
4 \\
\end{array}$ & 3 & $\begin{array}{c}306 . \\
6 \\
\end{array}$ & 3 & 303.23 & 303.23 & $0.00 \%$ & 3.02 & $1.10 \%$ \\
\hline $\begin{array}{c}\mathrm{RC} 10 \\
5\end{array}$ & 4 & $\begin{array}{c}411 . \\
3\end{array}$ & 3 & 303.23 & 303.23 & $0.00 \%$ & 3.02 & $26.28 \%$ \\
\hline $\begin{array}{c}\text { RC10 } \\
6\end{array}$ & 3 & $\begin{array}{c}345 . \\
5\end{array}$ & 3 & 303.23 & 303.23 & $0.00 \%$ & 3.02 & $12.23 \%$ \\
\hline $\begin{array}{c}\text { RC10 } \\
7\end{array}$ & 3 & $\begin{array}{c}298 . \\
3\end{array}$ & 3 & 303.23 & 303.23 & $0.00 \%$ & 3.02 & $-1.65 \%$ \\
\hline $\begin{array}{l}\text { Aver } \\
\text { age }\end{array}$ & 3.3 & $\begin{array}{c}358 . \\
2 \\
\end{array}$ & 3.1 & 317.38 & 316.48 & $0.22 \%$ & 2.97 & $10.68 \%$ \\
\hline \multicolumn{9}{|c|}{ Solomon_25_C2 : } \\
\hline C201 & 2 & $\begin{array}{c}214 . \\
7\end{array}$ & 1 & 215.91 & 215.91 & $0.00 \%$ & 0.03 & $-0.56 \%$ \\
\hline C202 & 2 & $\begin{array}{c}214 . \\
7 \\
\end{array}$ & 1 & 215.91 & 215.91 & $0.00 \%$ & 0.05 & $-0.56 \%$ \\
\hline C203 & 2 & $\begin{array}{c}214 . \\
7\end{array}$ & 1 & 215.91 & 215.91 & $0.00 \%$ & 0.03 & $-0.56 \%$ \\
\hline C204 & 1 & $\begin{array}{c}213 . \\
1\end{array}$ & 1 & 215.91 & 215.91 & $0.00 \%$ & 0.05 & $-1.32 \%$ \\
\hline C205 & 2 & $\begin{array}{c}214 . \\
7\end{array}$ & 1 & 215.91 & 215.91 & $0.00 \%$ & 0.05 & $-0.56 \%$ \\
\hline C206 & 2 & $\begin{array}{c}214 . \\
7\end{array}$ & 1 & 215.91 & 215.91 & $0.00 \%$ & 0.03 & $-0.56 \%$ \\
\hline C207 & 2 & $\begin{array}{c}214 . \\
5\end{array}$ & 1 & 215.91 & 215.91 & $0.00 \%$ & 0.03 & $-0.66 \%$ \\
\hline $\mathrm{C} 208$ & 2 & $\begin{array}{c}214 . \\
5\end{array}$ & 1 & 215.91 & 215.91 & $0.00 \%$ & 0.05 & $-0.66 \%$ \\
\hline $\begin{array}{l}\text { Aver } \\
\text { age }\end{array}$ & 1.9 & $\begin{array}{c}214 . \\
45 \\
\end{array}$ & 1 & 215.91 & 215.91 & $0.00 \%$ & 0.04 & $-0.68 \%$ \\
\hline \multicolumn{9}{|c|}{ Solomon_25_R2 : } \\
\hline R201 & 4 & $\begin{array}{c}463 . \\
3\end{array}$ & 1 & 358.2 & 358.2 & $0.00 \%$ & 0.05 & $22.69 \%$ \\
\hline $\mathrm{R} 202$ & 4 & $\begin{array}{c}410 . \\
5 \\
\end{array}$ & 1 & 358.2 & 358.2 & $0.00 \%$ & 0.03 & $12.74 \%$ \\
\hline $\mathrm{R} 203$ & 3 & $\begin{array}{c}391 . \\
4 \\
\end{array}$ & 1 & 358.2 & 358.2 & $0.00 \%$ & 0.05 & $8.48 \%$ \\
\hline $\mathrm{R} 204$ & 2 & 355 & 1 & 358.2 & 358.2 & $0.00 \%$ & 0.03 & $-0.90 \%$ \\
\hline R205 & 3 & 393 & 1 & 358.2 & 358.2 & $0.00 \%$ & 0.05 & $8.85 \%$ \\
\hline
\end{tabular}




\begin{tabular}{|c|c|c|c|c|c|c|c|c|}
\hline R206 & 3 & $\begin{array}{c}374 . \\
4\end{array}$ & 1 & 358.2 & 358.2 & $0.00 \%$ & 0.03 & $4.33 \%$ \\
\hline R207 & 3 & $\begin{array}{c}361 . \\
6\end{array}$ & 1 & 358.2 & 358.2 & $0.00 \%$ & 0.05 & $0.94 \%$ \\
\hline R208 & 1 & $\begin{array}{c}328 . \\
2 \\
\end{array}$ & 1 & 358.2 & 358.2 & $0.00 \%$ & 0.03 & $-9.14 \%$ \\
\hline R209 & 2 & $\begin{array}{c}370 . \\
7\end{array}$ & 1 & 358.2 & 358.2 & $0.00 \%$ & 0.08 & $3.37 \%$ \\
\hline R210 & 3 & $\begin{array}{c}404 . \\
6\end{array}$ & 1 & 358.2 & 358.2 & $0.00 \%$ & 0.05 & $11.47 \%$ \\
\hline R211 & 2 & $\begin{array}{c}350 . \\
9\end{array}$ & 1 & 358.2 & 358.2 & $0.00 \%$ & 0.05 & $-2.08 \%$ \\
\hline $\begin{array}{l}\text { Aver } \\
\text { age }\end{array}$ & 2.7 & $\begin{array}{c}382 . \\
1\end{array}$ & 1 & 358.2 & 358.2 & $0.00 \%$ & 0.05 & $5.52 \%$ \\
\hline \multicolumn{9}{|c|}{ Solomon_25_RC2 : } \\
\hline $\begin{array}{c}\mathrm{RC} 20 \\
1\end{array}$ & 3 & $\begin{array}{c}360 . \\
2\end{array}$ & 1 & 233.42 & 233.42 & $0.00 \%$ & 0.03 & $35.20 \%$ \\
\hline $\begin{array}{c}\mathrm{RC} 20 \\
2 \\
\end{array}$ & 3 & 338 & 1 & 233.42 & 233.42 & $0.00 \%$ & 0.03 & $30.94 \%$ \\
\hline $\begin{array}{c}\mathrm{RC} 20 \\
3\end{array}$ & 3 & $\begin{array}{c}326 . \\
9\end{array}$ & 1 & 233.42 & 233.42 & $0.00 \%$ & 0.03 & $28.60 \%$ \\
\hline $\begin{array}{c}\mathrm{RC} 20 \\
4\end{array}$ & 3 & $\begin{array}{c}299 . \\
7\end{array}$ & 1 & 233.42 & 233.42 & $0.00 \%$ & 0.03 & $22.12 \%$ \\
\hline $\begin{array}{c}\mathrm{RC} 20 \\
5\end{array}$ & 3 & 338 & 1 & 233.42 & 233.42 & $0.00 \%$ & 0.03 & $30.94 \%$ \\
\hline $\begin{array}{c}\mathrm{RC} 20 \\
6\end{array}$ & 3 & 324 & 1 & 233.42 & 233.42 & $0.00 \%$ & 0.05 & $27.96 \%$ \\
\hline $\begin{array}{c}\mathrm{RC} 20 \\
7\end{array}$ & 3 & $\begin{array}{c}298 . \\
3\end{array}$ & 1 & 233.42 & 233.42 & $0.00 \%$ & 0.03 & $21.75 \%$ \\
\hline $\begin{array}{l}\text { Aver } \\
\text { age }\end{array}$ & 3 & $\begin{array}{c}326 . \\
4\end{array}$ & 1 & 233.42 & 233.42 & $0.00 \%$ & 0.03 & $28.21 \%$ \\
\hline
\end{tabular}

Table 11 Results of Solomon 50 Test Instances

\begin{tabular}{|c|c|c|c|c|c|c|c|c|}
\hline \multirow[b]{2}{*}{$\begin{array}{c}\text { Instan } \\
\text { ce }\end{array}$} & \multicolumn{2}{|c|}{$\begin{array}{c}\text { Best Practice } \\
\text { Solution }\end{array}$} & \multicolumn{5}{|c|}{ Our Solution } & \multirow[b]{2}{*}{$\begin{array}{c}\text { Compa } \\
\text { rison }\end{array}$} \\
\hline & $\begin{array}{l}\# \text { of } \\
\text { Tru } \\
\text { cks }\end{array}$ & $\begin{array}{l}\text { Dista } \\
\text { nce }\end{array}$ & $\begin{array}{c}\text { \# of } \\
\text { Truck } \\
\quad \text { s }\end{array}$ & $\begin{array}{c}\text { Initial } \\
\text { Distance }\end{array}$ & $\begin{array}{c}\text { Improved } \\
\text { Distance }\end{array}$ & $\begin{array}{c}\text { Improveme } \\
\text { nt Rate }\end{array}$ & $\begin{array}{c}\text { Executi } \\
\text { on Time } \\
\text { (seconds } \\
\text { ) }\end{array}$ & \\
\hline \multicolumn{9}{|c|}{ Solomon_50_C1 : } \\
\hline C101 & 5 & 362.4 & 5 & 369.94 & 369.94 & $0.00 \%$ & 5.92 & $-2.08 \%$ \\
\hline C102 & 5 & 361.4 & 5 & 369.94 & 369.94 & $0.00 \%$ & 5.45 & $-2.36 \%$ \\
\hline
\end{tabular}




\begin{tabular}{|c|c|c|c|c|c|c|c|c|}
\hline C103 & 4 & 361.4 & 5 & 369.94 & 369.94 & $0.00 \%$ & 5.56 & $-2.36 \%$ \\
\hline C104 & 5 & 359 & 5 & 369.94 & 369.94 & $0.00 \%$ & 6.12 & $-3.05 \%$ \\
\hline C105 & 5 & 362.4 & 5 & 369.94 & 369.94 & $0.00 \%$ & 5.39 & $-2.08 \%$ \\
\hline C106 & 5 & 362.4 & 5 & 369.94 & 369.94 & $0.00 \%$ & 5.8 & $-2.08 \%$ \\
\hline C107 & 5 & 362.4 & 5 & 369.94 & 369.94 & $0.00 \%$ & 5.94 & $-2.08 \%$ \\
\hline C108 & 5 & 362.4 & 5 & 369.94 & 369.94 & $0.00 \%$ & 5.62 & $-2.08 \%$ \\
\hline C109 & 5 & 362.4 & 5 & 369.94 & 369.94 & $0.00 \%$ & 5.92 & $-2.08 \%$ \\
\hline $\begin{array}{c}\text { Averag } \\
\mathrm{e}\end{array}$ & 4.9 & 361.8 & 5 & 369.94 & 369.94 & $0.00 \%$ & 5.75 & $-2.25 \%$ \\
\hline \multicolumn{9}{|c|}{ Solomon_50_R1 : } \\
\hline R101 & 13 & 1047 & 8 & 781.94 & 662.88 & $15.23 \%$ & 17.84 & $36.69 \%$ \\
\hline R102 & 12 & 944.9 & 7 & 728.39 & 606.28 & $16.76 \%$ & 15.62 & $35.84 \%$ \\
\hline R103 & 9 & 772.9 & 7 & 769.91 & 599.97 & $22.07 \%$ & 12.5 & $22.37 \%$ \\
\hline R104 & 6 & 631.2 & 6 & 736.94 & 607.15 & $17.61 \%$ & 7.95 & $3.81 \%$ \\
\hline R105 & 10 & 906.6 & 7 & 751.19 & 662.34 & $11.83 \%$ & 11.75 & $26.94 \%$ \\
\hline R106 & 8 & 793.6 & 7 & 728.39 & 603.33 & $17.17 \%$ & 9.3 & $23.98 \%$ \\
\hline R107 & 7 & 720.4 & 7 & 769.91 & 603.32 & $21.64 \%$ & 11.73 & $16.25 \%$ \\
\hline R108 & 6 & 618.2 & 6 & 736.94 & 600.57 & $18.50 \%$ & 10.62 & $2.85 \%$ \\
\hline R109 & 8 & 803.2 & 7 & 734.68 & 656.08 & $10.70 \%$ & 7.52 & $18.32 \%$ \\
\hline R110 & 8 & 724.9 & 7 & 728.39 & 607.78 & $16.56 \%$ & 15.42 & $16.16 \%$ \\
\hline $\mathrm{R} 111$ & 8 & 724.9 & 7 & 728.39 & 603.23 & $17.18 \%$ & 14.8 & $16.78 \%$ \\
\hline $\mathrm{R} 112$ & 6 & 651.1 & 7 & 728.39 & 606.07 & $16.79 \%$ & 14.47 & $6.92 \%$ \\
\hline $\begin{array}{c}\text { Averag } \\
\mathrm{e}\end{array}$ & 8.4 & $\begin{array}{c}778.2 \\
4 \\
\end{array}$ & 6.9 & 743.62 & 618.25 & $16.84 \%$ & 12.46 & $18.91 \%$ \\
\hline \multicolumn{9}{|c|}{ Solomon_50_RC1 : } \\
\hline RC101 & 9 & 957.9 & 9 & 961.31 & 834.62 & $13.18 \%$ & 20.03 & $12.87 \%$ \\
\hline $\mathrm{RC102}$ & 8 & 844.3 & 7 & 723.57 & 652.17 & $9.87 \%$ & 16.64 & $22.76 \%$ \\
\hline RC103 & 6 & 712.6 & 7 & 723.57 & 652.17 & $9.87 \%$ & 16.64 & $8.48 \%$ \\
\hline RC104 & 5 & 546.5 & 7 & 723.57 & 648.33 & $10.40 \%$ & 17.12 & $18.63 \%$ \\
\hline RC105 & 9 & 888.9 & 7 & 794.11 & 778.96 & $1.91 \%$ & 16.06 & $12.37 \%$ \\
\hline RC106 & 7 & 791.9 & 7 & 794.11 & 778.96 & $1.91 \%$ & 15.97 & $1.63 \%$ \\
\hline RC107 & 6 & 664.5 & 7 & 794.11 & 792.09 & $0.25 \%$ & 17.62 & $19.20 \%$ \\
\hline RC108 & 6 & 598.1 & 7 & 794.11 & 778.96 & $1.91 \%$ & 17.09 & $\begin{array}{c}- \\
30.24 \%\end{array}$ \\
\hline $\begin{array}{c}\text { Avera } \\
\text { ge }\end{array}$ & 7 & 750.6 & 7.3 & 788.56 & 739.53 & $6.16 \%$ & 17.15 & $-1.25 \%$ \\
\hline \multicolumn{9}{|c|}{ Solomon_50_C2: } \\
\hline C201 & 3 & 360.2 & 2 & 411.35 & 378.5 & $7.99 \%$ & 3.27 & $-5.08 \%$ \\
\hline $\mathrm{C} 202$ & 3 & 360.2 & 2 & 410.6 & 369.75 & $9.95 \%$ & 3.09 & $-2.65 \%$ \\
\hline C203 & 3 & 359.8 & 2 & 410.6 & 369.75 & $9.95 \%$ & 3.09 & $-2.77 \%$ \\
\hline C204 & 2 & 353.4 & 2 & 410.6 & 369.75 & $9.95 \%$ & 3.37 & $-4.63 \%$ \\
\hline
\end{tabular}




\begin{tabular}{|c|c|c|c|c|c|c|c|c|}
\hline C205 & 3 & 359.8 & 2 & 410.6 & 369.75 & $9.95 \%$ & 3.12 & $-2.77 \%$ \\
\hline C206 & 3 & 359.8 & 2 & 410.6 & 369.75 & $9.95 \%$ & 3.33 & $-2.77 \%$ \\
\hline C207 & 3 & 359.6 & 2 & 410.6 & 369.75 & $9.95 \%$ & 3.11 & $-2.82 \%$ \\
\hline C208 & 2 & 350.5 & 2 & 410.6 & 369.75 & $9.95 \%$ & 3.13 & $-5.49 \%$ \\
\hline $\begin{array}{c}\text { Avera } \\
\text { ge }\end{array}$ & 2.8 & $\begin{array}{c}357.9 \\
125\end{array}$ & 2 & 410.69 & 370.84 & $9.70 \%$ & 3.19 & $-3.62 \%$ \\
\hline Solomon 5 50_R2: & \multicolumn{7}{|l|}{} \\
\hline R201 & 6 & 800.7 & 2 & 538.31 & 530.56 & $1.44 \%$ & 1.14 & $33.74 \%$ \\
\hline R202 & 5 & 712.2 & 2 & 548.78 & 532.96 & $2.88 \%$ & 0.92 & $25.17 \%$ \\
\hline R203 & 5 & 606.4 & 2 & 548.78 & 531.39 & $3.17 \%$ & 0.67 & $12.37 \%$ \\
\hline R204 & 2 & 509.5 & 2 & 548.78 & 531.39 & $3.17 \%$ & 0.67 & $-4.30 \%$ \\
\hline R205 & 5 & 703.3 & 2 & 548.26 & 531.97 & $2.97 \%$ & 0.98 & $24.36 \%$ \\
\hline R206 & 5 & 647 & 2 & 548.78 & 532.96 & $2.88 \%$ & 0.92 & $17.63 \%$ \\
\hline R207 & 4 & 584.6 & 2 & 548.78 & 531.39 & $3.17 \%$ & 0.67 & $9.10 \%$ \\
\hline R208 & 2 & 487.7 & 2 & 548.78 & 531.39 & $3.17 \%$ & 0.67 & $-8.96 \%$ \\
\hline R209 & 4 & 600.6 & 2 & 548.78 & 532.96 & $2.88 \%$ & 0.91 & $11.26 \%$ \\
\hline R210 & 5 & 663.4 & 2 & 541.24 & 532.96 & $1.53 \%$ & 0.91 & $19.66 \%$ \\
\hline R211 & 3 & 551.3 & 2 & 548.78 & 532.96 & $2.88 \%$ & 0.91 & $3.33 \%$ \\
\hline $\begin{array}{c}\text { Avera } \\
\text { ge }\end{array}$ & 4.2 & 624.2 & 2 & 547.10 & 532.08 & $2.74 \%$ & 0.85 & $13.03 \%$ \\
\hline Solomon_50_RC2 & & & & & & & \\
\hline RC201 & 5 & 684.8 & 2 & 474.16 & 474.16 & $0.00 \%$ & 0.5 & $30.76 \%$ \\
\hline RC202 & 5 & 613.6 & 1 & 406.11 & 406.11 & $0.00 \%$ & 0.05 & $33.82 \%$ \\
\hline RC203 & 4 & 555.3 & 1 & 406.11 & 406.11 & $0.00 \%$ & 0.05 & $26.87 \%$ \\
\hline RC204 & 3 & 444.2 & 1 & 406.11 & 406.11 & $0.00 \%$ & 0.03 & $8.57 \%$ \\
\hline RC205 & 5 & 631 & 1 & 406.11 & 406.11 & $0.00 \%$ & 0.03 & $35.64 \%$ \\
\hline RC206 & 5 & 610 & 2 & 474.16 & 474.16 & $0.00 \%$ & 0.48 & $22.27 \%$ \\
\hline RC207 & 4 & 558.6 & 1 & 406.11 & 406.11 & $0.00 \%$ & 0.03 & $27.30 \%$ \\
\hline $\begin{array}{c}\text { Averag } \\
\text { e }\end{array}$ & 4.4 & 585.4 & 1.3 & 425.55 & 425.55 & $0.00 \%$ & 0.17 & $26.46 \%$ \\
\hline
\end{tabular}

Table 12 Results of Solomon 100 Test Instances

\begin{tabular}{|c|c|c|c|c|c|c|c|c|c|}
\hline \multirow{3}{*}{$\begin{array}{c}\text { Insta } \\
\text { nce }\end{array}$} & \multicolumn{3}{|c|}{ Best Practice Solution } & \multicolumn{7}{c|}{ Our Solution } & Comp \\
\cline { 2 - 8 } & $\begin{array}{c}\text { Truc } \\
\text { ks }\end{array}$ & $\begin{array}{c}\text { Dist } \\
\text { anc } \\
\text { e }\end{array}$ & $\begin{array}{c}\text { Auth } \\
\text { ors }\end{array}$ & $\begin{array}{c}\text { \# of } \\
\text { Truc } \\
\text { ks }\end{array}$ & $\begin{array}{c}\text { Initial } \\
\text { Distan } \\
\text { ce }\end{array}$ & $\begin{array}{c}\text { Improve } \\
\text { d } \\
\text { Distance }\end{array}$ & $\begin{array}{c}\text { Improve } \\
\text { ment } \\
\text { Rate }\end{array}$ & $\begin{array}{c}\text { Execution } \\
\text { Time } \\
\text { (seconds) }\end{array}$ & $\begin{array}{c}\text { ariso } \\
n\end{array}$ \\
\hline \\
Solomon_100_C1 :
\end{tabular}




\begin{tabular}{|c|c|c|c|c|c|c|c|c|c|}
\hline $\mathrm{C} 101$ & 10 & $\begin{array}{c}828 . \\
94\end{array}$ & [129] & 10 & 1022.4 & 983.42 & $3.81 \%$ & 37.78 & $\begin{array}{c}- \\
18.64 \\
\%\end{array}$ \\
\hline $\mathrm{C} 102$ & 10 & $\begin{array}{c}828 . \\
94\end{array}$ & [129] & 10 & 1022.4 & 981.83 & $3.97 \%$ & 35.06 & $\begin{array}{c}- \\
18.44 \\
\%\end{array}$ \\
\hline $\mathrm{C} 103$ & 10 & $\begin{array}{c}828 . \\
06\end{array}$ & [129] & 10 & 1022.4 & 968.04 & $5.32 \%$ & 34.15 & $\begin{array}{c}- \\
16.90 \\
\%\end{array}$ \\
\hline $\mathrm{C} 104$ & 10 & $\begin{array}{c}824 . \\
78\end{array}$ & [129] & 10 & 1022.4 & 966.75 & $5.44 \%$ & 34.56 & $\begin{array}{c}- \\
17.21 \\
\% \\
\end{array}$ \\
\hline $\mathrm{C} 105$ & 10 & $\begin{array}{c}828 . \\
94\end{array}$ & [129] & 10 & 1022.4 & 972.79 & $4.85 \%$ & 37.7 & $\begin{array}{c}- \\
17.35 \\
\% \\
\end{array}$ \\
\hline $\mathrm{C} 106$ & 10 & $\begin{array}{c}828 . \\
94\end{array}$ & [129] & 10 & 1022.4 & 990.8 & $3.09 \%$ & 36.92 & $\begin{array}{c}- \\
19.53 \\
\%\end{array}$ \\
\hline $\mathrm{C} 107$ & 10 & $\begin{array}{c}828 . \\
94\end{array}$ & [129] & 10 & 1022.4 & 996.02 & $2.58 \%$ & 36.53 & $\begin{array}{c}- \\
20.16 \\
\% \\
\end{array}$ \\
\hline $\mathrm{C} 108$ & 10 & $\begin{array}{c}828 . \\
94\end{array}$ & [129] & 10 & 1022.4 & 969.63 & $5.16 \%$ & 36.81 & $\begin{array}{c}- \\
16.97 \\
\% \\
\end{array}$ \\
\hline C109 & 10 & $\begin{array}{c}828 . \\
94\end{array}$ & [129] & 10 & 1022.4 & 973.9 & $4.74 \%$ & 34.76 & $\begin{array}{c}- \\
17.49 \\
\%\end{array}$ \\
\hline $\begin{array}{c}\text { Aver } \\
\text { age }\end{array}$ & 10 & $\begin{array}{c}828 . \\
38\end{array}$ & & 10 & 1022.4 & 978.13 & $4.33 \%$ & 36.03 & $\begin{array}{c}- \\
18.08 \\
\%\end{array}$ \\
\hline \multicolumn{10}{|c|}{ Solomon_100_R1: } \\
\hline R101 & 19 & $\begin{array}{r}164 \\
5.79 \\
\end{array}$ & {$[130]$} & 11 & $\begin{array}{c}1139.7 \\
4 \\
\end{array}$ & 984.13 & $13.65 \%$ & 61.94 & $\begin{array}{c}40.20 \\
\%\end{array}$ \\
\hline R102 & 17 & $\begin{array}{l}148 \\
6.12 \\
\end{array}$ & {$[129]$} & 11 & $\begin{array}{c}1139.7 \\
4 \\
\end{array}$ & 945.35 & $17.06 \%$ & 75.87 & $\begin{array}{c}36.39 \\
\%\end{array}$ \\
\hline R103 & 13 & $\begin{array}{r}129 \\
2.68 \\
\end{array}$ & {$[131]$} & 11 & 1110.4 & 938.46 & $15.48 \%$ & 96.56 & $\begin{array}{c}27.40 \\
\%\end{array}$ \\
\hline R104 & 9 & $\begin{array}{l}100 \\
7.24 \\
\end{array}$ & [132] & 10 & $\begin{array}{c}1114.4 \\
5 \\
\end{array}$ & 951.87 & $14.59 \%$ & 78.72 & $\begin{array}{c}5.50 \\
\%\end{array}$ \\
\hline R105 & 14 & $\begin{array}{l}137 \\
7.11 \\
\end{array}$ & [129] & 11 & $\begin{array}{c}1139.7 \\
4\end{array}$ & 1001.52 & $12.13 \%$ & 57.23 & $\begin{array}{c}27.27 \\
\%\end{array}$ \\
\hline R106 & 12 & $\begin{array}{l}125 \\
1.98 \\
\end{array}$ & [132] & 11 & $\begin{array}{c}1139.7 \\
4 \\
\end{array}$ & 1003.96 & $11.91 \%$ & 58.17 & $\begin{array}{c}19.81 \\
\%\end{array}$ \\
\hline R107 & 10 & $\begin{array}{r}110 \\
4.66 \\
\end{array}$ & [133] & 11 & 1110.4 & 994.71 & $10.42 \%$ & 49.23 & $\begin{array}{c}9.95 \\
\% \\
\end{array}$ \\
\hline
\end{tabular}




\begin{tabular}{|c|c|c|c|c|c|c|c|c|c|}
\hline R108 & 9 & $\begin{array}{c}960 . \\
88\end{array}$ & {$[134]$} & 10 & $\begin{array}{c}1114.4 \\
5\end{array}$ & 951.9 & $14.59 \%$ & 77.43 & $\begin{array}{c}0.93 \\
\%\end{array}$ \\
\hline R109 & 11 & $\begin{array}{c}119 \\
4.73\end{array}$ & {$[135]$} & 11 & $\begin{array}{c}1130.4 \\
7\end{array}$ & 996.14 & $11.88 \%$ & 54.78 & $\begin{array}{c}16.62 \\
\%\end{array}$ \\
\hline R110 & 10 & $\begin{array}{c}111 \\
8.59\end{array}$ & {$[132]$} & 11 & $\begin{array}{c}1130.4 \\
7\end{array}$ & 999.45 & $11.59 \%$ & 56.95 & $\begin{array}{c}10.65 \\
\%\end{array}$ \\
\hline R111 & 10 & $\begin{array}{c}109 \\
6.72\end{array}$ & {$[136]$} & 11 & $\begin{array}{c}1130.4 \\
7\end{array}$ & 945.34 & $16.38 \%$ & 77.28 & $\begin{array}{c}13.80 \\
\%\end{array}$ \\
\hline R112 & 9 & $\begin{array}{c}982 . \\
14\end{array}$ & {$[137]$} & 11 & $\begin{array}{c}1130.4 \\
7\end{array}$ & 1012.75 & $10.41 \%$ & 58.72 & $\begin{array}{c}3.12 \\
\%\end{array}$ \\
\hline $\begin{array}{c}\text { Aver } \\
\text { age }\end{array}$ & 11.9 & $\begin{array}{c}120 \\
9.9\end{array}$ & & 10.8 & 1127.5 & 977.1 & $13.34 \%$ & 66.9 & $\begin{array}{c}17.12 \\
\%\end{array}$ \\
\hline
\end{tabular}

Solomon_100_RC1 :

\begin{tabular}{|c|c|c|c|c|c|c|c|c|c|}
\hline $\begin{array}{c}\mathrm{RC} 1 \\
01 \\
\end{array}$ & 14 & $\begin{array}{l}169 \\
6.94 \\
\end{array}$ & [138] & 11 & $\begin{array}{c}1271.7 \\
9 \\
\end{array}$ & 1143 & $10.13 \%$ & 63.34 & $\begin{array}{c}32.64 \\
\% \\
\end{array}$ \\
\hline $\begin{array}{c}\mathrm{RC} 1 \\
02\end{array}$ & 12 & $\begin{array}{l}155 \\
4.75\end{array}$ & [138] & 11 & $\begin{array}{c}1271.7 \\
9\end{array}$ & 1161.49 & $8.67 \%$ & 62.89 & $\begin{array}{c}25.29 \\
\%\end{array}$ \\
\hline $\begin{array}{c}\mathrm{RC} 1 \\
03 \\
\end{array}$ & 11 & $\begin{array}{l}126 \\
1.67 \\
\end{array}$ & [139] & 11 & $\begin{array}{c}1313.0 \\
1 \\
\end{array}$ & 1151.01 & $12.34 \%$ & 56.45 & $\begin{array}{c}8.77 \\
\% \\
\end{array}$ \\
\hline $\begin{array}{c}\mathrm{RC} 1 \\
04\end{array}$ & 10 & $\begin{array}{c}113 \\
5.48\end{array}$ & {$[140]$} & 11 & $\begin{array}{c}1313.0 \\
1\end{array}$ & 1164.05 & $11.34 \%$ & 58.97 & $\begin{array}{c}- \\
2.52 \\
\%\end{array}$ \\
\hline $\begin{array}{c}\mathrm{RCl} \\
05\end{array}$ & 13 & $\begin{array}{c}162 \\
9.44\end{array}$ & {$[134]$} & 11 & $\begin{array}{c}1271.7 \\
9 \\
\end{array}$ & 1150.08 & $9.57 \%$ & 63.79 & $\begin{array}{c}29.42 \\
\%\end{array}$ \\
\hline $\begin{array}{c}\mathrm{RCl} \\
06 \\
\end{array}$ & 11 & $\begin{array}{r}142 \\
4.73 \\
\end{array}$ & [134] & 11 & $\begin{array}{c}1271.7 \\
9\end{array}$ & 1140.03 & $10.36 \%$ & 61.06 & $\begin{array}{c}19.98 \\
\% \\
\end{array}$ \\
\hline $\begin{array}{c}\text { RCl } \\
07 \\
\end{array}$ & 11 & $\begin{array}{l}123 \\
0.48 \\
\end{array}$ & [133] & 11 & $\begin{array}{c}1271.7 \\
9 \\
\end{array}$ & 1146.78 & $9.83 \%$ & 62.34 & $\begin{array}{c}6.80 \\
\%\end{array}$ \\
\hline $\begin{array}{c}\mathrm{RC} 1 \\
08 \\
\end{array}$ & 10 & $\begin{array}{r}113 \\
9.82 \\
\end{array}$ & [138] & 11 & $\begin{array}{c}1271.7 \\
9 \\
\end{array}$ & 1094.9 & $13.91 \%$ & 89.93 & $\begin{array}{c}3.94 \\
\% \\
\end{array}$ \\
\hline $\begin{array}{c}\text { Aver } \\
\text { age }\end{array}$ & 11.5 & $\begin{array}{r}138 \\
4.16 \\
\end{array}$ & & 11 & $\begin{array}{c}1282.1 \\
0 \\
\end{array}$ & 1143.92 & $10.77 \%$ & 64.85 & $\begin{array}{c}15.54 \\
\%\end{array}$ \\
\hline \multicolumn{10}{|c|}{ Solomon_100_C2 : } \\
\hline $\mathrm{C} 201$ & 3 & $\begin{array}{c}591 . \\
56\end{array}$ & [129] & 4 & 835.62 & 699.79 & $16.25 \%$ & 33.4 & $\begin{array}{c}- \\
18.30 \\
\% \\
\end{array}$ \\
\hline $\mathrm{C} 202$ & 3 & $\begin{array}{c}591 . \\
56\end{array}$ & [129] & 4 & 835.62 & 703.59 & $15.80 \%$ & 3.28 & $\begin{array}{c}- \\
18.94 \\
\% \\
\end{array}$ \\
\hline C203 & 3 & $\begin{array}{c}591 . \\
17\end{array}$ & [129] & 3 & 835.62 & 691.6 & $17.24 \%$ & 9.64 & $\begin{array}{c}- \\
16.99 \\
\%\end{array}$ \\
\hline
\end{tabular}




\begin{tabular}{|c|c|c|c|c|c|c|c|c|c|}
\hline C204 & 3 & $\begin{array}{c}590 . \\
6\end{array}$ & [129] & 4 & 835.62 & 725.06 & $13.23 \%$ & 20.01 & $\begin{array}{c}- \\
22.77 \\
\%\end{array}$ \\
\hline C205 & 3 & $\begin{array}{c}588 . \\
88\end{array}$ & [129] & 3 & 835.62 & 691.17 & $17.29 \%$ & 46.08 & $\begin{array}{c}- \\
17.37 \\
\%\end{array}$ \\
\hline C206 & 3 & $\begin{array}{c}588 \\
49\end{array}$ & [129] & 3 & 835.62 & 685.8 & $17.93 \%$ & 45.4 & $\begin{array}{c}- \\
16.54 \\
\%\end{array}$ \\
\hline C207 & 3 & $\begin{array}{c}588 . \\
29\end{array}$ & [129] & 3 & 835.62 & 691.77 & $17.21 \%$ & 34.98 & $\begin{array}{c}- \\
17.59 \\
\% \\
\end{array}$ \\
\hline C208 & 3 & $\begin{array}{c}588 \\
32\end{array}$ & [129] & 3 & 835.62 & 691.7 & $17.22 \%$ & 32.67 & $\begin{array}{c}- \\
17.57 \\
\%\end{array}$ \\
\hline $\begin{array}{c}\text { Aver } \\
\text { age }\end{array}$ & 3 & $\begin{array}{c}589 \\
86\end{array}$ & & 3.4 & 835.62 & 697.56 & $16.52 \%$ & 28.18 & $\begin{array}{c}- \\
18.26 \\
\%\end{array}$ \\
\hline \multicolumn{10}{|c|}{ Solomon_100_R2 : } \\
\hline R201 & 4 & $\begin{array}{l}125 \\
2.37 \\
\end{array}$ & [135] & 2 & 769.11 & 747.16 & $2.85 \%$ & 20.5 & $\begin{array}{c}40.34 \\
\%\end{array}$ \\
\hline R202 & 3 & $\begin{array}{l}119 \\
1.7 \\
\end{array}$ & {$[136]$} & 2 & 769.11 & 747.16 & $2.85 \%$ & 20.73 & $\begin{array}{c}37.30 \\
\%\end{array}$ \\
\hline R203 & 3 & $\begin{array}{c}939 . \\
54 \\
\end{array}$ & [132] & 2 & 769.11 & 746.21 & $2.98 \%$ & 20.62 & $\begin{array}{c}20.58 \\
\%\end{array}$ \\
\hline R204 & 2 & $\begin{array}{c}825 . \\
52 \\
\end{array}$ & [141] & 2 & 769.11 & 746.21 & $2.98 \%$ & 20.95 & $\begin{array}{c}9.61 \\
\%\end{array}$ \\
\hline R205 & 3 & $\begin{array}{c}994 . \\
42\end{array}$ & [136] & 2 & 769.11 & 747.16 & $2.85 \%$ & 20.64 & $\begin{array}{c}24.86 \\
\%\end{array}$ \\
\hline R206 & 3 & $\begin{array}{c}906 . \\
14 \\
\end{array}$ & [142] & 2 & 769.11 & 747.16 & $2.85 \%$ & 20.69 & $\begin{array}{c}17.54 \\
\%\end{array}$ \\
\hline R207 & 2 & $\begin{array}{c}893 . \\
33 \\
\end{array}$ & [141] & 2 & 769.11 & 746.21 & $2.98 \%$ & 20.64 & $\begin{array}{c}16.47 \\
\% \\
\end{array}$ \\
\hline R208 & 2 & $\begin{array}{c}726 . \\
75\end{array}$ & [132] & 2 & 769.11 & 746.21 & $2.98 \%$ & 20.62 & $\begin{array}{c}- \\
2.68 \\
\% \\
\end{array}$ \\
\hline R209 & 3 & $\begin{array}{c}909 . \\
16 \\
\end{array}$ & [130] & 2 & 769.11 & 746.21 & $2.98 \%$ & 20.67 & $\begin{array}{c}17.92 \\
\% \\
\end{array}$ \\
\hline R210 & 3 & $\begin{array}{c}939 . \\
34 \\
\end{array}$ & [132] & 2 & 769.11 & 746.21 & $2.98 \%$ & 21.44 & $\begin{array}{c}20.56 \\
\% \\
\end{array}$ \\
\hline R211 & 2 & $\begin{array}{c}892 . \\
71 \\
\end{array}$ & [141] & 2 & 769.11 & 746.21 & $2.98 \%$ & 20.67 & $\begin{array}{c}16.41 \\
\%\end{array}$ \\
\hline $\begin{array}{c}\text { Aver } \\
\text { age }\end{array}$ & 2.7 & $\begin{array}{c}951 . \\
91 \\
\end{array}$ & & 2 & 769.11 & 746.56 & $2.93 \%$ & 20.74 & $\begin{array}{c}19.90 \\
\%\end{array}$ \\
\hline
\end{tabular}


Solomon_100_RC2 :

\begin{tabular}{|c|c|c|c|c|c|c|c|c|c|}
\hline $\begin{array}{c}\text { RC2 } \\
01\end{array}$ & 4 & $\begin{array}{c}140 \\
6.91\end{array}$ & {$[132]$} & 2 & 838.58 & 791.62 & $5.60 \%$ & 21.03 & $\begin{array}{c}43.73 \\
\%\end{array}$ \\
\hline $\begin{array}{c}\text { RC2 } \\
02\end{array}$ & 3 & $\begin{array}{c}136 \\
7.09\end{array}$ & {$[143]$} & 2 & 838.58 & 791.62 & $5.60 \%$ & 21.16 & $\begin{array}{c}42.09 \\
\%\end{array}$ \\
\hline $\begin{array}{c}\text { RC2 } \\
03\end{array}$ & 3 & $\begin{array}{c}104 \\
9.62\end{array}$ & {$[143]$} & 2 & 838.58 & 765.89 & $8.67 \%$ & 20.91 & $\begin{array}{c}27.03 \\
\%\end{array}$ \\
\hline $\begin{array}{c}\text { RC2 } \\
04\end{array}$ & 3 & $\begin{array}{c}798 \\
41\end{array}$ & {$[132]$} & 2 & 838.58 & 765.89 & $8.67 \%$ & 20.75 & $\begin{array}{c}4.07 \\
\%\end{array}$ \\
\hline $\begin{array}{c}\text { RC2 } \\
05\end{array}$ & 4 & $\begin{array}{c}129 \\
7.19\end{array}$ & {$[132]$} & 2 & 838.58 & 791.62 & $5.60 \%$ & 20.98 & $\begin{array}{c}38.97 \\
\%\end{array}$ \\
\hline $\begin{array}{c}\text { RC2 } \\
06\end{array}$ & 3 & $\begin{array}{c}114 \\
6.32\end{array}$ & {$[130]$} & 2 & 838.58 & 791.62 & $5.60 \%$ & 20.8 & $\begin{array}{c}30.94 \\
\%\end{array}$ \\
\hline $\begin{array}{c}\text { RC2 } \\
07\end{array}$ & 3 & $\begin{array}{c}106 \\
1.14\end{array}$ & {$[141]$} & 2 & 838.58 & 791.62 & $5.60 \%$ & 20.77 & $\begin{array}{c}25.40 \\
\%\end{array}$ \\
\hline $\begin{array}{c}\text { RC2 } \\
08\end{array}$ & 3 & $\begin{array}{c}828 . \\
14\end{array}$ & {$[144]$} & 2 & 838.58 & 791.62 & $5.60 \%$ & 20.78 & $\begin{array}{c}4.41 \\
\%\end{array}$ \\
\hline $\begin{array}{c}\text { Aver } \\
\text { age }\end{array}$ & 3.3 & $\begin{array}{c}1119 \\
.35\end{array}$ & & 2 & 838.58 & 785.19 & $6.37 \%$ & 20.90 & $\begin{array}{c}27.08 \\
\%\end{array}$ \\
\hline
\end{tabular}




\section{APPENDIX D THE INPUT DATA OF SCENARIO}

\section{ANALYSIS}

Table 13 Population and Vaccine Demands of Counties in Kentucky

\begin{tabular}{|l|l|l|l|}
\hline County & $\begin{array}{l}\text { Populatio } \\
\mathrm{n}\end{array}$ & $\begin{array}{l}\text { Pallets under Light } \\
\text { Demand }\end{array}$ & $\begin{array}{l}\text { Pallets under Heavy } \\
\text { Demand }\end{array}$ \\
\hline $\begin{array}{l}\text { the entire } \\
\text { Kentucky }\end{array}$ & 4339367 & 868 & 4339.367 \\
\hline Adair County & 18656 & 4 & 18.656 \\
\hline Allen County & 19956 & 4 & 19.956 \\
\hline Anderson County & 21421 & 5 & 21.421 \\
\hline Ballard County & 8249 & 2 & 8.249 \\
\hline Barren County & 42173 & 9 & 42.173 \\
\hline Bath County & 11591 & 3 & 11.591 \\
\hline Bell County & 28691 & 6 & 28.691 \\
\hline Boone County & 118811 & 24 & 118.811 \\
\hline Bourbon County & 19985 & 4 & 19.985 \\
\hline Boyd County & 49542 & 10 & 49.542 \\
\hline Boyle County & 28432 & 6 & 28.432 \\
\hline Bracken County & 8488 & 2 & 8.488 \\
\hline Breathitt County & 13878 & 3 & 13.878 \\
\hline $\begin{array}{l}\text { Breckinridge } \\
\text { County }\end{array}$ & 20059 & 5 & \\
\hline Bullitt County & 74319 & 15 & 20.059 \\
\hline Butler County & 12690 & 3 & 74.319 \\
\hline Caldwell County & 12984 & 3 & 12.69 \\
\hline Calloway County & 37191 & 8 & 12.984 \\
\hline Campbell County & 90336 & 19 & 37.191 \\
\hline Carlisle County & 5104 & 2 & 90.336 \\
\hline Carroll County & 10811 & 3 & 5.104 \\
\hline Carter County & 27720 & 6 & 10.811 \\
\hline Casey County & 15955 & 4 & 27.72 \\
\hline Christian County & 73955 & 15 & 15.955 \\
\hline & & & 73.955 \\
\hline
\end{tabular}




\begin{tabular}{|l|l|l|l|}
\hline Clark County & 35613 & 8 & 35.613 \\
\hline Clay County & 21730 & 5 & 21.73 \\
\hline Clinton County & 10272 & 3 & 10.272 \\
\hline Crittenden County & 9315 & 2 & 9.315 \\
\hline Cumberland County & 6856 & 2 & 6.856 \\
\hline Daviess County & 96656 & 20 & 96.656 \\
\hline Edmonson County & 12161 & 3 & 12.161 \\
\hline Elliott County & 7852 & 2 & 7.852 \\
\hline Estill County & 14672 & 3 & 14.672 \\
\hline Fayette County & 295803 & 60 & 295.803 \\
\hline Fleming County & 14348 & 3 & 14.348 \\
\hline Floyd County & 39451 & 8 & 39.451 \\
\hline Franklin County & 49285 & 10 & 49.285 \\
\hline Fulton County & 6813 & 2 & 6.813 \\
\hline Gallatin County & 8589 & 2 & 8.589 \\
\hline Garrard County & 16912 & 4 & 16.912 \\
\hline Grant County & 24662 & 5 & 24.662 \\
\hline Graves County & 37121 & 8 & 37.121 \\
\hline Grayson County & 25746 & 6 & 25.746 \\
\hline Green County & 11258 & 3 & 11.258 \\
\hline Greenup County & 36910 & 8 & 36.91 \\
\hline Hancock County & 8565 & 2 & 8.565 \\
\hline Hardin County & 105543 & 22 & 105.543 \\
\hline Harlan County & 29278 & 6 & 29.278 \\
\hline Harrison County & 18846 & 4 & 18.846 \\
\hline Hart County & 18199 & 4 & 18.199 \\
\hline Henderson County & 46250 & 10 & 46.25 \\
\hline Henry County & 15416 & 4 & 15.416 \\
\hline Hickman County & 4902 & 1 & 4.902 \\
\hline Hopkins County & 46920 & 10 & 46.92 \\
\hline Jackson County & 13494 & 3 & 13.494 \\
\hline Jefferson County & 741096 & 149 & 741.096 \\
\hline Jessamine County & 48586 & 10 & 48.586 \\
\hline Johnson County & 23356 & 5 & 23.356 \\
\hline Kenton County & 159720 & 32 & 159.72 \\
\hline Knott County & 16346 & 4 & 16.346 \\
\hline Knox County & 31883 & 7 & 31.883 \\
\hline Larue County & 14193 & 3 & 14.193 \\
\hline Laurel County & 58849 & 12 & 58.849 \\
\hline Lawrence County & 15860 & 4 & 15.86 \\
\hline Lee County & 7887 & 2 & 7.887 \\
\hline & & & \\
\hline
\end{tabular}




\begin{tabular}{|l|l|l|l|}
\hline Leslie County & 11310 & 3 & 11.31 \\
\hline Letcher County & 24519 & 5 & 24.519 \\
\hline Lewis County & 13870 & 3 & 13.87 \\
\hline Lincoln County & 24742 & 5 & 24.742 \\
\hline Livingston County & 9519 & 2 & 9.519 \\
\hline Logan County & 26835 & 6 & 26.835 \\
\hline Lyon County & 8314 & 2 & 8.314 \\
\hline McCracken County & 65565 & 14 & 65.565 \\
\hline McCreary County & 18306 & 4 & 18.306 \\
\hline McLean County & 9531 & 2 & 9.531 \\
\hline Madison County & 82916 & 17 & 82.916 \\
\hline Magoffin County & 13333 & 3 & 13.333 \\
\hline Marion County & 19820 & 4 & 19.82 \\
\hline Marshall County & 31448 & 7 & 31.448 \\
\hline Martin County & 12929 & 3 & 12.929 \\
\hline Mason County & 17490 & 4 & 17.49 \\
\hline Meade County & 28602 & 6 & 28.602 \\
\hline Menifee County & 6306 & 2 & 6.306 \\
\hline Mercer County & 21331 & 5 & 21.331 \\
\hline Metcalfe County & 10099 & 3 & 10.099 \\
\hline Monroe County & 10963 & 3 & 10.963 \\
\hline Montgomery County & 26499 & 6 & 26.499 \\
\hline Morgan County & 13923 & 3 & 13.923 \\
\hline Muhlenberg County & 31499 & 7 & 31.499 \\
\hline Nelson County & 43437 & 9 & 43.437 \\
\hline Nicholas County & 7135 & 2 & 7.135 \\
\hline Ohio County & 23842 & 5 & 23.842 \\
\hline Oldham County & 60316 & 13 & 60.316 \\
\hline Owen County & 10841 & 3 & 10.841 \\
\hline Owsley County & 4755 & 1 & 4.755 \\
\hline Pendleton County & 14877 & 3 & 14.877 \\
\hline Perry County & 28712 & 6 & 28.712 \\
\hline Pike County & 65024 & 14 & 65.024 \\
\hline Powell County & 12613 & 3 & 12.613 \\
\hline Pulaski County & 63063 & 13 & 63.063 \\
\hline Robertson County & 2282 & 1 & 2.282 \\
\hline Rockcastle County & 17056 & 4 & 17.056 \\
\hline Rowan County & 23333 & 5 & 23.333 \\
\hline Russell County & 17565 & 4 & 17.565 \\
\hline Scott County & 47173 & 10 & 47.173 \\
\hline Shelby County & 42074 & 9 & 42.074 \\
\hline & & & \\
\hline
\end{tabular}




\begin{tabular}{|l|l|l|l|}
\hline Simpson County & 17327 & 4 & 17.327 \\
\hline Spencer County & 17061 & 4 & 17.061 \\
\hline Taylor County & 24512 & 5 & 24.512 \\
\hline Todd County & 12460 & 3 & 12.46 \\
\hline Trigg County & 14339 & 3 & 14.339 \\
\hline Trimble County & 8809 & 2 & 8.809 \\
\hline Union County & 15007 & 4 & 15.007 \\
\hline Warren County & 113792 & 23 & 113.792 \\
\hline Washington County & 11717 & 3 & 11.717 \\
\hline Wayne County & 20813 & 5 & 20.813 \\
\hline Webster County & 13621 & 3 & 13.621 \\
\hline Whitley County & 35637 & 8 & 35.637 \\
\hline Wolfe County & 7355 & 2 & 7.355 \\
\hline Woodford County & 24939 & 5 & 24.939 \\
\hline
\end{tabular}




\title{
CURRICULUM VITAE
}

\author{
Yepeng Sun
}

\section{Contact Information}

Email: sunyepeng@yahoo.com

LinkedIn: sunyepeng@yahoo.com

\section{$\underline{\text { Research Interests }}$}

Applied Operations Research, Supply Chain Management, Logistics, Healthcare Systems Engineering, Management Information Systems, Decision Support Systems, System Engineering, Software Engineering

\section{$\underline{\text { Education }}$}

Ph.D in Industrial Engineering at University of Louisville, USA (since September, 2009)

M.S.E in Industrial Engineering at University of Louisville, USA (August, 2007_ September, 2009) 
M.S.E in Software System Engineering at Aalborg University, Denmark (September, 2004-September, 2006)

Bachelor of Science and Engineering in Computer Science and Technology at Northeastern University, China (August, 1996-August, 2000)

\section{Working Experience}

LoDI Research Assistant in Department of Industrial Engineering at University of Louisville (since August, 2009)

Software Developer in SoShare Internet Co Ltd in Beijing (February, 2007-June, 2007)

Software Developer in Application Solutions and Technologies Inc, and IBM China Development Lab in Beijing (2003-2004)

Software Developer in Advanced System Development Co Ltd and IBM China Development Lab in Beijing (2000-2003)

\section{Professional Skills}

Analysis Software: Lingo (mathematical programming), MiniTab (statistics analysis), Arena (simulation), Excel, ArcGis, Repast Agent-based Simulation Toolkits, etc

Common Software: Microsoft Word, PowerPoint, Project, Visio, Access, etc 
Programming Languages: C\#, C/C++, Java, Visual Basic, UML, SQL, LATEX, etc

OS Platforms: Microsoft Windows, AIX, Solaris, Linux

Database Platforms: DB2, Oracle, MySql, Microsoft SQL Server

Application Software: IBM Websphere Business Integration ( a work flow engine), IBM Electronic Payment Systems

Verification (Formal Methods) Software: Uppaal, Spin, Blast

Languages: Fluent in Chinese and English

\section{Awards and Honors}

Fellowship at University of Louisville (August, 2007-July, 2009)

2011 Graduate Dean's Citation at School of Interdisciplinary and Graduate Studies at University of Louisville (November 2011), Received it for the significant accomplishments during my graduate career at University of Louisville.

Research Assistantship at Department of Industrial Engineering at University of Louisville (August, 2009 - July, 2011)

Sponsored Research Tuition Award offered by School of Interdisciplinary and Graduate Studies at University of Louisville (August, 2010 - May, 2011) 
The 2010 Manufacturing \& Logistics Network Academic Scholarship (\$1000) offered by Greater Louisville Inc (November 11, 2010)

The APICS Scholar offered by the Association of Operations Management in the 2009 APICS international Conference \& Expo in Toronto, Canada ( October 4-6, 2009).

\section{$\underline{\text { Affiliations }}$}

Institute for Operations Research and the Management Sciences (INFORMS)

Institute of Industrial Engineers (IIE)

Logistics and Distribution Institute (LoDI)

The Association of Operations Management (APICS)

The Decision Sciences Institute (DSI)

\section{$\underline{\text { Publications }}$}

Y.P. Sun, S. S. Heragu and G. W. Evans. Kentucky Strategic National Stockpile Logistics Network Design. Proceedings of the 2011 Industrial Engineering Research Conference, Reno, Nevada, May 21-25, 2011. 